NBER WORKING PAPER SERIES

DEADLY EMBRACE: SOVEREIGN AND FINANCIAL BALANCE SHEETS DOOM
LOOPS

Emmanuel Farhi

Jean Tirole

Working Paper 21843

http://www.nber.org/papers/w21843

\author{
NATIONAL BUREAU OF ECONOMIC RESEARCH \\ 1050 Massachusetts Avenue \\ Cambridge, MA 02138 \\ January 2016
}

The research leading to these results has received funding from the European Research Council (Grant Agreements \#249429 and \#669217). Financial support of the research initiative "market risk and value creation" of the Chaire SCOR under the aegis of the Fondation du Risque is also acknowledged. We thank seminar participants at numerous institutions, as well five referees, an associate editor, a managing editor, Manuel Amador, Xavier Freixas, Gita Gopinath, Olivier Jeanne, Anton Korinek, Guido Lorenzoni, Thomas Philippon, and Vania Stravrakeva for useful comments and suggestions. The views expressed herein are those of the authors and do not necessarily reflect the views of the National Bureau of Economic Research.

At least one co-author has disclosed a financial relationship of potential relevance for this research. Further information is available online at http://www.nber.org/papers/w21843.ack

NBER working papers are circulated for discussion and comment purposes. They have not been peerreviewed or been subject to the review by the NBER Board of Directors that accompanies official NBER publications.

(C) 2016 by Emmanuel Farhi and Jean Tirole. All rights reserved. Short sections of text, not to exceed two paragraphs, may be quoted without explicit permission provided that full credit, including $(\subset$ notice, is given to the source. 
Deadly Embrace: Sovereign and Financial Balance Sheets Doom Loops

Emmanuel Farhi and Jean Tirole

NBER Working Paper No. 21843

January 2016, Revised November 2016

JEL No. E0,F34,F36,F65,G28,H63

\section{ABSTRACT}

The recent unravelling of the Eurozone's financial integration raised concerns about feedback loops between sovereign and banking insolvency. This paper provides a theory of the feedback loop that allows for both domestic bailouts of the banking system and sovereign debt forgiveness by international creditors or solidarity by other countries. Our theory has important implications for the re-nationalization of sovereign debt, macroprudential regulation, and the rationale for banking unions.

Emmanuel Farhi

Harvard University

Department of Economics

Littauer Center

Cambridge, MA 02138

and NBER

emmanuel.farhi@gmail.com

Jean Tirole

Toulouse School of Economics

21 allée de Brienne - MF 529

31015 Toulouse Cedex 6

FRANCE

jean.tirole@tse-fr.eu 


\title{
Deadly Embrace: Sovereign and Financial Balance Sheets Doom Loops
}

\author{
Emmanuel Farhi Jean Tirole* \\ Harvard University TSE
}

October 28, 2016

\begin{abstract}
The recent unravelling of the Eurozone's financial integration raised concerns about feedback loops between sovereign and banking insolvency. This paper provides a theory of the feedback loop that allows for both domestic bailouts of the banking system and sovereign debt forgiveness by international creditors or solidarity by other countries. Our theory has important implications for the re-nationalization of sovereign debt, macroprudential regulation, and the rationale for banking unions.
\end{abstract}

Keywords: feedback loop, bailouts, sovereign default, banking unions.

JEL numbers: F34, F36, F65, G28, H63.

\section{Introduction}

The ongoing European crisis first manifested itself in 2009-2010 through increasing sovereign spreads in the periphery (Figure 1). Around the same time, bank and sovereign CDS spreads started to move in lockstep, raising questions as to whether a doom loop in which sovereign fragility would jeopardize banks and in turn bank distress would imperil public finances and sovereign debt sustainability, might not be in operation. Figure 2 depicts the joint evolution in Europe's two poster children. In Ireland, sovereign spreads were negligible until investors felt that the banking system was becoming a serious issue for the country as a whole; Greece illustrates the reverse dynamics, with public finances becoming an issue for the banks. But regardless of whether the initial shock concerned bank balance sheets or sovereign debt, the spread and the bank CDSs started to co-move. Figure 3 shows that the crisis coincided with a reversal in the secular trend toward more capital market integration to make way to a refragmentation phase characterized by a re-nationalization of sovereign debt holdings. This

*The research leading to these results has received funding from the European Research Council (Grant Agreements \#249429 and \#669217). Financial support of the research initiative "market risk and value creation" of the Chaire SCOR under the aegis of the Fondation du Risque is also acknowledged. We thank seminar participants at numerous institutions, as well five referees, an associate editor, a managing editor, Manuel Amador, Xavier Freixas, Gita Gopinath, Olivier Jeanne, Anton Korinek, Guido Lorenzoni, Thomas Philippon, and Vania Stravrakeva for useful comments and suggestions. 


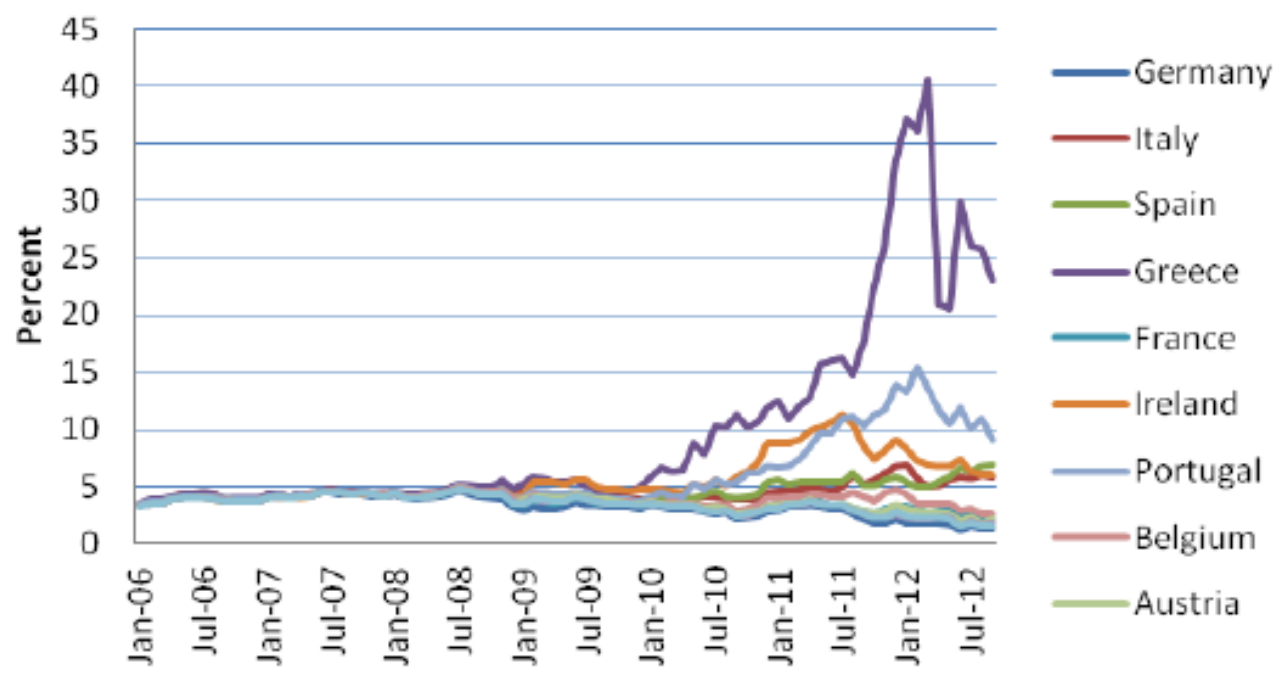

Figure 1: Sovereign bond yields. This figure, taken from Battistini et al (2014), plots sovereign bond yields for major European countries between 01/01/2006 and 07/31/2012. The data are from Datastream.

reversal was particularly pregnant in Southern Europe, but mechanically happened also in the core countries.

Rarely has an economic concept faced such opprobrium as the doom loop, from the IMF ${ }^{1}$ and central bankers to the political establishment and the European Commission, providing a major impetus for the creation of the European banking union.

This paper seeks to relate these developments to domestic bailouts of the banking system by the Sovereign on the one hand, and sovereign debt forgiveness by international creditors or country bailouts by other countries on the other hand. An important feature of this "double-decker bailout" theory is that the fates of Sovereigns and their banks are deeply intertwined, and yet consolidating their balance sheet would be misleading.

The paper's main contribution is to detail the doom loop and re-nationalization mechanisms. The paper shows that a re-nationalization of financial markets occurs upon the accrual of bad news about the banks' balance sheet or the Sovereign's ability to reimburse its debts. The first channel goes through banks' incentives; the "bailout put" (the unpriced option value of the implicit bailout protection against the downside risk of their domestic sovereign debt holdings) has a higher value to them in riskier financial straits, and so in bad times domestic banks will devote more resources to concealing their direct and indirect exposures to the Sovereign. The second channel builds on the Sovereign's incentives; anticipating that the collateral damages which its failure would impose on other countries or on foreign creditors will enable it to obtain assistance or debt forgiveness, and thereby a sustained access to capital markets, the Sovereign may be tempted to relax its grip on banks as it now

\footnotetext{
${ }^{1}$ See e.g. Lagarde (2012).
} 

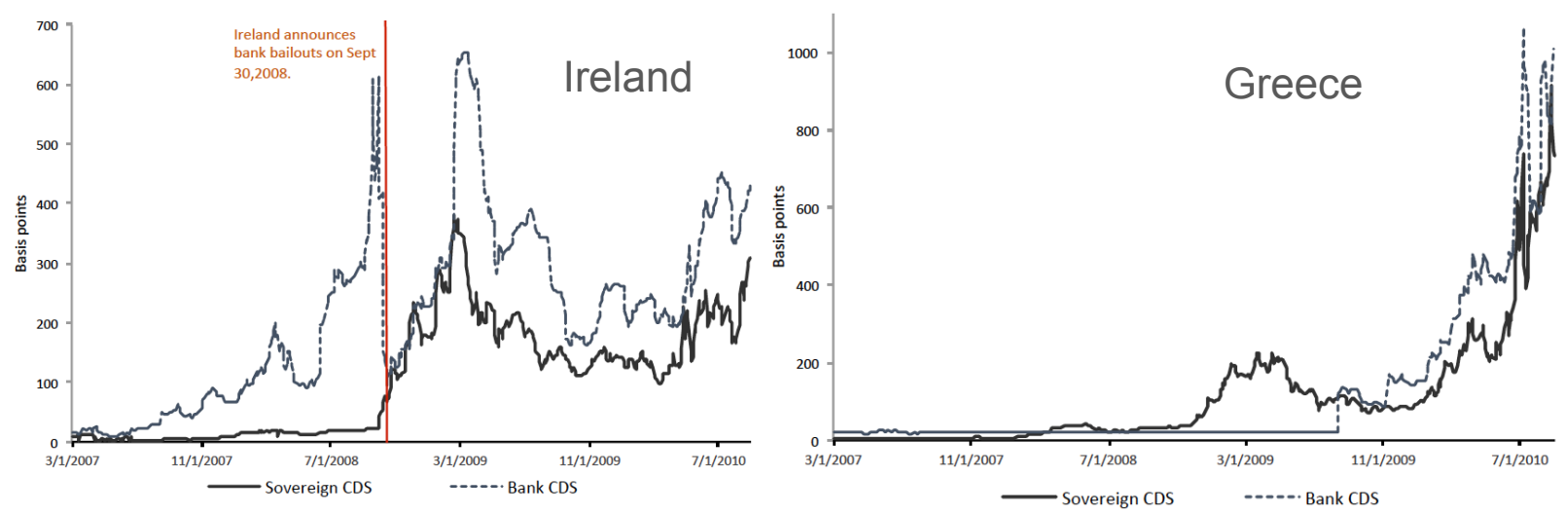

Figure 2: Sovereign CDS spreads and bank CDS spreads of Ireland and Greece. This figure plots the sovereign CDS spreads and bank CDS spreads for Ireland and Greece for the period 3/1/2007 to 8/31/2010. The bank CDS spreads is computed as the equal-weighted average of bank CDS spreads for banks headquartered in Ireland (Allied Irish Bank, Bank of Ireland, Irish Life and Permanent, Governor and Co., BOI) and Greece (Alpha Bank, Eurobank, National Bank of Greece) respectively. The data are spliced from CMA and Reuters databases in Datastream based on availability.

shares the potential cost of domestic banks' risk taking with other countries.

It is also the first paper to provide a rationale for externalized banking supervision (a feature of many banking unions). It actually unveils two distinct rationales. For a fragile debtor country, externalization acts as a commitment not to loosen its banking supervision ex post and thereby imperil its debt's sustainability to extract bigger concessions from foreign legacy creditors; a tougher supervision ultimately benefits the domestic country by reducing its ex-ante cost of borrowing. Externalization can alternatively be motivated by externality arguments reflecting the demands of foreign countries instead of the domestic country. Lax domestic supervision increases the probability that other countries will need to come to the rescue of the distressed one, but does so inefficiently by increasing the rents extracted by the banking system; the domestic and the foreign countries can all be made better off by combining a commitment to solidarity from other countries (another feature of many banking unions) with an externalization of supervision, illustrating a form of complementarity between prudential and fiscal integration. The paper also discusses alternative externality arguments. The doom loop is not essential for some of these insights, but the paper shows that it significantly strengthens them.

Section 2 sets up the framework, which has three dates, 0,1 and 2 . At date 0 , the Sovereign issues domestic bonds that (in this basic version) mature at date 2; the expectation of the date2 fiscal capacity drives the sovereign spread. Domestic banks, which will need money for their date- 1 banking activities, manage their liquidity by holding domestic sovereign bonds and (again, in the basic version of the model) foreign sovereign bonds. Foreign bonds are safe while domestic sovereign bonds are risky, and so the standard diversification argument 


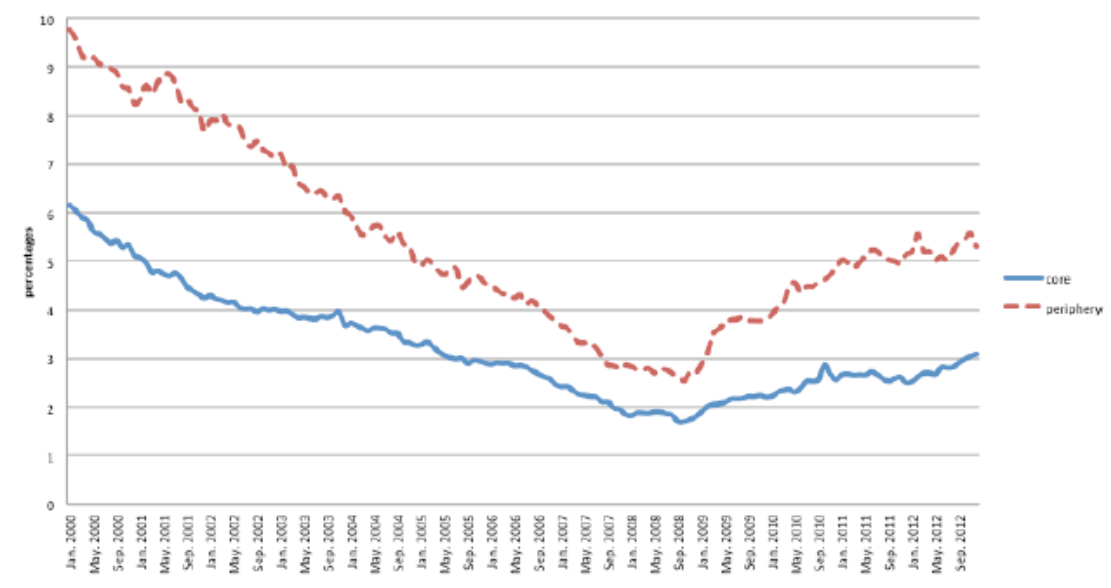

Figure 3: Domestic sovereign debt holdings of periphery vs. core-country banks. This figure, taken from Battistini et al (2014), plots domestic sovereign debt holdings of periphery vs. core-country banks as a proportion of the total assets of banks, for the period 01/01/2000 to 09/31/2012. The data are from the ECB.

would call for holding no domestic bonds. The Sovereign has some supervisory capability, but can choose at date 0 to be more lenient in its monitoring of (direct and indirect) bank exposures. At date 1 news accrues, that affects the banks' solvency (a financial shock) and/or the Sovereign's date-2 fiscal capability (a fiscal shock). While the Sovereign puts less weight on banks than on consumers and so ex ante dislikes transferring resources to the banking sector, it cares sufficiently about economic activity that in bad states of nature, it cannot refrain from bailing out banks when facing the fait accompli of a banking liquidity shortfall.

Section 3 unveils the basic mechanism: As banks use sovereign bonds as a store of liquidity, holding them until they need the resources to invest, the solvency of the Sovereign is reduced for two reasons when the economy suffers an adverse shock. First, there is a direct negative effect of the shock on economic activity and thus on the fiscal revenues of the Sovereign. Second, there is an indirect effect of the shock that operates through the balance sheets of banks. The initial fall in the price of public debt hurts the net worth of banks and thus their investment. If the Sovereign attaches a sufficiently high value to investment, it bails out the banks. The key point is that these bailouts are financed by issuing additional debt, and this increase in the stock of debt decreases its price even further. Basically, for every dollar of bailout that the Sovereign provides to the banks, public debt must increase by more than a dollar. Thus, there is a "doom loop", "deadly embrace" or two-way link between sovereign and financial balance sheets. A weakening of financial balance sheets leads to a weakening of the balance sheet of the Sovereign because it prompts bailouts that increase the stock of public debt. At the same time, a weakening of the balance sheet of the Sovereign has direct effects on financial balance sheets because banks hold public debt. The multiplier reflecting the loss in sovereign bond price increases with the extent of home bias. 
Section 3 then investigates the banks' and the Sovereign's incentives to seek and prevent risk taking, respectively. When banks can count on bailouts by the Sovereign, they optimally diversify as little as supervision allows them to, so as to enjoy the maximal put on taxpayer money. Conversely, the Sovereign would like to limit bailouts and force diversification on the banks. We connect these results with the celebrated Bulow-Rogoff $(1988,1991)$ argument against debt buybacks. In an economy with no cost of default and no financial intermediaries, Bulow and Rogoff show that debt buybacks are a giveaway to legacy foreign creditors and reduce the country's welfare. The banks' purchase of domestic bonds resembles a buyback. We first show that if the default cost is sufficiently large, the Bulow-Rogoff result is overturned. But when the buyback is operated through financial intermediaries that may require a bailout by the Sovereign, the Bulow-Rogoff result is reinstated. This result emphasizes that consolidating the balance sheets of the Sovereign and its banks is mistaken, even when the former fully bails out the latter.

While direct holdings of domestic bonds are easily measured during a stress test, they may not be so on a continuous basis; furthermore, and mainly, banks may have shrouded exposures to the domestic bond market though derivatives, guarantees or a correlation of the banking book with domestic bonds. We accordingly assume that supervision is imperfect and study the extent to which banks are willing to incur costs so as to evade diversification regulation. We provide a first rationale for the re-nationalization of financial markets in bad times: the bailout put enjoyed by banks is more valuable to banks in periods of crisis, vindicating efforts to evade regulations on exposures.

When debt reimbursement prospects are bleak following an adverse date- 1 shock, the legacy sovereign debt ends up on the wrong side of the legacy creditors' Laffer curve once likely bailouts and debt increases are factored in; so legacy creditors may then engage in debt forgiveness. Similarly, countries have an incentive to exercise solidarity and bail out the country (or, equivalently in the presence of bank bailouts, its banks) so as to prevent spillovers on their own economy and society. Section 4 shows that these two forms of transfers to the country make it optimal for the Sovereign to turn a blind eye on undiversified bank portfolios at date 0 exactly when the situation looks grim, a prediction that fits well with the recent re-nationalization of sovereign debt in the Eurozone. In this context we provide the two above-mentioned arguments, a commitment-based one and an externality-based one, in favor of a banking union with centralized supervision.

Our model assumes that the only way for domestic banks to take risk is by investing in risky domestic sovereign bonds. Of course, in practice, banks can take risk by investing in a variety of risky assets: risky foreign debt, equities, currencies, etc. There would also be incentives for lax supervision as well as a rationale for a banking union in the presence of debt forgiveness or country solidarity in an alternative model with an alternative risky asset 
instead of domestic sovereign debt. However, in Section 5, we argue that domestic sovereign debt plays has special attributes that make it particularly relevant for these arguments. First, domestic sovereign debt gives rise to the doom loop while other risky assets do not. Second, the return on risky domestic sovereign debt has a specific covariance structure with the liquidity shocks of domestic banks and with the fiscal shocks of the domestic Sovereign. For instance, it is typically more correlated with both than the return on risky foreign sovereign debt, so that risk shifting and lax supervision are more likely to take place with domestic risky domestic sovereign debt than with risky foreign sovereign debt.

Finally, we pursue a number of extensions and robustness checks in Appendix B, which we summarize in Section 6. Missing proofs can be found in Appendix A.

Relationship to the literature. Our paper connects with several strands of literature. First, it is related to a recent literature on doom loops in closed economies (see e.g. Acharya et al 2015, Cooper-Nikolov 2013, and Bocola 2016). Because of its closed-economy focus, this literature does not analyze topics such as debt re-nationalization, and domestic vs. international banking supervision that feature prominently in our analysis.

Second, our paper is related to an emerging literature on sovereign debt re-nationalization in open economies. Overall, this literature offers alternative hypotheses for sovereign debt re-nationalization and therefore predictions and policy implications that differ from the unique ones of our model. Our contribution is therefore complementary with existing work, and demonstrates the richness of the economics of interactions between sovereign and bank solvency. The proposed theories of debt re-nationalization can be classified into three broad categories: (i) discrimination theories; (ii) risk-shifting theories; and (iii) financial repression theories.

Discrimination theories (i) rely on selective domestic sovereign defaults on foreign banks but not domestic banks. As a result, domestic banks secure a higher returns on domestic sovereign bonds than foreign banks. This difference is higher in bad times when sovereign bond yields are high, leading to a re-nationalization of domestic sovereign debt (see e.g. Broner et al 2013).

Risk-shifting theories (ii) rely on domestic banks preferring the risk profiles of domestic sovereign bonds. This preference is stronger in bad times when sovereign bond yields are high, leading to a re-nationalization of domestic sovereign debt. This is the logic underlying Gennaioli et al (2014a), where domestic banks find domestic sovereign bonds attractive because their ex-post return is positively correlated with their ex-post marginal productivity. A slightly different and more extreme version of this theory which is often discussed (see e.g. Acharya-Steffen 2015 and Acharya et al 2015) assumes that domestic banks automatically go bankrupt in the event of a domestic sovereign default and domestic bank equity-holders find 
domestic sovereign bonds attractive because they can shift the associated ex-post losses to the bank creditors.

Financial repression theories (iii) rely on moral suasion by which the Sovereign may coerce or incentivize domestic banks to buy domestic sovereign bonds at above market prices in order to reduce its financing cost. This motive is stronger in bad times when sovereign yields are high, leading to re-nationalization of domestic sovereign debt. Chari et al (2014) develop a model along these lines in the context of a closed economy.

Our theory of debt re-nationalization can be broadly categorized as a risk-shifting theory, but of a different form than that proposed in the literature. In our model, banks take risks by loading up on domestic sovereign bonds. This can happen for two reasons: (a) because banks find a way to evade domestic supervision (as in Section 3.3); or (b) because domestic supervisors relax domestic supervision (as in Section 4). Mechanism (a) is most comparable to the risk-shifting theories mentioned above but risk shifting by domestic banks into domestic bonds occurs for a different reason: Because they are protected by bailouts, and so they can shift the ex-post losses associated with bad domestic fiscal news to domestic taxpayers (instead of shifting them to bank creditors in the risk-shifting theories mentioned above). Mechanism (b) arises when the cost of bailouts can itself be shifted to international creditors via debt forgiveness or sovereign transfers from foreign countries. Mechanism (b) bears some resemblance with Uhlig (2014) who proposes a model where the Sovereign of a country in a monetary union can, by relaxing financial supervision and letting banks load up on domestic sovereign bonds, achieve its objective of increasing long-term government spending. Domestic banks are willing to load up on domestic sovereign bonds because it is exogenously assumed that they can shift some of the ex-post losses to the monetary union's central bank and to the domestic taxpayer. This reduces sovereign financing costs. Livshits and Schoors (2009) develop a related model in a closed economy where a domestic supervisor can have an incentive to let banks load up on risky sovereign bonds in order to reduce sovereign financing costs. Banks go along because they can shift the ex-post losses to domestic depositors in the even of a sovereign default.

These theories have different implications for whether sovereign debt re-nationalization is associated with a doom loop or not, and whether it amplifies or mitigates domestic sovereign credit worthiness concerns. In our model, there are doom loops and the two mechanisms for debt re-nationalization amplify domestic sovereign credit worthiness or domestic banks' health concerns: Under mechanism (a), it leads to more bailouts and more domestic sovereign defaults; and under mechanism (b), it leads to more bailouts and more debt forgiveness or more sovereign transfers from foreign countries. In Broner et al (2013), unlike in our paper, there is no doom loop between banks and sovereigns but instead a one-way contagion from 
sovereign risk to domestic economic risk, and no financial supervision. ${ }^{2}$ Like in our paper, sovereign debt re-nationalization amplifies domestic sovereign credit worthiness concerns, but for a different reason: because increased domestic sovereign debt holdings by domestic banks crowds out investment in the real economy. In Gennaioli et al (2013), unlike in our paper, there is no doom loop, and debt re-nationalization mitigates domestic sovereign credit worthiness concerns because of the disciplining effect of bank holdings of domestic debt on sovereign debt repayment. ${ }^{3}$ This disciplining effect is also emphasized in Chari et al (2014). ${ }^{4}$

Our paper is unique in explicitly analyzing the role of lax financial supervision in sovereign debt re-nationalization in a welfare-based framework and showing that it gives rise to a rationale for banking unions in the form of delegation of financial supervision to a supranational authority: Either because of a time-inconsistency problem in domestic financial supervision when there is debt forgiveness; or because of supervisory externalities when there are sovereign transfers from foreign countries, in which case it comes together with commitments to solidarity. . $^{\prime} 6$

These theories are difficult to tell apart empirically. Acharya-Steffen (2015) and Acharya et al (2015) use a cross-sectional data strategy. Acharya-Steffen (2015) find some evidence for risk-shifting theories (large banks and banks with high short-term leverage have more exposure to periphery debt, especially in periphery countries). They document that some of this shifting of risk comes together with regulatory arbitrage whereby banks exploit the low risk weights of risky sovereign debt (banks with high risk-weighted assets and low Tier-1 capital have more exposure to periphery debt). They also find some evidence for moral suasion theories (periphery banks which have been bailed out have more exposure to periphery debt). Acharya et al (2015) find additional evidence for risk-shifting theories but not for moral suasion theories (using different measures of government influence). The evidence presented in these papers is therefore broadly supportive of the importance of risk-shifting theories, but does not permit to tell apart the different risk-shifting theories (shifting domestic sovereign risk from bank equity-holders to bank creditors vs. from banks to taxpayers).

\footnotetext{
${ }^{2}$ Two-way contagion arises in an extension of their model in which the cost of default is proportional to the amount of defaulted debt, with the proportion decreasing with the capital stock.

${ }^{3}$ See Perez (2015) for some evidence consistent with this effect in a set of emerging economies.

${ }^{4}$ These disciplining effects arise because default costs are small enough that defaults are strategic at the margin. We purposefully abstract from these well-understood effects in our model by assuming that default costs are large enough that defaults are mechanical at the margin (domestic sovereign debt is always repaid if it can be repaid). Which assumption is more reasonable is a matter of empirical debate. Our assumption allows us to isolate to abstract from strategic default considerations and to focus squarely on the rich budgetary implications of doom loops and sovereign debt re-nationalization.

${ }^{5}$ The time-inconsistency problem in financial supervision is related to the one identified in the debt dilution literature (see e.g. Bizer and DeMarzo 1992).

${ }^{6}$ Broner et al (2013) put forth a different rationale for a banking union: A banking union is assumed to reduce discrimination between domestic and foreign investors.
} 


\section{Model}

\subsection{Setup}

We consider the following economy. There are three dates $t \in\{0,1,2\}$ and a single good at every date.

The economy is populated by international investors, a continuum of mass one of domestic bankers and a continuum of mass one of domestic consumers. In addition, there is a domestic government, which we call the Sovereign.

Uncertainty is gradually resolved over time. At date 1, a state of the world is realized $s \in S$, with (full support) probability distribution $d \pi(s)$, where $S$ is an interval of $\mathbb{R}^{+}$. The bankers' balance sheets and the fiscal capacity of the Sovereign depend on the realization of the state of the world $s$.

Private agents: international investors, bankers and consumers. International investors have a large endowment in every period. Their utility $V_{t}^{*}=\mathbb{E}_{t}\left[\sum_{s=t}^{2} c_{s}^{*}\right]$ at date $t$ is linear over consumption, and so the international rate of interest is equal to 0.

Consumers' utility $V_{t}^{C}=\mathbb{E}_{t}\left[c_{2}^{C}\right]$ at date $t$ is linear over consumption at date 2 . They have a random endowment $E \in[0, \infty)$ at date 2, with probability distribution function $f(E \mid s)$ and cumulative distribution function $F(E \mid s)$. The Sovereign's only fiscal resources are at date 2: The Sovereign can tax the (random) endowment $E$ of domestic consumers. The endowment $E$ can hence be interpreted as the fiscal capacity of the Sovereign. We assume that $\frac{\partial(f(E \mid s) /(1-F(E \mid s)))}{\partial s} \leq 0$ and that $\frac{\partial(f(E \mid s) /(1-F(E \mid s)))}{\partial E}>0$. The first inequality will imply that decreases in $s$ are bad news for the fiscal capacity of the Sovereign; the second is a monotone hazard rate condition that will imply quasi-concave Laffer curves. The two conditions are equivalent if $s$ shifts the distribution uniformly so that $F(E \mid s)=F(E-s)$. As usual, one can think of $\mathrm{E}$ as the consumers' disposable income beyond some incompressible level of consumption.

Bankers' utility $V_{t}^{B}=\mathbb{E}_{t}\left[c_{2}^{B}\right]$ at date $t$ is linear over consumption at date 2. They have an endowment $A$ at date 0 . At date 1 , in state $s$, they have a fixed-size investment opportunity which pays off at date 2 . They must invest $I(s)$ in order to reap payoff $\rho_{1}(s)$ where $\rho_{1}(s)>$ $I(s)$. The dependence of $I$ on $s$ more generally stands for liquidity (or financial) shocks faced by banks. We assume that $\frac{d I(s)}{d s} \leq 0$ so that low $s$ states are states in which banks badly need cash. We also define $\underline{I}=\min _{s \in S} I(s)$ and $\bar{I}=\max _{s \in S} I(s)$. For the investment to be feasible, though, the banker needs either to have enough date- 1 cash to cover $I(s)$, or to receive a bailout from the Sovereign equal to (at least) the shortfall.

We assume that the return from the investment project of bankers cannot be pledged to outside investors, and as result, bankers cannot raise outside funding at date 1 (see Appendix 
B.3 for a relaxation of this assumption). Instead, they must self-finance the investment project $I(s)$. Therefore, at date 0 , bankers trade their endowment $A$ for financial assets (stores of value), part or all of which they sell at date 1 to finance their investment project. ${ }^{7}$ We assume that $A \geq \bar{I}$ so that if bankers manage or decide to preserve their wealth between dates 0 and 1 , they can always finance their investment project. But they may decide otherwise and face of shortage of funds, in which case the Sovereign will need to choose between a bailout and the absence of investment.

Assets. In the basic model, there are no domestic stores of values, except for sovereign bonds, whose supply is limited by the country's ability to reimburse. Financial assets thus are assumed to come in two forms, domestic sovereign bonds in amount $B_{0}$, and foreign bonds in unlimited supply. Both domestic and foreign bonds are claims to a unit of good at date 2 .

We look for a symmetric equilibrium, in which banks all choose the same portfolio. We denote by $b_{0}$ and $b_{0}^{*}$ the representative bank's holdings of domestic sovereign bonds and foreign bonds. We assume that there are no short sales so that $b_{0}^{*} \geq 0$ and $b_{0} \geq 0$.

Foreign bonds-which could be either private bonds or foreign sovereign bonds-are safe, and hence their price is always 1 . By contrast, we assume that domestic bonds are risky because the domestic Sovereign might default. We denote their price in period 0 by $p_{0}$ and their price in period 1 by $p_{1}(s)$. We assume that the amount that the Sovereign needs to finance at $t=0$ is greater than $A: p_{0} B_{0}>A$ so that the marginal holder of domestic bonds is an international investor.

Welfare. Letting $\mu(s)$ denote the mass of bankers who undertake their investment project, the Sovereign evaluates at each point in time welfare $\mathcal{W}_{t}$ by subtracting default costs (to be introduced below) from $\mathbb{E}_{t}\left[c_{2}^{C}+\beta^{B} c_{2}^{B}+\beta^{I}(s) \mu(s)\right]$. The latter expression is a weighted average of consumer consumption $c_{2}^{C}$, banker welfare $c_{2}^{B}=\rho_{1}(s) \mu(s)$ and total investment $\mu(s)$. We assume that $0<\beta^{B}<1$, and so pure consumption transfers to bankers are costly. We assume that the Sovereign puts substantial weight on economic activity and bankers $\beta^{I}(s)+\beta^{B} \rho_{1}(s)>I(s)$ ensuring that it wants to use taxpayer money to make sure the bank's investment happens.

Microfoundations. This paragraph can be skipped without loss for the understanding of the paper. We sketch credit-crunch foundations of this welfare function, following Holmström and Tirole (1997) to which we refer for a more elaborate model. At date 0, each banker makes an investment in knowledge/staff so as to be able to invest in a mass 1 of firms, each with investment need $I(s)$ at date 1 and no net worth. Suppose that a fraction $\mu(s) \leq 1$ of

\footnotetext{
${ }^{7}$ This feature resembles Woodford (1990).
} 
these firms are financed at date 1 . At date 2, firms succeed or fail (then return 0 ). Success is guaranteed if none of the banker, the managers and the workers shirks. Otherwise, success accrues with probability 0 . Shirking for a banker brings benefit $\rho_{1}(s)$, shirking for a firm manager brings benefit $\rho_{1}^{M}(s)$, shirking for a firm worker brings benefit $\rho_{1}^{W}(s)$. Therefore incentive payments $\rho_{1}(s), \rho_{1}^{M}(s)$, and $\rho_{1}^{W}(s)$ per firm are required to discipline its banker, manager and workers. There is no payoff beyond the incentive payoffs of these stakeholders (we relax this assumption in Appendix B.3). We assume for simplicity that managers and workers are cashless, so that only the banker can finance investment in the firm at date 1 . We also assume that $\rho_{1}(s)>I(s)$ so that it is in the private interest of the banker to finance as many of these firms as it is able to. In total, in order the finance a fraction $\mu(s)$ of firms, a total amount $\mu(s) I(s)$ of bank capital is needed. In this model, $\beta^{I}(s)=\tilde{\beta}^{M} \rho_{1}^{M}(s)+\tilde{\beta}^{W} \rho_{1}^{W}(s)$ and $\beta^{B}=\tilde{\beta}^{B}$ where $\tilde{\beta}^{M}, \tilde{\beta}^{W}$, and $\tilde{\beta}^{B}$ are the three categories of stakeholders' welfare weights.

What makes "banks" banks? The term $\beta^{I}(s) \mu(s)$ in the social welfare function captures an externality on other agents in the economy, namely the welfare benefit for other banking stakeholders (borrowers, workers), from the banks' ability to invest. This modeling of social preferences thus allows for a wide range of preferences among economic agents. A heavy weight $\beta^{I}$ put by the Sovereign on banking activities and the concomitant bailouts is what distinguishes the "banks" from other enterprises, while $\beta^{B}<1$ ensures that the Sovereign would not ex ante like to bail out the banks.

The "bailout" terminology can be justified as follows. A bank that has insufficient liquidity to cover the investment cost $I(s)$ at date 1 must forgo its investment project unless the Sovereign steps in and supplies the shortfall. As described, such a targeted bailout prevents a substantial downsizing relative to expectations, but is not triggered by the threat of bankruptcy as the bank issue no debt at date 0 . However, one can write a mathematically equivalent model in which the bank faces no date-1 liquidity shock but owes pre-existing debt at date $1 .{ }^{8}$ If the return from assets owned by the bank's assets is short of the date- 1 debt repayment, then the bank goes bankrupt and $\mu(s)=0$ unless the Sovereign brings cash. In this reinterpretation, bankruptcy occurs off-the-equilibrium path and is prevented by a bailout.

Sovereign debt, bailouts, defaults. The domestic Sovereign makes decisions sequentially, without commitment. At date 1, the Sovereign decides whether to undertake a bailout of its

\footnotetext{
${ }^{8}$ In this alternative model, banks owe $I(s)$ in hard debt at date 1 (it can neither be renegotiated nor repurchased) and each bank owns a mass one of investment projects at date 0 . If a bank repays its debt, its investment projects pays off at date 2. If a bank cannot repay its debt, it goes bankrupt and its investment projects do not pay off at date 2 . This model is isomorphic to the one in the paper. The only difference is that there is outright discrete bankruptcy rather than continuous downsizing, but it makes no difference for the analysis since bailouts are always maximal.
} 
domestic banks. At date 2, the Sovereign repays its debt or defaults.

The Sovereign issues some outstanding bonds $B_{0}$ at date 0 . We assume for the moment that these bonds mature at date 2 (in Appendix B.1, we investigate whether conclusions are altered by a shorter maturity and whether the Sovereign optimally issues long-term bonds).

At date 1, the Sovereign inspects the balance sheets of banks that apply for a bailout and so can, if it so desires, tailor individual bailout levels to specific liquidity shortages of applying banks (which in equilibrium will end up being identical). ${ }^{9}$ We denote by $X(s)$ the total transfer to the banks. In order to finance this transfer, the Sovereign must issue new bonds $B_{1}(s)-B_{0}$. Throughout the paper, we maintain the assumption that the Sovereign can always raise enough resources to bail out all banks; that is, there exists $B_{1}(s)$ such that $p_{1}(s)\left(B_{1}(s)-B_{0}\right)=X(s)$ where the date-1 price $p_{1}(s)$ reflects both the direct effect of $s$ and the increase in sovereign debt. ${ }^{10}$ We relax this assumption in Appendix B.2.

Our assumption that $\beta^{I}(s)+\beta^{B} \rho_{1}(s)>I(s)$ ensures that Sovereign always chooses to bail out the financial sector if such a bailout is needed, implying that $X(s)=\max \{I(s)-$ $\left.\left(b_{0}^{*}+p_{1}(s) b_{0}\right), 0\right\} .{ }^{11}$

At date 2, the Sovereign decides whether to default on its debt. The Sovereign cannot discriminate between foreign and domestic bond holders, and hence cannot selectively default on foreigners. The Sovereign incurs a fixed $\operatorname{cost} \Phi$ if it defaults on its debt, which we assume is high enough $\Phi>B_{0} .{ }^{12}$ This implies in particular that the Sovereign only defaults if it cannot pay its debt, that is if and only if $B_{1}(s)>E$.

Supervisory game. As we will note, banking bailouts provide banks with an incentive to take risk. Conversely, and in the absence of sovereign debt forgiveness, the supervisor would like to limit risk taking. In general, an individual bank's exposure to domestic bonds depends on a costly supervisory effort to detect hidden exposures and on the bank's costly effort to make these exposures opaque. ${ }^{13}$

\footnotetext{
${ }^{9}$ Alternatively, we could have followed Farhi and Tirole (2012) or Mengus (2013a,b) in assuming that individual portfolios are imperfectly observed at the bailout date and that these portfolios are endogenously heterogeneous. This would make bailouts more costly and the analysis more complex, without altering the basic insights in our context.

${ }^{10}$ The assumption that the Sovereign sets the amount it promises to reimburse, $B_{1}(s)$, rather than the amount it borrows eliminates any multiplicity associated with erratic expectations as in Calvo (1988).

${ }^{11}$ Note that the Sovereign does not issue new bonds solely for the purpose of financing date-1 consumption. Formally, this is the case in our model, as domestic residents consume at date 2 only. But, even if, say, consumers derive utility from date- 1 consumption, it can be shown that, as long as the default cost $\Phi$ is sufficiently large, the Sovereign never issues new debt to finance date-1 consumption, whether or not it bails out its banks.

${ }^{12}$ Starting with $B_{0}<\Phi$, the Sovereign would never issue $B_{1}(s)>\Phi$. Such an issuance would yield zero revenues since it would lead to default with probability 1 and hence be associated with a zero price $p_{1}(s)=0$.

${ }^{13}$ That direct and indirect exposures may be hard to assess, is shared by a literature that emphasizes the difficulty of monitoring banks: See Farhi-Tirole (2012) and Mengus (2013a, b), as well as in Philippon-Skreta (2012) and Tirole (2012) in their study of the design of government interventions to rescue the financial sector in the presence of asymmetric information on banks' balance sheets.
} 


\begin{tabular}{|c|c|c|}
\hline $\begin{array}{l}\text { - Domestic debt } \\
\text { market clears at } p_{0} \\
\text { (WTP of foreign } \\
\text { investors) } \\
\text { - Supervisor chooses } \\
r \leq \bar{r} \text { (unobserved by } \\
\text { market) } \\
\text { - Banks observe } r \text { and } \\
\text { privately select their } \\
\text { portfolios }\left\{b_{0}, b_{0}^{*} \geq r\right\} \\
\text { such that } \\
A=b_{0}^{*}+p_{0} b_{0} .\end{array}$ & $\begin{array}{l}\text { - State of nature } s \text { is realized, } \\
\text { determining fiscal prospects } \\
f(E \mid s) \text { and financial needs } I(s) \text {. } \\
\text { - Government issues } B_{1}(s)-B_{0} \text { to } \\
\text { finance rescue package } X(s) \text {. } \\
\text { Banks invest } I(s) \text { if they can. }\end{array}$ & $\begin{array}{l}\text { Government } \\
\text { (non-selectively) } \\
\text { defaults iff } \\
E<B_{1}(s) .\end{array}$ \\
\hline
\end{tabular}

Figure 4: Timeline.

Rather than formalize the supervisory game in its entire generality we assume that there is an exogenous supervisory capability $\bar{r}$. For a given supervisory capability $\bar{r}$, the supervisor can then decide to be lenient by setting an effective minimum diversification requirement $r \leq \bar{r}$. Except in Section 3.3, we assume that the supervisor can perfectly enforce the effective minimum diversification requirement $r$, so that a banker must set $b_{0}^{*} \geq r$.

Informational assumptions. We make the following informational assumptions. The supervisory capability $\bar{r}$ and the amount of debt $B_{0}$ are publicly observable at date 0 . The decision regarding supervisory leniency $r$ and the portfolios of banks are not observable to international investors at date 0 . The bailout $X(s)$ and the amount of debt $B_{1}(s)$ are publicly observable at date $1 .{ }^{14}$

The Sovereign's supervisory capability $\bar{r}$ in practice depends on the size and expertise of the supervisory staff and on the prudential rules disallowing or disincentivizing the use of complex products whose risk is hard to assess. The banks' holdings $b_{0}$ should be interpreted as a mixture of things: straight bonds, derivative products that involve contingencies based on bond prices, and more generally exposures to the domestic economy. The supervisor's imperfect information about $b_{0}$ therefore has a variety of sources: straight bond holdings may not be monitored in real time; derivative products involve difficult-to-assess exposures to sovereign bond prices; finally, banks are exposed in many ways to the domestic economy,

\footnotetext{
${ }^{14}$ It does not matter whether the banks already acquire some domestic debt at date 0 before the supervisory stance $r$ is decided and then readjust their portfolios, or simply form their portfolios in one shot after $r$ is decided. This is because $r$ is unobservable, and hence $p_{0}$ is independent of $r$. It also does not matter whether $r$ and the portfolio of banks are publicly observable at date 1 or not. The assumption that $p_{0} B_{0}>A$ is a conservative assumption that ensures that the marginal investor remains an international investor even if supervision is relaxed relative to market expectations.
} 
whose sectors are (to varying degrees) affected by the Sovereign's state. Finally, the choice of supervisory intensity $r \leq \bar{r}$ can be interpreted as a form of moral hazard, in which the supervisor turns a blind eye on dangerous exposures; one can think of $\bar{r}$ as the de jure regulatory requirement and $r$ as the de facto supervisory reality. To the extent that $\bar{r}$ is dictated by a supranational institution (e.g. the Basel Committee or the regional transpositions of its rules), domestic authorities have no incentive to disclose their non-compliance $(r<\bar{r}) .{ }^{15}$ Figure 4 summarizes the timeline.

\subsection{Equilibrium}

In this section, we characterize the equilibrium of the model.

Bond prices and issuance Laffer Curve. Because the marginal investor in domestic bonds is a risk-neutral international investor, the prices of domestic bonds at dates 0 and 1 simply reflect the relevant conditional default probability:

$$
\begin{gathered}
p_{1}(s)=1-F\left(B_{1}(s) \mid s\right), \\
p_{0}=\int p_{1}(s) d \pi(s) .
\end{gathered}
$$

At date 1 in state $s$, the Sovereign can thus collect $\left(B_{1}-B_{0}\right)\left[1-F\left(B_{1} \mid s\right)\right]$ by issuing $B_{1}-$ $B_{0}$. This revenue is strictly quasi-concave in $B_{1}$ and increasing in $s$ from our assumptions on the distribution of the date-2 endowment $E$. We call it the issuance Laffer curve. ${ }^{16}$

Bankers' portfolio choice. In a symmetric equilibrium, bankers invest their net worth into foreign bonds $b_{0}^{*} \geq 0$ and domestic bonds $b_{0} \geq 0$ so that

$$
A=b_{0}^{*}+p_{0} b_{0} .
$$

At date 1, their pre-bailout net worth is $b_{0}^{*}+p_{1}(s) b_{0}$. If their pre-bailout net worth falls short of the investment size $I(s)$, they receive a bailout $X(s)=I(s)-\left(b_{0}^{*}+p_{1}(s) b_{0}\right)$ from the Sovereign. If their pre-bailout net worth exceeds the investment size $I(s)$, they simply save

\footnotetext{
${ }^{15}$ The non-observability of $r$ is therefore reasonable; but we have checked that the qualitative results also hold in the slightly more complex case in which supervisory intensity is observed by the market at date 0 . The first version of this paper (March 12, 2014) actually focused on that case.

${ }^{16}$ Three related date-1 Laffer curves will play a key role in the paper. First, the Laffer curve reflects the date-1 market value $B_{1}\left[1-F\left(B_{1} \mid s\right)\right]$ of debt with the face value of debt $B_{1}$. Second, the issuance Laffer curve described in the text above refers to the date- 1 market value $\left(B_{1}-B_{0}\right)\left[1-F\left(B_{1} \mid s\right)\right]$ of the newly issued debt with face value $B_{1}-B_{0}$ if it already owes legacy debt with face value $B_{0}$. Third, the legacy creditors' Laffer curve refers the date-1 market value $B_{0}\left[1-F\left(B_{1} \mid s\right)\right]$ of debt with face value $B_{0}$. Sections 2 and 3 only discuss the issuance Laffer curve. The Laffer curve and the legacy creditors' Laffer curve come into play in Sections 4 and 5.
} 
the difference by acquiring either domestic or international bonds (at this stage, they are indifferent between both since they are risk neutral over date- 2 consumption).

Their expected utility is therefore $V_{0}^{B}=\int\left[\rho_{1}(s)+\max \left\{b_{0}^{*}+p_{1}(s) b_{0}-I(s), 0\right\}\right] d \pi(s)$. Because $p_{0}=\int p_{1}(s) d \pi(s), I(s)$ is decreasing in $s$, and $A \geq \bar{I}$, each banker chooses $b_{0}^{*}=r .{ }^{17}$ This is intuitive: Bankers have an incentive to take as much risk as possible to extract the biggest possible expected bailout from the Sovereign. Thus all bankers behave identically and take as much risk as is tolerated by supervision.

Impact of bailouts on date-1 bond issuance. At date 1 in state $s$, financing the bailout

$$
X(s)=\max \left\{I(s)-r-(A-r) \frac{p_{1}(s)}{p_{0}}, 0\right\}
$$

requires issuing $B_{1}(s)-B_{0}$ new bonds with

$$
p_{1}(s)\left[B_{1}(s)-B_{0}\right]=X(s) .
$$

Date- 1 debt $B_{1}(s) \geq B_{0}$ is the smallest solution of the following fixed-point equation

$$
\left[1-F\left(B_{1}(s) \mid s\right)\right]\left[B_{1}(s)-B_{0}\right]=\max \left\{I(s)-r-(A-r) \frac{1-F\left(B_{1}(s) \mid s\right)}{p_{0}}, 0\right\} .
$$

The difference between the left-hand side and the right-hand side of this equation is quasiconcave because of our monotone hazard ratio property, and so if it has a solution (which we assume), this solution $B_{1}(s) \geq B_{0}$ is unique on the upward sloping part of the issuance Laffer curve.

A straightforward investigation of condition (3) shows that debt $B_{1}(s)$ (its price $p_{1}(s)$ ) is decreasing (increasing) in s until a threshold $\tilde{s}$ at which bailouts are no longer needed $(X(\tilde{s})=0) .^{18}$

Supervisory intensity. When setting the effective minimum diversification requirement $r \leq \bar{r}$, the supervisor seeks to maximize welfare

${ }^{17}$ Because $p_{1}(s)$ is increasing in $s$ and $I(s)$ is decreasing in $s$, there exists $\tilde{s}$ such that $b_{0}^{*}\left(1-\frac{p_{1}(s)}{p_{0}}\right)+\frac{p_{1}(s)}{p_{0}} A-$ $I(s) \geq 0$ if and only if $s \geq \tilde{s}$. Note that if $p_{1}(s) \geq p_{0}$, then $s \geq \tilde{s}$. Now consider $b_{0}^{* \prime}>b_{0}^{*}$. We necessarily have $\tilde{s}^{\prime} \leq \tilde{s}$. This implies that $V_{0}^{B \prime}-V_{0}^{B} \leq \int_{s \geq \tilde{s}^{\prime}}\left(b_{0}^{* \prime}-b_{0}\right)\left(1-\frac{p_{1}(s)}{p_{0}}\right) d \pi(s) \leq 0$.

${ }^{18}$ More precisely, there exists a cutoff $\tilde{s}$ such bailouts occur if and only if $s<\tilde{s}$, so that $B_{1}(s)>B_{0}$ if $s<\tilde{s}$ and $B_{1}(s)=B_{0}$ for $s \geq \tilde{s}$. Furthermore, we can show that $\frac{d B_{1}(s)}{d s}<0$ for $s<\tilde{s}$ and similarly that $\frac{d p_{1}(s)}{d s}>0$ for $s<\tilde{s}$, and for all $s$ if $\frac{\partial(f(E \mid s) /(1-F(E \mid s)))}{\partial s}<0$ (strict inequality) . 


$$
\begin{aligned}
\mathcal{W}_{0}=\int\left[\int_{B_{1}(s)}^{\infty}\right. & {\left.\left[E-B_{1}(s)\right] f(E \mid s) d E+\int_{0}^{B_{1}(s)}[E-\Phi] f(E \mid s) d E\right] d \pi(s) } \\
& +\int \beta^{B}\left[\rho_{1}(s)+\max \left\{r+(A-r) \frac{p_{1}(s)}{p_{0}}-I(s), 0\right\}\right] d \pi(s)+\int \beta^{I}(s) d \pi(s),
\end{aligned}
$$

taking $p_{0}$ as given (because $r$ is not publicly observable at date 0 ) but taking into account the impact of $r$ on $p_{1}(s)$ and $B_{1}(s)$ through

$$
\begin{gathered}
p_{1}(s)=1-F\left(B_{1}(s) \mid s\right), \\
p_{1}(s)\left[B_{1}(s)-B_{0}\right]=\max \left\{I(s)-r-(A-r) \frac{p_{1}(s)}{p_{0}}, 0\right\} .
\end{gathered}
$$

Welfare decomposition. Using the equilibrium equations (1), (2), and (3), we can derive an enlightening efficiency-rent decomposition of equilibrium welfare

$$
\mathcal{W}_{0}=\mathcal{E}_{0}-\mathcal{R}_{0}
$$

with

$$
\begin{aligned}
\mathcal{E}_{0}=\int\left[\int_{B_{1}(s)}^{\infty}\left[E-B_{0}\right] f(E \mid s) d E+\int_{0}^{B_{1}(s)}[E\right. & -\Phi] f(E \mid s) d E] d \pi(s) \\
& +\int\left[\beta^{I}(s)+\beta^{B}\left[\rho_{1}(s)-I(s)+A\right]\right] d \pi(s)
\end{aligned}
$$

and

$$
\mathcal{R}_{0}=-\left(1-\beta^{B}\right) \int \min \left\{r+(A-r) \frac{p_{1}(s)}{p_{0}}-I(s), 0\right\} d \pi(s),
$$

which using the equilibrium martingale property of prices (2), has the alternative expression

$$
\mathcal{R}_{0}=\left(1-\beta^{B}\right) \int\left[\max \left\{r+(A-r) \frac{p_{1}(s)}{p_{0}}-I(s), 0\right\}-[A-I(s)]\right] d \pi(s) .
$$

The term $\mathcal{E}_{0}$ is a pure efficiency term. It accounts for the cost $p_{0} B_{0}$ of legacy debt repayment and the cost of defaults $\Phi \int F\left(B_{1}(s) \mid s\right) d \pi(s) .{ }^{19}$ The term $\mathcal{R}_{0} \geq 0$ is a pure distributive term, which is positive because the banks engage in risk-taking and thereby obtain a "bailout put"

\footnotetext{
${ }^{19}$ The cost of legacy debt repayment $p_{0} B_{0}$ can be seen as the cost of repayment of foreign legacy creditors. It occurs both ex ante at date 0 for the foreign legacy creditors who have sold their debt to bankers and ex post at date 2 for those who have held on to it.
} 
on taxpayer money

$$
\mathcal{P}_{0}=-\int \min \left\{r+(A-r) \frac{p_{1}(s)}{p_{0}}-I(s), 0\right\} d \pi(s)
$$

It accounts for the cost of the rents extracted by bankers at the expense of domestic consumers because of bailouts. These rents reduce welfare because bankers carry a lower welfare weight than consumers $\beta^{B}<1$ so that $\mathcal{R}_{0}=\left(1-\beta^{B}\right) \mathcal{P}_{0}$.

It is important to keep in mind that the decomposition $\mathcal{W}_{0}=\mathcal{E}_{0}-\mathcal{R}_{0}$ in (4) as well as the alternative expression (7) for $\mathcal{R}_{0}$ make use of the martingale property of equilibrium prices (2). As a result, they are only valid in equilibrium. They cannot be used off equilibrium to analyze the ex-post incentives of supervisors to set the effective diversification requirement $r$, for a given $p_{0}$, because (2) might not hold. Instead we then use a more general decomposition

$$
\mathcal{W}_{0}=\mathcal{E}_{0}-\mathcal{R}_{0}+\mathcal{C}_{0}
$$

with $\mathcal{E}_{0}$ given by (5), $\mathcal{R}_{0}$ given by (6), and $\mathcal{C}_{0}$ given by

$$
\mathcal{C}_{0}=\beta^{B} \int\left[r+(A-r) \frac{p_{1}(s)}{p_{0}}-A\right] d \pi(s)
$$

The term $\mathcal{C}_{0}$ is a corrective term that accounts for the rents that bankers extract at the expense of foreign legacy creditors when the martingale property of prices (2) does not hold. This is because the price $p_{0}$ at which banker purchase debt from foreign legacy creditors deviates from the expected future probability of repayment $\int p_{1}(s) d \pi(s)$. We have $\mathcal{C}_{0}=0$ in equilibrium when (2) holds so that $p_{0}=\int p_{1}(s) d \pi(s)$. But off equilibrium, we have $\mathcal{C}_{0}>0$ if $p_{0}<\int p_{1}(s) d \pi(s)$ and $\mathcal{C}_{0}<0$ if $p_{0}>\int p_{1}(s) d \pi(s)$.

\section{Sovereign and Financial Balance Sheets Doom Loops}

We can now show how a shock to banks' or the Sovereign's balance sheet (or both) is amplified through a mutual feedback loop: for instance, when the banks' balance sheet is already fragile, a higher liquidity need experienced by banks requires a larger bailout, implies a lower price of sovereign debt, which in turn further deteriorates the banks' balance sheet, and so forth. We then prove two very intuitive propositions: For a given supervisory capability, it is never optimal for the supervisor to engage in supervisory leniency; furthermore the Sovereign would like to force banks to fully diversify if it had the means to do so. The common thread behind these two results is that risk-taking by banks generates both a costly redistribution from consumers to bankers and a loss of efficiency associated with more fre- 
quent defaults. We then compare these maximum-diversification results with the BulowRogoff no-debt-buyback precept, and show that these similar conclusions are motivated by completely different mechanisms. We finally show that when the model is extended so as to give banks the possibility, at a cost, to partially evade diversification (for a given regulatory intensity $r$ ), then they choose re-nationalization strategies when bad news accrue. ${ }^{20}$

\subsection{Amplification Mechanism}

This feedback loop can be seen through the following fixed-point equation for the date-1 price of domestic sovereign bonds

$$
p_{1}(s)=1-F\left(B_{1}(s) \mid s\right),
$$

where

$$
B_{1}(s)=B_{0}+\max \left\{\frac{I(s)-r}{p_{1}(s)}-\frac{A-r}{p_{0}}, 0\right\} .
$$

Using the implicit function theorem, we can then derive the following comparative statics result, assuming that a bailout occurs in state $s$, i.e. that $s<\tilde{s}$.

Proposition 1 (Feedback Loop). The sensitivity of date-1 bond prices $p_{1}(s)$ to the state $s<\tilde{s}$ when a bailout is required is given by

$$
\frac{d p_{1}(s)}{d s}=\frac{-\frac{\partial F\left(B_{1}(s) \mid s\right)}{\partial s}-\frac{1}{p_{1}(s)} f\left(B_{1}(s) \mid s\right) \frac{d I(s)}{d s}}{1-\frac{I(s)-r}{p_{1}^{2}(s)} f\left(B_{1}(s) \mid s\right)} .
$$

The numerator on the right-hand side of equation (12) encapsulates the direct effect of the change in $s$ on the debt price $p_{1}(s)$ if there were no change in the price at which the Sovereign issues bonds to finance the bailout and at which bankers liquidate their sovereign bond holdings. The first term in the numerator captures the direct change in the probability of no-default at constant investment size $I(s)$. The second term in the numerator captures the direct impact of the change in the investment size $I(s)$.

The denominator takes the form of a multiplier, which represents the indirect effect of a change in $s$ on the debt price $p_{1}(s)$ through the change in the price at which the Sovereign

\footnotetext{
${ }^{20}$ In our model, ruling out bailouts, if possible, would be desirable. Bianchi (2016), Stavrakeva (2013), and Keister (2016) argue that bailouts can have desirable properties despite the associated moral hazard. In Bianchi (2016) and Stavrakeva (2013), this occurs because bailouts help relax borrowing constraints in crises. In Keister (2016), this happens because bailouts mitigate the incentives of depositors to run on banks in an environment à la Diamond-Dybvig (1983). These papers stress that the optimal policy mix might involve bank bailouts combined with macroprudential policy. This possibility could arise in our model, but we mostly focus on the case where it does not by assuming that banks have enough net worth to take advantage of future investment opportunities provided that they manage their liquidity prudently.
} 
issues bonds and at which bankers liquidate their sovereign bond holdings. The multiplier is higher, the larger the amount of foreign-held debt $B_{1}(s)-\left(B_{0}-b_{0}\right)=\frac{I(s)-r}{p_{1}(s)}$ that must be issued to finance the bailout (and hence the higher the amount of domestic debt held by domestic banks, i.e. the lower is $r$ ), and the larger the semi-elasticity $\frac{1}{p_{1}(s)} f\left(B_{1}(s) \mid s\right)$ of the debt price $p_{1}(s)$ to additional debt issuances. This multiplier captures the feedback loop between banks and the Sovereign as an amplification mechanism: An increase in default probability reduces the price $p_{1}(s)$, which increases the required bailout $X(s)$ and hence the quantity of bonds $B_{1}(s)-B_{0}$ that must be issued at date 1 , which further reduces the price $p_{1}(s)$, etc., ad infinitum; similarly, an increase in banks' financing needs which increases the required bailout $X(s)$ and hence the quantity of bonds $B_{1}(s)-B_{0}$ that must be issued at date 1 , which reduces the price $p_{1}(s)$, and increases the required bailout $X(s)$, etc. ad infinitum. ${ }^{21}$

Can balance sheets be consolidated? It is instructive to view the doom loop through the lens of balance sheet consolidation. In a nutshell, we argue that given $p_{0}$ and $B_{0}$, the banks' and the Sovereign's balance sheets: (1) can be consolidated in the bailout region for the purpose of predicting the level of state-contingent sovereign debt $B_{1}(s)$ owed at date 2 , and therefore the likelihood of sovereign default; (2) cannot be consolidated for the same purpose in the no-bailout region; and (3) cannot be consolidated for the purpose of predicting the domestic distribution of welfare as well as total domestic welfare.

Points (1) and (2) can be understood as follows. At date 0, banks have positions $b_{0}$ and $b_{0}^{*}$ in domestic and foreign debt. Similarly, the Sovereign has positions $-B_{0}$ and 0 in the two assets. The consolidated positions in the two assets are $b_{0}-B_{0}$ and $b_{0}^{*}$. In the no-bailout region, sovereign default at date 2 hinges on $B_{1}(s)=B_{0}$. And so the probability of sovereign default is not pinned down by consolidated positions, which also incorporate banks' positions. By contrast, in the bailout region, $B_{1}(s)$ is a function solely of consolidated positions: $\left[1-F\left(B_{1}(s) \mid s\right)\right]\left[B_{1}(s)-\left(B_{0}-b_{0}\right)\right]=I(s)-b_{0}^{*}$. Point (3) is immediate since the rents of bankers $\mathcal{R}_{0}=-\left(1-\beta^{B}\right) \int_{s \leq \tilde{s}} \min \left\{b_{0}^{*}+b_{0} \frac{1-F\left(B_{1}(s) \mid s\right)}{p_{0}}-I(s), 0\right\} d \pi(s)$ are not pinned down by consolidated positions.

No Supervisory Leniency. In this basic model, it is never optimal for the supervisor to engage in supervisory leniency.

\footnotetext{
${ }^{21}$ We have assumed that the marginal buyer, the international investors, exhibits no risk-aversion. It would be interesting to analyze whether the presence of risk-aversion by international investors would amplify the doom loop (it would affect both $p_{0}$ and $p_{1}(s)$ ) and whether a shock to the stochastic discount factor of international investors could actually trigger the doom loop in the case with short debt maturity. In addition, if the marginal buyer were a domestic bank anticipating to be bailed out, bond prices would not fall as much, so that could dampen the doom loop (and perhaps provide a reason for financial repression).
} 
Proposition 2 (No Supervisory Leniency). As long as there are bailouts, it is never optimal for the supervisor to engage in supervisory leniency and so $r=\bar{r}$.

The proof of Proposition 2 uses the decomposition $\mathcal{W}_{0}=\mathcal{E}_{0}-\mathcal{R}_{0}+\mathcal{C}_{0}$ given in (8) taking $p_{0}$ as given. Supervisory leniency has four effects on welfare. First, it has an efficiency benefit by reducing expected legacy debt repayments because it leads to more defaults. Second, it has an efficiency cost by increasing expected default costs. Under our maintained assumption of large default costs, the net effect of these first two effects is a reduction in efficiency $\mathcal{E}_{0}$. Third, it has a distributive cost by increasing the rents extracted by bankers at the expense of consumers because of bank bailouts, increasing $\mathcal{R}_{0}$. Fourth, it has a distributive cost because bankers must now purchase debt from foreign legacy creditors at a price which exceeds expected repayment, reducing $\mathcal{C}_{0}$. Overall, the total effect of supervisory leniency is therefore a reduction in welfare.

Remark: While the logic of Proposition 2 makes good economic sense, Sovereigns usually do not seem to limit their banks' abilities to hold their debt in times of distress. The next section's task will be to shed light on why this may be so.

First-Best Frictionless Supervision. Let us now investigate a related but different question. We perform a comparative statics exercise with respect to supervisory capability $\bar{r}$. This differs from the regulatory intensity (the choice of $r$ ) question because the Sovereign internalizes its impact on the date- 0 price of debt $p_{0}$ when choosing supervisory capacity $\bar{r}$, but not when choosing actual supervision $r \leq \bar{r}$ given supervisory capacity $\bar{r}$. We perform this comparative static exercise under two alternative assumptions: (a) that the face value of debt $B_{0}$ is kept constant; or (b) that the market value of debt $p_{0} B_{0}$ is kept constant. Which of (a) or (b) is most reasonable depends on the situation one is trying to capture. One could argue that (b) is more relevant for long-run comparisons across countries or supervisory regimes, while (a) is more relevant to analyze short-run responses to unanticipated shocks or situations as in Bulow-Rogoff $(1988,1991)$ (see below).

The occurrence of default is minimized when $\bar{r}=\bar{I}$ so that bankers can always finance their investment $I(s)$ without requiring a bailout. ${ }^{22}$ Reducing $\bar{r}$ below $\bar{I}$ on the other hand would reduce welfare. Indeed, the effect of reducing $\bar{r}$ below $\bar{I}$ on welfare can be analyzed using the decomposition $\mathcal{W}_{0}=\mathcal{E}_{0}-\mathcal{R}_{0}$ given in (4). First, if the face value of debt is kept constant, it has an efficiency benefit by reducing expected repayments to foreigners because it leads to more defaults (this efficiency benefit is inexistent if instead the market value of debt is kept constant). Second, it has an efficiency cost by increasing expected default costs. Under our maintained assumption of large default costs, the net effect is a reduction in $\mathcal{E}_{0}$.

\footnotetext{
${ }^{22}$ The welfare of bankers as well as total welfare are then independent of the amount $b_{0}^{*} \geq \bar{r}$ invested in foreign bonds above the floor $\bar{r}$, where we have used the fact that $r=\bar{r}$.
} 
Third, it has a distributive cost by increasing the rents extracted by bankers at the expense of consumers because of bank bailouts. This increases $\mathcal{R}_{0}$. Overall, the total effect of lower supervisory capability is therefore a reduction in welfare.

Proposition 3 (First-Best Frictionless Supervisory Capability). Setting $\bar{r}=\bar{I}$, if feasible, maximizes ex-ante welfare $\mathcal{W}_{0}$.

The optimal frictionless first-best supervision actually prevents the feedback loop from occurring in the first place by prohibiting domestic banks from holding domestic sovereign debt to an extent that could make them illiquid. We have already discussed in Section 2.1 some reasons why we might observe suboptimal supervision $\bar{r}<\bar{I}$, creating the possibility of the feedback loops that are the focus of this paper. These considerations lead us to adopt a pragmatic position and treat $\bar{r}$ as a parameter.

Remark: The rationale for supervision uncovered in Propositions 2 and 3 has a macroprudential dimension. Indeed, the benefits of liquidity regulation depend on the risk taken by the banking system as a whole. The more risk the banking system as whole takes, the riskier domestic sovereign debt, and the higher the probability of a sovereign default. Moreover, as we show in Appendix A.3, higher aggregate risk taking also increases the incentives risk taking by individual banks. The benefits of tighter supervision therefore have a clear macroeconomic dimension, over and above their usual microeconomic one.

Remark: We will encounter throughout the paper a number of corner solutions. These are the result of deliberate modeling choices: To simplify the exposition and isolate the fundamental forces at work, we have chosen to keep our model very parsimonious and to build in a lot of linearity, leading to such corner solutions. The qualitative insights that we obtain do not depend on corner solutions. For example, if we had introduced convex costs of supervisory intensity and capability, then the no-supervisory leniency and maximal supervisory capability results in Propositions 2 and 3 would have taken less extreme forms.

\subsection{Connection to Bulow-Rogoff's Debt Buybacks Result}

Engaging in supervisory leniency, or lowering supervisory capacity triggers a form of debt buyback of domestic sovereign debt by domestic banks. Propositions 2 and 3 establish that such debt buybacks are undesirable, ex post and ex ante respectively.

It is interesting to relate these results to the well-known result by Bulow-Rogoff (1988, 1991) that debt buybacks are undesirable. Their result is derived in a model that has similarities and differences with ours. Like our model, their model has mechanical defaults (defaults occur if the Sovereign cannot pay). Unlike our model, their model has zero default costs, and it has only consumers but no banks and no bailouts. We now proceed to unpack the respective roles of these different assumptions. As we shall see, our results, and the logic behind 
them, are very different from those of Bulow-Rogoff. But in order to maximize the comparability with their results, we focus on the choice of regulatory capacity as in Proposition 3, where there is an effect of the associated debt buyback on the date- 0 price of debt which is internalized by the Sovereign. For the same reason, we focus on the case where the face value of debt, rather than the market value of debt, is kept constant. We rely on the decomposition $\mathcal{W}_{0}=\mathcal{E}_{0}-\mathcal{R}_{0}$ given in (4).

The essence of the Bulow-Rogoff argument is as follows. Consider the same environment as in our model, but with no default costs $(\Phi=0)$ and no banks $(A=\bar{I}=0)$. A debt buyback by the Sovereign which reduces debt from $B_{0}$ to $B_{0}+\Delta B_{0}$ with $\Delta B_{0}<0$, financed by taxes on consumers at date 0 , results in new no-default states $\Delta N D=\left\{(s, E) \mid E \in\left[B_{0}+\Delta B_{0}, B_{0}\right)\right\}$. This leads to a positive change in foreign welfare

$$
\Delta \mathcal{W}_{0}^{*}=\mathbb{E}_{0}\left[B_{0} 1_{\{(s, E) \in \Delta N D\}}\right]>0
$$

and a negative change in domestic welfare

$$
\Delta \mathcal{W}_{0}=\Delta \mathcal{E}_{0}=-\Delta \mathcal{W}_{0}^{*}<0
$$

Basically, the game is zero sum between domestics and foreigners. Foreigners gain from the buyback because it reduces the amount of outstanding debt, increases the probability of repayment, and increases the date- 0 price of debt. ${ }^{23}$ The gains of foreigners are at the expense of domestics, who end up repaying more often. A debt buyback is therefore a bad deal.

Now introduce default costs $(\Phi>0)$, but continue to assume that there are only consumers but no banks $(A=\bar{I}=0)$. Repeating the same exercise, we still have

$$
\Delta \mathcal{W}_{0}^{*}=\mathbb{E}_{0}\left[B_{0} 1_{\{(s, E) \in \Delta N D\}}\right]>0
$$

but we now have

$$
\Delta \mathcal{W}_{0}=\Delta \mathcal{E}_{0}=\mathbb{E}_{0}\left[\left(\Phi-B_{0}\right) 1_{\{(s, E) \in \Delta N D\}}\right]=\mathbb{E}_{0}\left[\Phi 1_{\{(s, E) \in \Delta N D\}}\right]-\Delta \mathcal{W}_{0}^{*}>-\Delta \mathcal{W}_{0}^{*}
$$

Because of default costs, the game between domestics and foreigners is not zero sum anymore: Debt buybacks have efficiency gains because they economize on default costs. With large enough default costs, debt buybacks are a good deal: Both domestics and foreigners gain from a debt buyback.

Now introduce not only default costs $(\Phi>0)$ but also banks $(A>0$ and $\bar{I}>0)$ to get

\footnotetext{
${ }^{23}$ Foreigners are indifferent between selling and holding on to domestic sovereign debt. Those who sell benefit from the increased date- 0 price. Those who do not sell benefit from the reduced probability of default.
} 
our model as analyzed in Proposition 3. Start from $\bar{r}=\bar{I}$ and lower supervisory capacity to $\bar{r}+\Delta \bar{r}$ with $\Delta \bar{r}<0$. This leads to a debt buyback of domestic sovereign debt by domestic banks. Despite the presence of default costs, this reduces domestic welfare. Indeed, the debt buyback leads to greater bank bailouts $\Delta X(s) \geq 0$ and additional post-bailout debt $\Delta B_{1}(s) \geq$ 0 . As a result, there are new default states $\Delta D=\left\{(s, E) \mid E \in\left[B_{1}(s), B_{1}(s)+\Delta B_{1}(s)\right)\right\}$ instead of new no-default states. This reduces foreign welfare

$$
\Delta \mathcal{W}_{0}^{*}=-\mathbb{E}_{0}\left[B_{0} 1_{\{(s, E) \in \Delta D(s)\}}\right] \leq 0
$$

and domestic welfare

$$
\Delta \mathcal{W}_{0}=\Delta \mathcal{E}_{0}-\Delta \mathcal{R}_{0}=-\mathbb{E}_{0}\left[\left(\Phi-B_{0}\right) 1_{\{(s, E) \in \Delta D(s)\}}\right]-\left(1-\beta^{B}\right) \mathbb{E}_{0}[\Delta X(s)] \leq 0 .
$$

The reduction in domestic welfare arises from efficiency costs in the form of larger expected default costs net of debt repayments $\Delta \mathcal{E}_{0}=-\mathbb{E}_{0}\left[\left(\Phi-B_{0}\right) 1_{\{(s, E) \in \Delta D(s)\}}\right] \leq 0$, and from distributive costs in the form of extra rents extracted by bankers at the expense of consumers $\Delta \mathcal{R}_{0}=\left(1-\beta^{B}\right) \mathbb{E}_{0}[\Delta X(s)] \geq 0$.

Like in Bulow-Rogoff, in our setting, debt buybacks reduce domestic welfare. But there are important differences. First, in our setting and unlike in theirs, there are default costs. Second, in our setting and unlike in theirs, it matters which institutions perform the debt buyback: Debt buybacks by the Sovereign can improve domestic welfare, but debt buybacks by banks reduce domestic welfare. Third, in our setting and unlike in theirs, debt buybacks by banks reduce foreign welfare as well as domestic welfare.

The takeaway from this discussion is that balance sheet consolidation leads to misleading conclusions. In the presence of large default costs, debt buybacks are a good deal, but not if they occur through domestic banks. This result, and the logic behind it, are fundamentally different from those of Bulow-Rogoff. They can only be uncovered in a setting with enough granularity to capture the special position of the financial sector and its relation with the Sovereign.

\subsection{Debt Re-Nationalization}

We now unveil a first driver of re-nationalization of portfolios in bad times: When banks have some discretion with regards to their level of diversification (which was not the case so far, as their choice was bound to match the regulatory intensity $r$ ), then their incentive not to diversify is higher when bad news, say about fiscal capacity, accrues. The intuition is that bad news raises the value of the bailout put, and so banks are more willing to incur costs to reduce their diversification (for example by concealing more their exposure to the 
Sovereign). More precisely, we assume (for the sake of this section only) that a bank's ability to engage in risk taking depends not only on supervisory policy, but also on its own ability to make its balance sheet opaque.

Taking the supervisory effort $r$ as a given, assume that each bank, indexed by $i \in[0,1]$, can select its individual level of foreign holdings $b_{0}^{*}(i)$ at non-monetary cost $\Psi\left(r-b_{0}^{*}(i)\right)$, with $\Psi(x)=0$ for $x \leq 0$ and $\Psi(x)$ a strictly increasing and convex function for $x \geq 0$. We look for a symmetric equilibrium in which all banks choose the same $b_{0}^{*}(i)=b_{0}^{*}$ for all $i$. For simplicity, we focus on fiscal shocks and assume that $I(s)=\bar{I}$ is independent of $s$. We also assume that $A=\bar{I}$. It is easy to see that the absence of supervisory leniency $r=\bar{r}$ extends to the setting of this section. We therefore make use of the fact that $r=\bar{r}$ throughout.

We consider shifts $F(E \mid s ; \xi)$ and $f(E \mid s ; \xi)$ in the distribution of fiscal capacity $E$ given the state of the world $s$ indexed by the parameter $\xi$ (these shifts are public information at date 0 and hence affect $p_{0}$ ). We perform the local comparative statics around an initial value $\xi_{0}$. All equilibrium variables are indexed by $\xi$, and we consider partial and total derivatives of these variables with respect to $\xi$ at $\xi=\xi_{0}$.

We say that the shifter $\xi$ is risk-increasing at $\xi_{0}$ if $\left.\frac{\partial F\left(B_{1}(s ; \xi) \mid s ; \xi\right)}{\partial \xi}\right|_{\xi=\xi_{0}}>0$ for $s<\tilde{s}\left(\xi_{0}\right)$ and $\left.\frac{\partial F\left(B_{1}(s ; \xi) \mid s ; \xi\right)}{\partial \xi}\right|_{\xi=\xi_{0}}=0$ for $s \geq \tilde{s}\left(\tilde{\xi}_{0}\right)$. Concretely, this means that an infinitesimal increase in $\xi$ leads to an adverse shift in the distribution of fiscal capacity (in the first-order stochastic dominance sense) for states $s<\tilde{s}\left(\xi_{0}\right)$ in which there is a bailout, but not for states $s \geq \tilde{s}\left(\xi_{0}\right)$ for which there is no bailout.

To lighten the notation, whenever this cannot lead to any confusion, we leave the dependence of all variables on $\xi$ implicit. We also omit that the derivatives are taken at $\xi=\xi_{0}$. Hence for example, we write $p_{0}$ instead of $p_{0}(\xi)$ and $\frac{d p_{0}}{d \xi}$ instead of $\left.\frac{d p_{0}(\xi)}{d \xi}\right|_{\xi=\xi_{0}}$.

Proposition 4 (Bad Fiscal Shocks and Debt Re-nationalization). Suppose that $I(s)=\bar{I}$ is independent of s, that $A=\bar{I}$, and that the shifter $\xi$ is risk-increasing. Then an adverse shock in the form of an increase in $\xi$ leads to a reduction in the price of debt (a reduction in $p_{0}$ ) and an increase in the exposure of domestic banks to domestic sovereign risk (a reduction in diversification $b_{0}^{*}$ ):

$$
\frac{d b_{0}^{*}}{d \tilde{\zeta}}=\frac{\int_{s \geq \tilde{s}} \frac{p_{1}(s)}{p_{0}^{2}} d \pi(s)}{\Psi^{\prime \prime}\left(\bar{r}-b_{0}^{*}\right)} \frac{d p_{0}}{d \tilde{\zeta}}<0 .
$$

When the shifter $\xi$ is risk-increasing, an infinitesimal increase in $\xi$ does not change the date-1 price of debt $p_{1}(s)$ in the no-bailout states $s \geq \tilde{s}$, but decreases it on average in the bailout states $s<\tilde{s}$, leading to a decrease in the date-0 price of debt $p_{0}$. As a result the returns to holding domestic sovereign debt for a bank $\frac{p_{1}(s)}{p_{0}}$ increase in the no-bailout states, and are unchanged in the bailout states because the bank is bailed out. This increases the attractiveness of risky domestic sovereign debt for domestic banks, and leads banks to 
increase their exposure $A-b_{0}^{*}$ to risky domestic sovereign debt and decrease their exposure $b_{0}^{*}$ to safe foreign sovereign debt. This in turn increases the size of bailouts on average in bailout states, further reduces the date- 1 price of debt $p_{1}(s)$ on average in these states and the date- 0 price of debt $p_{0}$, further increases the attractiveness of risky domestic sovereign debt for domestic banks, leading banks to further increase their exposure $A-b_{0}^{*}$ to risky domestic sovereign debt and to decrease their exposure $b_{0}^{*}$ to safe foreign sovereign debt, etc. ad infinitum. This feedback loop amplifies the initial effect on $p_{0}, p_{1}(s)$, and $b_{0}^{*}$ through a multiplier effect. ${ }^{24}$

In Appendix A.3, we show that the introduction of a supervisory evasion cost function adds yet another insight: supervisory evasion activities are complements. Intuitively, increased risk-taking by other banks makes domestic sovereign bonds riskier and increases the value of the bailout put, inducing individual banks to exert further efforts to take on more sovereign debt. There is more amplification, the stronger are the strategic complementarities, as measured by the inverse of the curvature $\Psi^{\prime \prime}\left(\bar{r}-b_{0}^{*}\right)$ of the supervisory evasion cost function, which determines the slope of an individual bank's best response to the portfolios of other banks.

Proposition 4 defines a precise sense in which bad fiscal news can lead to debt re-nationalization. It offers a possible explanation for the well-known fact that such a re-nationalization of sovereign debt was observed in Europe as the recent crisis intensified. ${ }^{25}$ Here this is due to the imperfect ability of the Sovereign to limit the exposure of banks to domestic sovereign default risk through supervision. The rationale for re-nationalization is based on the idea that risky domestic sovereign bonds are more attractive to banks in bad times. ${ }^{26}$

We return to debt re-nationalization in Section 4.1, where we propose a different mechanism, which relies on the desirability for the Sovereign to allow banks to load up on domestic sovereign default risk in order to push legacy creditors to forgive more debt or foreign countries to extend sovereign transfers, even if the Sovereign can perfectly supervise the banking system.

\footnotetext{
${ }^{24}$ See the denominator in

$$
\frac{d p_{0}}{d \tilde{\xi}}=\frac{-\int_{s<\tilde{s}} \frac{\frac{\partial F\left(B_{1}(s) \mid s\right)}{\partial \tilde{s}}}{1-\frac{A-r}{p_{1}(s)^{2}} f\left(B_{1}(s) \mid s\right)} d \pi(s)}{1+\int_{s<\tilde{s}} \frac{f\left(B_{1}(s) \mid s\right) \frac{A-b_{0}^{*}}{p_{0}^{2}}}{1-\frac{A-r}{p_{1}(s)^{2}} f\left(B_{1}(s) \mid s\right)} d \pi(s)-\frac{\int_{s \geq \tilde{s}} \frac{p_{1}(s)}{p_{0}^{2}} d \pi(s)}{\Psi^{\prime \prime \prime}\left(\tilde{r}-b_{0}^{*}\right)} \int_{s<\tilde{s}} \frac{f\left(B_{1}(s) \mid s\right)\left[\frac{1}{p_{1}(s)}-\frac{1}{p_{0}}\right]}{1-\frac{A-r}{p_{1}(s)^{2}} f\left(B_{1}(s) \mid s\right)} d \pi(s)}<0 .
$$

${ }^{25}$ See Broner et al (2013), Genaioli et al (2014,a,b) and Uhlig (2014) for careful documentations.

${ }^{26}$ In bad times monitoring banks is also more attractive to the supervisor. Proposition 4 nonetheless would still hold as long as the supervisory capability does not adjust rapidly with the state of nature.
} 


\section{Lax Supervision, Debt Re-Nationalization, and Banking Unions}

This section provides two different reasons why supervision is likely to be lax when consequences are borne in part by foreigners. As lax supervision ultimately hurts either the country itself or foreigners, we will then discuss the implications of our analysis for the existence of a banking union, in the sense of a single supervisory mechanism.

We first modify the basic model by introducing the possibility of debt forgiveness at date 1 , and show that it gives rise to an incentive for lax supervision whereby the domestic Sovereign, anticipating concessions from legacy creditors, turns a blind eye when its banks take on domestic sovereign risk exposures and sets $r<\bar{r}$, leading to debt re-nationalization. If the ex-post leniency of domestic supervisors is anticipated ex ante at the time of sovereign debt issuance, then it is priced in the form of higher spreads. There is an externality on foreign investors only ex post. The Sovereign is better off committing ex ante to a tough ex-post supervisory stance $r=\bar{r}$, but is tempted to relax it ex post to $r<\bar{r}$. The Sovereign, who lacks commitment, benefits from relinquishing its supervisory powers to a supranational supervisor by joining a banking union.

We then assume away debt forgiveness, and introduce instead the possibility that foreign countries incur a collateral damage when the domestic country defaults. At the intermediate date, they can make a transfer to the country. This transfer is shown to increase with the home bias (in the region in which there are bailouts). Thus supervisory leniency is costly to the country as transfers from abroad increase. Supervision might therefore be lenient and lead to debt re-nationalization. Delegation to a supranational supervisor combined with a commitment to sufficient ex-post transfers improves total (domestic and foreign) welfare by internalizing an externality of domestic supervision on foreign countries. This provides an externality-based rationale for banking unions where, in contrast with the previous commitment-based rationale, requires both delegated supervision and transfer commitments.

To be certain, the rationale for a banking union can also be found in externalities unrelated to debt forgiveness or transfers from foreign countries. A lax supervision may hurt foreigners because foreign banks hold domestic sovereign debt ${ }^{27}$ or have exposures to domestic banks, because domestic banks have subsidiaries abroad that will be shut down or downsized in case of difficulties (presumably before the domestic entity), etc. For example, in Appendix B.4, we develop a model with foreign banks in the foreign safe country which can invest in domestic risky sovereign bonds and show that this builds a case for a banking union to internalize externalities of domestic supervision on foreign banks through the riskiness of domestic sovereign debt.

\footnotetext{
${ }^{27}$ See for example the exposure of French and German banks to Greek sovereign debt.
} 


\subsection{Debt Forgiveness}

We model date- 1 debt forgiveness as follows. We assume that after the state of nature $s$ is observed at date 1 , bondholders can forgive some of the legacy debt to an arbitrary $\tilde{B}_{0} \leq B_{0}$, before the Sovereign undertakes the bailout policy. ${ }^{28}$ When some debt forgiveness can improve the outcome of the legacy creditors, a mutually beneficial negotiation can take place between legacy creditors and the Sovereign. The outcome of the negotiation depends on the ability of legacy creditors to coordinate and on the distribution of bargaining power between legacy creditors and the Sovereign. ${ }^{29}$ We assume that legacy creditors are able to coordinate, and have all the bargaining power: They collectively make a take-it-or-leave-it offer to the Sovereign. Bondholders factor in the subsequent bailout when choosing how much to forgive. Banks either have no stake (i.e. when they will receive a bailout) or have perfectly congruent interests with international investors (when not bailed out). So we can take the decision of bondholders to be that of international investors.

Legacy creditors engage in debt forgiveness $\bar{B}_{0}(s)<B_{0}$ when legacy debt $B_{0}$ is on the wrong side of the legacy creditors' Laffer curve $p_{1}\left(s ; \tilde{B}_{0}\right) \tilde{B}_{0}$, where $\bar{B}_{0}(s)$ is the peak of the legacy creditors' Laffer curve. We have introduced the notation $p_{1}\left(s ; \tilde{B}_{0}\right)=1-F\left(B_{1}\left(s ; \tilde{B}_{0}\right) \mid s\right)$ to make the dependence of the date- 1 price of debt on the post-debt-forgiveness debt stock $\tilde{B}_{0}$ explicit. ${ }^{30,31}$

A remarkable property is that debt forgiveness, when it happens, leads to a final debt $B_{1}(s)$ at the peak $\bar{B}_{1}(s)$ of the Laffer curve $\left[1-F\left(B_{1} \mid s\right)\right] B_{1}$. This is obvious when there is no bailout; then $B_{1}(s)=\tilde{B}_{0}$ and so international investors maximize $\left[1-F\left(\tilde{B}_{0} \mid s\right)\right] \tilde{B}_{0}$, leading to $B_{1}(s)=\bar{B}_{1}(s)$. Suppose, next, that there is a bailout: $B_{1}=B_{1}(s)$ satisfies

$$
\left[1-F\left(B_{1} \mid s\right)\right]\left(B_{1}-\tilde{B}_{0}\right)=X(s)
$$

where $X(s)$ is an affine function of $\left[1-F\left(B_{1} \mid s\right)\right] \tilde{B}_{0}$ (the banks' sovereign debt holdings have shrunk by a factor $\frac{\tilde{B}_{0}}{B_{0}}$ and their price is $\left.\left[1-F\left(B_{1} \mid s\right)\right]\right) .^{32}$ The above bailout equation therefore shows that what the legacy creditors attempt to maximize, $\left[1-F\left(B_{1} \mid s\right)\right] \tilde{B}_{0}$, is an increasing

\footnotetext{
${ }^{28}$ Would the foreign investors not want to combine the debt write-down with a restriction on the amount of new debt that can be issued so as to avoid subsequent debt dilution when the bailout is operated? This would actually make no difference: We have assumed that $\beta^{I}(s)$ is sufficiently large that the Sovereign wants to bail out the banks no matter what. Such a covenant would therefore not lead to an agreement, and so the investors might as well forgive debt without including such a covenant.

${ }^{29}$ Of course organizing debt forgiveness requires coordination among legacy creditors to neutralize the freeriding incentives of individual creditors.

${ }^{30}$ We assume that banks do not free-ride on the renegotiation. All our results would go through if we assumed instead that banks could perfectly free-ride on the renegotiation.

${ }^{31}$ The possibility of debt forgiveness does not rely on the presence of banks or the existence of bailouts. See Hatchondo-Martinez-Sosa Padilla (2014) for a recent analysis.

${ }^{32}$ In this case, $X(s)$ is given by $X(s)=I(s)-r-\frac{A-r}{p_{0} B_{0}} \tilde{B}_{0}\left[1-F\left(B_{1}(s) \mid s\right)\right]$.
} 
(and affine) function of $\left[1-F\left(B_{1} \mid s\right)\right] B_{1}$, which explains why final debt is still at the peak of the Laffer curve (see the proof of Proposition 5 for a more formal account).

Proposition 5 (Legacy Creditors' Laffer Curve and Debt Forgiveness). Consider the equilibrium for a given fixed diversification requirement $r \in[0, \bar{r}] .{ }^{33}$ Suppose that there are states $s$ where debt forgiveness takes place so that $B_{0}(s)=\bar{B}_{0}(s)$ and focus on these states. Then the amount of date-1 debt after debt forgiveness and issuance associated with the peak $\bar{B}_{0}(s)$ of the legacy creditors' Laffer curve is at the peak $\bar{B}_{1}(s)$ of the Laffer curve $\left[1-F\left(B_{1} \mid s\right)\right] B_{1}$. In addition, $\bar{B}_{0}(s)$ is increasing in $s$ so that worse states are associated with more debt forgiveness.

The possibility of debt forgiveness can make it optimal for the Sovereign to engage in supervisory leniency $r<\bar{r}$ so as to extract larger concessions from legacy creditors. Another way to put this is that the Sovereign may have incentives to let its domestic banks load up on domestic sovereign debt in order to extract concessions from legacy creditors.

Assume for simplicity that $I(s)$ is independent of $s$ and that $A=\bar{I}$, and consider the equilibrium for a given fixed diversification requirement $r \in[0, \bar{r}]$. All equilibrium variables are indexed by $r$ but we leave this dependence implicit to make the notation lighter. Suppose first that if there is no bailout, then there is debt forgiveness if and only $s \leq \bar{s}$, where the threshold $\bar{s}$ is defined implicitly by the equation

$$
1=B_{0} \frac{f\left(B_{0} \mid \bar{s}\right)}{1-F\left(B_{0} \mid \bar{s}\right)} .
$$

Assuming that there is debt forgiveness, there is a bailout if and only if $s \leq \tilde{s}$, where, using the fact that $I(s)$ is independent of $s$ and that $A=\bar{I}$, the threshold $\tilde{s}$ is defined implicitly by the equation

$$
\frac{\bar{B}_{1}(\tilde{s})}{B_{0}} \frac{1-F\left(\bar{B}_{1}(\tilde{s}) \mid \tilde{s}\right)}{p_{0}}=1
$$

where $\bar{B}_{1}(s)$ is the peak of the Laffer curve with $\bar{B}_{1}(s) \frac{f\left(\bar{B}_{1}(s) \mid s\right)}{1-F\left(\bar{B}_{1}(s) \mid s\right)}=1$. If these two thresholds are ordered $\tilde{s}<\bar{s}$, then it is possible to prove that there is a bailout if and only if $s \leq \tilde{s}$, and debt forgiveness if and only if $s \leq \bar{s} .{ }^{34}$ This configuration is guaranteed to arise in bad times

\footnotetext{
${ }^{33}$ This means that we consider an equilibrium of a modified policy game where the supervisor is forced to choose the diversification requirement $r$. We will later consider the equilibrium choice of $r$.

${ }^{34}$ We only need to verify that the condition for no bailout if there is no debt forgiveness $\frac{1-F\left(B_{0} \mid s\right)}{p_{0}} \geq 1$ holds for $s>\bar{s}$, and that the condition for debt forgiveness if there is a bailout $\frac{f\left(B_{1}(s) \mid s\right)}{1-F\left(B_{1}(s) \mid s\right)} B_{0}\left[1+\frac{A-r}{p_{1}(s) B_{0}}\left(1-\frac{p_{1}(s)}{p_{0}}\right)\right] \geq 1$ holds for $s \leq \tilde{s}$. The first part follows immediately from the observation that $s>\bar{s}$ implies that $s>\tilde{s}$ and hence that $\frac{1-F\left(B_{0} \mid s\right)}{p_{0}} \geq \frac{1-F\left(B_{0} \mid \tilde{s}\right)}{p_{0}}$, together with the observation that $\frac{1-F\left(B_{0} \mid \tilde{s}\right)}{p_{0}} \geq \frac{1-F\left(B_{0}(\tilde{s}) \mid \tilde{s}\right)}{p_{0}}=\frac{1-F\left(B_{1}(\tilde{s}) \mid \tilde{s}\right)}{p_{0}}=\frac{B_{0}}{B_{1}(\tilde{s})}=$ $\frac{B_{0}}{B_{0}(\tilde{s})} \geq 1$. The second part follows immediately from the observation that $s \leq \tilde{s}$ implies that $s<\bar{s}$ and hence that $B_{0} \geq B_{1}(s)$ and that $\frac{f\left(B_{1}(s) \mid s\right)}{1-F\left(B_{1}(s) \mid s\right)} B_{0} \geq \frac{f\left(B_{1}(s) \mid s\right)}{1-F\left(B_{1}(s) \mid s\right)} B_{1}(s)=1$.
} 
when $B_{0}$ is large. ${ }^{35}$ We then say that the equilibrium is bailout-shifting to capture the idea that under this configuration, the cost of bailouts is entirely shifted to foreigners through debt forgiveness.

Proposition 6 (Debt Forgiveness, Strategic Supervisory Leniency, and Debt Re-Nationalization). Suppose that $I(s)$ is independent of $s$, that $A=\bar{I}$, and that the distribution $\pi(s)$ admits a continuous density $d \pi(s)=\Pi(s) d$ s. Consider the equilibrium with no supervisory leniency $r=\bar{r}$. Assume that for this maximal diversification requirement, the equilibrium is bailout-shifting. Then for any lower diversification requirement $r \leq \bar{r}$, the equilibrium with a fixed diversification requirement $r$ is bailout shifting. Moreover, the only equilibrium with endogenous supervisory leniency features maximal supervisory leniency $r=0$.

This proposition provides conditions under which it is optimal for the Sovereign to engage in full supervisory leniency and allow domestic banks to take only domestic debt, and to risk needing a bailout when the Sovereign experiences a bad fiscal shock. Supervisory leniency allows the Sovereign to extract more concessions from legacy creditors. ${ }^{36}$ Domestic consumers are left as well off because they are entirely shielded from the extra cost of bailouts, which are completely covered by extra debt forgiveness by foreigners, and because expected default costs are unchanged. Bankers are strictly better off in the no-bailout states because domestic sovereign debt has a higher return, and they are as well off in the bailout states because they are bailed out. ${ }^{37}$

In terms of the decomposition $\mathcal{W}_{0}=\mathcal{E}_{0}-\mathcal{R}_{0}+\mathcal{C}_{0}$ given in (8) and adjusted for debt forgiveness, supervisory leniency (lowering $r$ ) has the following effects given $p_{0}$ and $B_{0}$. First, it has an efficiency benefit because it leads to more debt forgiveness but not more defaults, increasing $\mathcal{E}_{0}$. Second, is has a distributive cost because it increases the rents extracted by

\footnotetext{
${ }^{35}$ That $\tilde{s}<\bar{s}$ for $B_{0}$ large enough can be seen as follows. As $B_{0}$ grows, $\bar{s}$ converges to the upper bound $s^{\max } \in \mathbb{\mathbb { R }}$ of the support of the $s$ distribution. At the same time, $p_{0} B_{0}$ converges to the constant $\int \bar{B}_{0}(s)\left[1-F\left(\bar{B}_{1}(s) \mid s\right)\right] \pi(s) d s$, which implies that $\tilde{s}$ converges to the interior point of the support of the $s$ distribution defined implicitly by $\frac{\bar{B}_{1}(\tilde{s})\left[1-F\left(\bar{B}_{1}(\tilde{s}) \mid \tilde{s}\right)\right]}{\int \bar{B}_{0}(s)\left[1-F\left(\bar{B}_{1}(s) \mid s\right)\right] \pi(s) d s}=1$.

${ }^{36}$ We refer the reader to Appendix C.3 for an illustration of Proposition 6 in the context of a simple example which can be solved in closed form.

${ }^{37}$ It is interesting to analyze how our results are affected when some banks already hold domestic sovereign debt at the time when the Sovereign decides its supervisory stance $r$. To do so, consider an overlapping generations extension of the model where a separate "generation -1 " of banks with mass $m_{-1}$ is introduced. Each of these banks has net worth $A_{-1}+p_{0} b_{0,-1}$ at date 0 , where $b_{0,-1}$ is their domestic sovereign debt holdings and $A_{-1}$ includes holdings of safe foreign sovereign bonds. Each of these banks must reinvest $I_{-1}$ at date 0 in order to get the payoff $\rho_{1,-1}$ (otherwise it gets 0 ) at date 1 in which case stakeholders also get $\beta_{-1}^{I}$ (otherwise they get $0)$. At date 0 , the Sovereign engages in a total bailout $m_{-1} \max \left\{I_{-1}-\left(A_{-1}+p_{0} b_{0,-1}\right), 0\right\}$ of "generation -1 " banks, which is financed either by using up some of the saved-up proceeds of the initial legacy debt issuance, or by taxing a separate "generation -1 " of consumers which carry a welfare weight of 1 . The important point is that because the choice of $r$ is not observable, it does not change the price $p_{0}$, and hence does not change the size of the bailout of "generation -1" banks. Therefore Proposition 6 still holds in this extended model: the fact that some domestic banks already hold domestic sovereign debt does not change the incentives to engage in supervisory leniency.
} 
bankers because of bailouts, increasing $\mathcal{R}_{0}$. Third, it has another distributive cost because bankers now purchase debt from legacy creditors at a price which is higher than the expected repayment (net of debt forgiveness), decreasing $\mathcal{C}_{0}$. Proposition 6 shows that the benefit outweighs the costs.

Proposition 6 offers a possible explanation for the well-known fact that a re-nationalization of sovereign debt was observed in Europe as the recent crisis intensified. In Section 3.3, we proposed a different mechanism based on the imperfect ability of the Sovereign to limit the exposure of banks to domestic sovereign default risk through supervision.

Remark: The maximal supervisory leniency result is striking, but relies on the bailout shifting assumption, which does not hold for $B_{0}$ small. The more general conclusion is that we should expect some supervisory leniency, and more so in times of fiscal stress. We refer the reader to Appendix C.3 where we develop an illustrative example where the bailout shifting assumption does not hold uniformly, and where there is some but not necessarily maximal supervisory leniency.

Remark: Excessively lax supervision can pre-date the crisis. Indeed, our formalism allows for agency costs within the Sovereign, as the supervisor may put excessive (relative to the population) weight on bankers' welfare or too much weight on real estate lending for instance. Proposition 6 then means that the prospect of debt forgiveness may make supervisors even more lenient than they would be otherwise.

We build on this analysis and put ourselves under the hypotheses of Proposition 6. We show that foreign investors are made worse off by the relaxation of supervision of domestic banks by the domestic Sovereign: Once they have lent, their welfare is maximized by a tough supervision $r=\bar{r}$. Of course their welfare is adversely impacted only if this relaxation of supervision is not anticipated at the time of the debt issuance, otherwise it is fully priced in. Interestingly, in this latter case, domestic welfare can be increased by a tough supervision $r=\bar{r}$. But this requires commitment on the part of the domestic Sovereign not to relax supervision after the debt is issued.

One of the important aspects of banking unions is the transfer of banking supervision from the national to the supranational level. Such a transfer weakens or removes the temptation of Sovereigns to strategically allow their banks to load up on domestic sovereign bonds to extract larger concessions from legacy creditors. It can therefore facilitate the implementation of the commitment solution with a high diversification requirement $r=\bar{r}$. This is because the international supervisor's objective function naturally puts more weight on international investors than the domestic Sovereign, making it less tempting to relax supervi- 
sion ex post. $^{38,39}$

Consider the debt level $B_{0}^{\prime}$ that generates the same amount of revenue $p_{0}^{\prime} B_{0}^{\prime}=p_{0} B_{0}$ at date 0 when the effective diversification requirement is $r^{\prime}=0$ as the debt level $B_{0}$ when the effective diversification requirement is $r=\bar{r}$. And compare the equilibrium with a fixed diversification requirement $r=\bar{r}$ and debt level $B_{0}$ to the equilibrium with endogenous supervisory leniency $r^{\prime}=0$ and debt level $B_{0}^{\prime}$. We denote all variables associated with the latter equilibrium with prime superscripts. We make the additional assumption that the former equilibrium is "bailout-shifting" with $\tilde{s}<\bar{s}^{40}$

We use the decomposition $\mathcal{W}_{0}=\mathcal{E}_{0}-\mathcal{R}_{0}$ given in (4) adjusted for debt forgiveness. We show below that $\mathcal{W}_{0}^{\prime}=\mathcal{E}_{0}^{\prime}-\mathcal{R}_{0}^{\prime}<\mathcal{W}_{0}=\mathcal{E}_{0}-\mathcal{R}_{0}$. This occurs for two reasons. First, with supervisory leniency anticipated at the issuance stage, we have $p_{0}^{\prime}<p_{0}$ and hence $B_{0}^{\prime}>B_{0}$ since $p_{0}^{\prime} B_{0}^{\prime}=p_{0} B_{0}$. The increase in legacy debt increases default occurrences, increases expected default costs, and reduces welfare as captured by $\mathcal{E}_{0}^{\prime}<\mathcal{E}_{0}$. Second, bankers collect bigger rents. The rents of bankers only come at the expense of consumers because supervisory leniency is fully priced in by foreign investors at the issuance stage. The increase in the rents of bankers therefore decreases the welfare of consumers one for one. Since consumers carry a higher welfare weight than banks, this also reduces welfare as captured by $\mathcal{R}_{0}^{\prime}>\mathcal{R}_{0} \cdot{ }^{41}$

Proposition 7 (Banking Union). Consider the same hypotheses as in Proposition 6. If the relaxation of supervision is fully priced in by international investors at the time of the issuance of date-0 debt, then the domestic Sovereign faces a time-inconsistency cost. It is made better off by promising not to engage in supervisory leniency and to set a high effective diversification requirement $r=\bar{r}$ before issuing debt at date 0 , but it is tempted to relax this requirement after the issuance and lower $r$ below $\bar{r}$. A banking union whereby supervision is delegated to a supranational supervisor who puts the same welfare weight on international investors and domestic consumers (instead of zero weight on international investors for the domestic supervisor) removes this temptation, implements the commitment solution, and improves domestic welfare and total (domestic and foreign) welfare.

\footnotetext{
${ }^{38}$ Another possibility is that the international supervisor has a better ability to commit to regulation than the domestic Sovereign, perhaps because it is dealing with more countries and more banks and can hence build a reputation more easily.

${ }^{39}$ Foreigners are powerless to resist the re-nationalization of domestic debt unless they are able to coordinate not to sell their domestic sovereign bonds to domestic banks, which unlike debt relief negotiations, seems to have few real world counterparts. To the extent that foreign investors are located in different countries, foreign national supervisors would also need to coordinate in order to facilitate this outcome.

${ }^{40}$ The difference with Proposition 6 is that $B_{0}^{\prime} \neq B_{0}$. Under this assumption, one can show that $B_{0}^{\prime}>B_{0}$, $\tilde{s}^{\prime}=\tilde{s}$ and that $\bar{s}^{\prime}>\bar{s}$, so that $\tilde{s}^{\prime}<\bar{s}^{\prime}$ the equilibrium with endogenous supervisory leniency $r^{\prime}=0$ and debt $B_{0}^{\prime}$ is "bailout-shifting".

${ }^{41}$ We refer the reader to Appendix C.4 for an illustration of Proposition 7 in the context of a simple example which can be solved in closed form.
} 


\subsection{Country Solidarity and International Transfers}

Instead of investors forgiving debt as their holdings lie on the wrong side of the legacy creditors' Laffer curve, we could have neighboring countries providing liquidity assistance as they know that they will be impacted by the economic and geopolitical consequences of a future default. To capture this, we assume that the neighboring countries incur spillover cost $\Gamma>0$ in case of default and can operate a (state-contingent) transfer $T \geq 0$ to the Sovereign at date 1 (see e.g. Tirole 2015); by contrast, we assume away debt forgiveness by the private sector, either because of lack of coordination or because debt holdings are on the right side of the legacy creditors' Laffer curve.

We only summarize our analysis and refer the reader to Appendix A.7 for a detailed treatment. For simplicity, we assume throughout that $I(s)=\bar{I}=A$ and that $F(E \mid s)=$ $F(E-s)$ with $f$ decreasing. The debt issuance equation is: $\left[1-F\left(B_{1} \mid s\right)\right]\left(B_{1}-B_{0}\right)=X(s)-T$ and foreign countries' objective function is $-\Gamma F\left(B_{1} \mid s\right)-T$, where $X(s)=\max \{(A-r)(1-$ $\left.\left.\frac{1-F\left(B_{1} \mid s\right)}{p_{0}}\right), 0\right\} .{ }^{42}$

When $\Gamma$ is large enough, the equilibrium given the fixed diversification requirement $r=0$ is bailout shifting in the sense that, as in Section 4.1, there exist two thresholds $\tilde{s}<\bar{s}$ such that bailouts occur only when transfers are strictly positive. There is then an additional threshold $\tilde{s}<\tilde{s}$ such that: For $s \geq \bar{s}$, there are neither transfers nor bailouts $(T(s)=X(s)=0)$, and date-1 debt is equal to legacy debt $\left(B_{1}(s)=B_{0}\right)$; for $\tilde{s} \leq s<\bar{s}$, there are transfers $(T(s)>0)$ but no bailouts $(X(s)=0)$, and date- 1 debt $B_{1}(s)<B_{0}$ increases less than one for one with $s$; for $\tilde{\tilde{s}} \leq s<\tilde{s}$, there are transfers $(T(s)>0)$ and still no bailouts $(X(s)=0)$, but date-1 debt $B_{1}(s)<B_{0}$ increases one for one with $s$ so as to prevent bailouts; and for $s<\tilde{s}$, there are transfers $(T(s)>0)$ and bailouts $(X(s)>0)$, and date- 1 debt $B_{1}(s)<B_{0}$ increases less than one for one with $s$.

The threshold $\tilde{s}$ is decreasing in $r \leq \bar{r}$ and $\bar{s}$ is independent of $r \leq \bar{r}$, so that the equilibrium given the fixed diversification requirement $r$ remains bailout shifting for all $r \leq \bar{r}$. For a given $p_{0}$ and $B_{0}, B_{1}(s)$ is independent of $r$ when $s>\tilde{s}$, but is strictly increasing in $r$ when $s<\tilde{\tilde{s}}$ . This last property is key, and means that for a given $p_{0}$ and $B_{0}$, a lower $r$ leads to an increase in transfer $T(s)$ that exceeds the increase in required bailout $X(s)$, leading to a lower debt burden $B_{1}(s)$. This arises because the doom loop, which is stronger when $r$ is lower, makes transfers more attractive at the margin for foreigners at any level $B_{1}(s)$ by magnifying the reduction in the probability of default resulting from a transfers. As a result, the only equilibrium features maximal supervisory leniency $r=0$.

Proposition 8. (Lax Supervision and Re-Nationalization) Assume that there is no debt forgiveness,

\footnotetext{
${ }^{42}$ Note that $T$ can be used at the discretion of the Sovereign. Since funds are fungible, in the bailout region, one can think of transfers as either deployed towards the rescue of banks or towards the reduction of debt.
} 
but that other countries incur collateral damage $\Gamma>0$ when the country defaults at date 2 and that they can operate a transfer $T(s) \geq 0$ of their choice at date 1 . Assume that $I(s)=\bar{I}=A$, that $F(E \mid s)=F(E-s)$ with $f$ decreasing, and that the equilibrium given the fixed diversification requirement $r=\bar{r}$ is bailout shifting, which is guaranteed to hold if $\Gamma$ is large enough. Then for all $r \leq \bar{r}$, the equilibrium given the fixed diversification requirement $r$ is bailout shifting. The only equilibrium with endogenous supervisory leniency features maximal supervisory leniency $r=0$.

We now discuss the benefits of banking unions. Under the assumptions of the proposition , the ex-post state-contingent transfers of foreign countries provide powerful insurance to the Sovereign. Ex-post debt $B_{1}(s)$ is always weakly lower than legacy debt $B_{0}$, and strictly so when transfers are strictly positive. This in turn increases the date- 0 price of debt $p_{0}$, and allows the Sovereign the raise the same amount of revenues $p_{0} B_{0}$ by issuing less debt $B_{0}$, which in turn reduces the occurrence of defaults and the associated collateral damage. But at date 1 , these beneficial effects of solidarity on $p_{0}$ and $B_{0}$ are not internalized by foreigners. It is therefore possible that tougher supervision, by decreasing the incentives for foreigners to provide transfers ex post, actually decrease both domestic and foreign welfare. Relying on lax supervision however, is inefficient since it leads to higher rents for bankers.

Starting from a status quo of no banking union and lax supervision, foreigners can improve their welfare while keeping the welfare of the domestic country constant by making the following take-it-or-leave-it offer to the domestic Sovereign. Suppose that the Sovereign puts arbitrarily small weight on bankers so that $\beta^{B} \simeq 0$. In exchange for the delegation of supervision to a central supervisor who puts full weight on foreigners and hence implements tough supervision $r=\bar{r}$, foreigners commit to providing a sufficient amount of transfers to lead to the same ex-post debt $B_{1}(s)$ as the one that prevails under the status quo. These promised state-contingent transfers are minimal transfers in the sense that foreigners can always provide larger, but not smaller, transfers ex post. If the Sovereign accepts the offer, then the ex-post transfers coincide with the promised state-contingent transfers, debt prices $p_{0}$ and $p_{1}(s)$ are the same as under the status quo, and the same amount of debt $B_{0}$ is issued at date $0 .{ }^{43}$ With no weight on bankers, domestic welfare is unchanged, but the welfare of bankers is reduced and foreign welfare increased by the same amount.

Proposition 9. (Banking Union) Under the hypotheses of Proposition 8, even in the absence of debt forgiveness, supervisory leniency may occur, as it allows the domestic Sovereign to extract expost transfers from the foreign country. Lax domestic supervision reduces foreign welfare, which is

\footnotetext{
${ }^{43}$ The promises are binding ex post for $s<\tilde{s}$ when there are both bailouts and transfers (foreigners would choose lower transfers ex post absent the promise) but not for $s \geq \tilde{\tilde{s}}$.
} 
not internalized by the domestic supervisor (in fact it is exploited by the domestic supervisor). A banking union whereby supervision is delegated to a supranational supervisor who puts full weight on foreign consumers (instead of zero weight on foreign consumers for the domestic supervisor) and a commitment by foreigners to a set of minimal ex-post transfers leads to maximal supervision $r=\bar{r}$ and improves both domestic and foreign welfare as long as $\beta^{B}$ is not too large.

Remark: Compared with the status quo of no banking union and lax supervision, it is sometimes also possible to increase foreign welfare and domestic welfare by only committing to a set of minimal ex-post transfers, without imposing delegated supervision, but the reverse is not true. However, it is always possible to further increase foreign welfare while keeping domestic welfare weakly higher than at the status quo by jointly committing to a set of minimal ex-post transfers and requiring delegated supervision. This emphasizes an important complementarity between fiscal and prudential integration.

Remark: Transfers were assumed to be made to the Sovereign. But at date 1 and in bailout states, public and bank monies are fungible: the Sovereign ends up making up for the banks' shortfall. So transfers could alternatively be made to banks. Political economy and other reasons indeed led those transfers to be operated through the ECB acting as a lender-of-lastresort, or more broadly through intra-European loans or transfers destined to contain the effects of bank failures.

\section{The Specialness of Sovereign Debt}

We have assumed that the only way for domestic banks to take risk is by investing in risky domestic sovereign bonds. Of course, in practice, banks can take risk by investing in a variety of risky assets: risky foreign debt, equities, currencies, etc. Most of the results in Section 4 would go through in an alternative model with an alternative risky asset instead of domestic sovereign debt: There would be incentives for lax supervision as well as a rationale for a banking union in the presence of debt forgiveness or country solidarity.

In this section, we argue that domestic sovereign debt has special attributes that make it particularly relevant for these arguments, over and above the fact that banks are very active in the sovereign debt market for a variety of historical and institutional reasons. First, domestic sovereign debt gives rise to the doom loop, i.e. a two-way feedback loop between banks and sovereigns while other risky assets do not. Second, the return on risky domestic sovereign debt has a specific covariance structure with the liquidity shocks of domestic banks and with the fiscal shocks of the domestic Sovereign; in particular, it is typically more correlated with both than the return on risky foreign sovereign debt. 


\subsection{Doom Loop}

For conciseness, we demonstrate the importance of the doom loop for the arguments of Section 4 by providing two illustrative results, one regarding the benefits of banking unions in the presence of debt forgiveness, and one regarding lax supervision in the presence of country solidarity and international transfers.

We first put ourselves under the hypotheses of Proposition 7 regarding the benefits of shared supervision in the presence of debt forgiveness. We consider a fictitious economy where the only difference with the true economy is that banks can invest $r$ in a safe foreign bond and $A-r$ in an exogenous risky asset with exogenous return $R_{1}(s)$ between dates 0 and 1, where $r$ is the diversification requirement. We assume that the return on the risky asset in the fictitious economy is the same as the post-debt-forgiveness return of the risky domestic sovereign bond under the equilibrium of the true economy with a fixed diversification requirement $\bar{r}$, i.e. that $R_{1}(s)=\frac{B_{0}(s)}{B_{0}} \frac{p_{1}(s)}{p_{0}}$. Then with a fixed diversification requirement $\bar{r}$, domestic sovereign bond prices $p_{0}$ and $p_{1}(s)$, bailout requirements $X(s)$, debt levels $B_{0}$, $B_{0}(s)$ and $B_{1}(s)$, and thresholds $\bar{s}$ and $\tilde{s}$, are identical under the fictitious economy and under the true economy. ${ }^{4}$

The two economies differ when supervision is relaxed $(r<\bar{r})$ because the return on the domestic sovereign debt changes via the doom loop, whereas the return of the exogenous risky asset remains constant in the fictitious economy. Along the lines of Proposition 7, we endogenize legacy debt by imposing that the revenues raised by the issuance of legacy debt at date 0 remain constant (accounting for the fact that investors correctly anticipate the equilibrium level of supervisory leniency $r$ ).

Proposition 10 (Doom Loop with Debt Forgiveness). Consider the same hypotheses as in Proposition 7. The results in Proposition 7 hold both in the true economy with a doom loop where domestic banks can invest in risky domestic sovereign bonds and in the fictitious economy with no doom loop where domestic banks can invest in the exogenous risky asset: Without a banking union (in the sense of shared supervision), there is maximal supervisory leniency $r=0$; with a banking union, there is no supervisory leniency $r=\bar{r}$; and a banking union achieves positive welfare gains. However, the welfare gains achieved by a banking union (in the sense of shared supervision) are magnified by the doom loop: they are larger in the true economy than in the fictitious economy.

Under shared supervision, there is no supervisory leniency, and the two economies are the same by construction. The intuition for the magnification of the welfare gains from shared supervision by the doom loop is that when supervision is relaxed under domestic

\footnotetext{
${ }^{44}$ The only tricky issue regards the equality of debt forgiveness $B_{0}(s)$ in both economies. It can easily be verified by noting that the result that the peak of the legacy creditors' Laffer curve leads to the peak of the Laffer curve extends to the fictitious economy, and that the Laffer curve is the same in both economies.
} 
supervision, the doom loop makes domestic sovereign debt riskier than the exogenous risky asset, leading to (1) bigger bailouts and more ex-post debt forgiveness (which is priced-in ex ante by international investors, leading to lower ex-ante domestic sovereign debt prices), higher legacy debt, more defaults, and lower efficiency; (2) more rents for bankers. ${ }^{45}$

We now put ourselves under the hypotheses of Proposition 8 regarding lax supervision in the absence of debt forgiveness but with country solidarity and international transfers. In the true economy, there is maximal supervisory leniency $r=0$. We consider a fictitious economy where we introduce an exogenous risky asset with the same payoff as domestic sovereign bonds $R_{1}(s)=\frac{p_{1}(s)}{p_{0}}$ in the true economy. In the fictitious economy, banks can invest in safe foreign sovereign bonds, risky domestic sovereign bonds, and the exogenous risky asset. We assume that the Sovereign can perfectly control the portfolios of banks. This means that we assume not only that supervisory capability is perfect so that $\bar{r}=A$, but also that the Sovereign can perfectly determine the relative holdings of all assets.

Proposition 11 (Doom Loop with Country Solidarity). Consider the same hypotheses as in Proposition 8. Then in the fictitious economy where banks can invest both in risky domestic sovereign bonds and the exogenous risky asset, the Sovereign forces its banks to invest all their net worth $A$ in risky domestic sovereign bonds, and so to invest neither in safe foreign sovereign bonds nor in the exogenous risky asset.

The intuition is that allowing banks to max out risky domestic sovereign bonds rather than the exogenous risky asset leads to higher ex-post transfers $T(s)$ by foreigners (in equilibrium, banks themselves are actually indifferent between these two risky assets at the margin since they have the same returns). This is because as explained above, foreigners get a bigger "bang for the buck" from a marginal transfer in terms of marginal reduction in the probability of default, the more powerful the doom loop, i.e. the higher the bank holdings of domestic sovereign bonds.

\subsection{Return Covariance}

As noted in the introduction, risk shifting by a troubled European country's banks could have occurred through the purchase of another troubled country's bonds rather than through a re-nationalization of the domestic financial market.

In this section, we therefore consider multiple risky countries. We show that, provided that balance sheet shocks and fiscal shocks within a country are at least slightly positively

\footnotetext{
${ }^{45}$ Similar arguments can be brought to bear on "austerity" and fiscal consolidation. To the extent that resources can be used at date 0 to reduce debt, and that there is no banking union, then there is more to gain from doing so in the true economy than in the fictitious economy. Hence doom loops reinforce the case for fiscal consolidation.
} 
correlated and that fiscal shocks across countries are not perfectly correlated (reasonable assumptions), risk shifting solely through domestic bond holding is a strict equilibrium.

We also show that, with multiple risky countries, and in the presence of debt forgiveness our "double-decker bailout" theory predicts that when the outlook is bad, Sovereigns in risky countries have an incentive to relax supervision and let their banks load up on risky domestic sovereign debt (and not risky foreign sovereign debt) as long as the shocks hitting the two countries are not perfectly correlated. This would also apply with country solidarity and international transfers instead of debt forgiveness, as already emphasized in Proposition 11 above: That domestic risky sovereign debt leads to a doom loop but not foreign risky sovereign debt is enough by itself to justify that the domestic Sovereign forces its banks to max out on domestic risky sovereign bonds even when the shocks to the two countries are perfectly correlated; the fact that they are not only reinforces the argument but in the interest of space, we do not show it formally. We could also derive analogues to the Propositions 7and 9 regarding the benefits of banking unions, but for conciseness, we refrain from doing so.

The structure of the model is the same as in the basic model, but there are now two symmetric risky countries $\mathcal{A}$ and $\mathcal{B}$, together with the foreign (safe) country. We consider banks in countries $\mathcal{A}$ and $\mathcal{B}$, but for simplicity, we abstract from banks in the foreign (safe) country. We denote by $s^{i}$ the state of the world at date 1 in country $i$, and we denote by $\pi$ the joint distribution of $\left(s^{\mathcal{A}}, s^{\mathcal{B}}\right)$. We focus on symmetric equilibria throughout.

In each country $i \in\{\mathcal{A}, \mathcal{B}\}$, banks have an endowment $A$ at date 0 and some investment opportunities $I\left(s^{i}\right)$ with private and social returns (for country $i$ ) given by $\rho_{1}\left(s^{i}\right)$ and $\beta^{I}\left(s^{i}\right)$. Banks invest their net worth at date 0 in a portfolio of safe foreign bonds, risky domestic bonds and risky foreign bonds. The return on their portfolio at date 1 determines their net worth at date 1. If it falls short of their investment need, then they are bailed out by their country's Sovereign.

We denote by $p_{0}$ the price of debt at date 0 in both risky countries. We assume that in each country $i \in\{\mathcal{A}, \mathcal{B}\}$, supervision forces banks of country $i$ to hold a portfolio with holdings of safe foreign sovereign bonds of at least $r \leq \bar{r}$, but does not place constraints on the relative holding of risky sovereign debt of countries $\mathcal{A}$ and $\mathcal{B}$. We start by assuming that there is no debt forgiveness and no international transfers (we reintroduce this possibility later). Each Sovereign chooses not to engage in supervisory leniency and sets $r=\bar{r}$, which we assume from now on.

In each country $i$, we denote by $b_{0}^{*} \geq \bar{r}, b_{0}^{d} \geq 0$ and $b_{0}^{f} \geq 0$ the holdings of foreign safe debt, risky domestic debt (of country $i$ ) and risky foreign debt (of country $-i$ ) with $b_{0}^{*}+p_{0}\left(b_{0}^{d}+b_{0}^{f}\right)=A$. We denote by $p_{1}\left(s^{d}, s^{f}\right)$ the price of debt at date 1 when the domestic when country $i$ is in state $s^{i}=s^{d}$ and country $-i$ is in state $s^{-i}=s^{f}$. 
Proposition 12 (Home Bias with Multiple Risky Countries). Suppose that $s^{d}$ and $s^{f}$ are not co-monotone and that $I(s)$ is strictly decreasing in $s$. Then there exists a symmetric equilibrium where banks in each country $i \in\{\mathcal{A}, \mathcal{B}\}$ choose to hold as little safe foreign bonds and as much risky domestic bonds as allowed by supervision, but no risky foreign bonds: $b_{0}^{*}=\bar{r}, b_{0}^{d}=\frac{A-\bar{r}}{p_{0}}$ and $b_{0}^{f}=0$. This equilibrium is strict.

The intuition is simple. Because balance sheet shocks in a given country are perfectly correlated with fiscal shocks in this country, but imperfectly correlated with fiscal shocks in other countries, bankers maximize the bailout that they extract from the Sovereign by loading up on risky domestic sovereign bonds rather than into risky foreign sovereign bonds. ${ }^{46}$

In this setting, because as shown in Proposition 12, banks in country $i \in\{\mathcal{A}, \mathcal{B}\}$ choose to hold no debt from country $-i$, there is no interaction between the two risky countries $A$ and $B$ : Debt prices and quantities in each risky country are determined independently exactly as in Section 2. All of our results in Section 3 carry through with no modification. . $^{4,48}$

We now introduce the possibility of debt forgiveness and examine how the results in Section 4 regarding strategic supervisory leniency generalize to a setting with multiple risky countries. In the interest of space, we focus on debt forgiveness as in Section 4.1 and prove an equivalent of Proposition 6.

In particular, we want to show that Sovereigns have an incentive to let their own banks load up on domestic risky bonds but not on foreign risky bonds. To make that point in the starkest possible way, we assume that supervision is perfect: In each country $i$, the Sovereign can exactly control the portfolio $\left(b_{0}^{*}, b_{0}^{d}, b_{0}^{f}\right)$ of its banks through supervision. This means that we not only assume that supervisory capability as we have defined it so far is perfect so that $\bar{r}=A$, but also in addition that the Sovereign can now perfectly determine the relative holdings of risky sovereign debt of countries $A$ and $B$.

We can derive the following counterpart to Proposition 6 and show that Sovereigns in risky countries have an incentive to let their banks load up on risky domestic sovereign debt as opposed to risky foreign sovereign debt, in order to maximize the concessions from legacy creditors. This maximizes the rents of domestic banks, and at the same time entirely shifts the cost of domestic bailouts from domestic consumers to foreign investors by ensuring that all domestic bailouts take place in states with domestic sovereign debt forgiveness.

\footnotetext{
${ }^{46}$ We refer the reader to Appendix C.5 for an illustration of Proposition 12 in the context of a simple example which can be solved in closed form.

${ }^{47}$ Some of our results were proved in the case where $I(s)$ is independent of $s$ whereas we require here that $I(s)$ is strictly decreasing in $s$. In these cases, we can simply take the limit when the range of $I(s)$ collapses to a point.

${ }^{48}$ The results in Section 3.3 are particularly interesting in this context. Propositions 14 and 4 apply with no modification. In response to a bad fiscal shock, there is a re-nationalization of sovereign debt markets: Banks in country $i$ increase their holdings of risky domestic sovereign debt from country $i$ but not their holdings of risky foreign sovereign debt from country $-i$.
} 
Proposition 13 (Lax Supervision with Multiple Risky Countries and Debt Forgiveness). Suppose that $I(s)$ is independent of $s$ and that $A=\bar{I}$, and that the distribution $\pi\left(s^{d}, s^{f}\right)$ admits a continuous density $d \pi\left(s^{d}, s^{f}\right)=\Pi\left(s^{d}, s^{f}\right) d s^{d} d s^{f}$. In addition, suppose that in the limit where $A$ and $\bar{I}$ are small, for the equilibrium with a single risky country and no supervisory leniency $r=\bar{r}$, the equilibrium is "bailout-shifting" with $\tilde{s}<\bar{s}$, and that $s^{d}$ and $s^{f}$ are not co-monotone. Then in the limit where $A$ and $\bar{I}$ are small, it is optimal for the Sovereign in country $i$ to force its banks to invest all their net worth $A$ in risky domestic sovereign bonds, and to invest zero in safe foreign sovereign bonds and zero in risky foreign sovereign bonds: $b_{0}^{*}=0, b_{0}^{d}=\frac{A}{p_{0}}$ and $b_{0}^{f}=0 .{ }^{49}$

Obviously, if the Sovereign could not determine the relative holdings of domestic and foreign risky bond holdings, but only impose an effective requirement $b_{0}^{*} \geq r$, then we would obtain (in the limit where $\underline{I}$ tends to $\bar{I}=A$ from below) that it is optimal to set $r=0$. Banks would then by themselves load up on domestic risky bonds, choosing $b_{0}^{d}=\frac{A}{p_{0}}$ and $b_{0}^{f}=0$. Proposition 13 shows that even if the supervisor could perfectly control the portfolios of banks, it would choose to encourage them to load up on domestic risky bonds.

\section{Extensions}

The analysis so far has relied on strong assumptions: Sovereign debt maturity follows an asset and liability management precept of matching maturity and fiscal receipts; the Sovereign can always finance bailouts; bankers cannot pledge income and therefore cannot borrow. We have relaxed all of these assumptions. We content ourselves with a brief description of the findings. The formal analysis can be found in Appendix B.

Appendix B.1 compares our economy with long-term sovereign bonds which are claims to coupons accruing at date 2 with an economy where sovereign bonds are short-term, oneperiod bonds which are rolled over at date 1. Intuitively, a short maturity has both benefits and costs. The cost is that a short maturity is bad for fiscal hedging. The benefit is that a short maturity reduces the risk-shifting possibilities of banks. A short maturity is therefore a costly substitute to supervision. As a result, a long maturity is preferable when supervision is efficient enough ( $\bar{r}$ is high enough) or when the banking sector is small enough ( $A$ and $\bar{I}$ are small enough). As a corollary, countries with effective supervision or with a small banking sector are less likely to shift sovereign debt towards short maturities when the probability of default increases.

Appendix B.2 relaxes the assumption that no matter what portfolios banks hold, the Sovereign can always raise enough funds at date 1 to bail them out completely. In states

\footnotetext{
${ }^{49}$ Assuming that $A$ and $\bar{I}$ are small considerably simplifies the analysis by allowing to neglect the change in debt prices induced by changes in portfolios in the calculation of the rents of bankers.
} 
of the world where funds are insufficient to bail out all the banks, the Sovereign optimally bails out as many banks as possible, saving first the banks with the highest pre-bailout net worth. This pecking order maximizes the number of banks that can be saved and hence ex-post welfare. While banks are ex-ante identical, equilibria can be asymmetric due to the rat race among banks to be on the top of the bailout pecking order. Namely, equilibrium resembles that of equilibria of full-information first-price auctions or wars of attrition. The complication comes from the fact that the object that competitors vie for-here subsidies-is itself endogenous, as the pot of subsidies depends on the distribution of "bids", namely the holdings of foreign bonds.

Appendix B.3 investigates the role of leverage. The feedback loop is stronger, because of a new mechanism operating through the endogenous leverage of banks. As sovereign risk rises, banks have to reduce leverage. This is because banks' borrowing spreads increase, reflecting the increased probability of a default on the private debt that they issue. This requires a larger bailout, which puts further pressure on the Sovereign budget etc., ad infinitum. The resulting multiplier is particularly high if the Sovereign does not enforce private claims of international investors on domestic banks when it defaults on sovereign debt.

\section{$7 \quad$ Future Research}

The paper's main insights were summarized in the introduction, so we briefly discuss possible alleys for the study of the doom loop, fragmentation and the supervisory structure. Our research leaves open a number of fascinating questions. First, we have assumed that the bailouts take the fiscal route. As observed recently in many countries, central banks may participate in the bailout, perhaps risking inflation and devaluation. While our analysis is consistent with the central bank participating in the bailout, it assumes that the cost of such non-conventional intervention is a fiscal one rather than inflation or devaluation. Second, we have assumed that sovereign defaults are not strategic (the Sovereign defaults only if it cannot repay). If defaults are strategic, domestic exposure choices by domestic banks influence the incentives to default (the Sovereign is less likely to default if its debt is held domestically), opening up the possibility of complex strategic interactions between banks and sovereigns, and conferring a benefit (disciplining the Sovereign) upon debt re-nationalization. Finally, further research should be devoted to the governance of the banking union, and in particular to the interactions between prudential and fiscal integrations. 


\section{References}

[1] Acharya, V., Drechsler, I., and P. Schnabl (2015) "A Pyrrhic Victory? Bank Bailouts and Sovereign Credit Risk," Journal of Finance, 69(6): 2689-2739.

[2] Acharya, V. and S. Steffen (2015) “The Greatest Carry Trade Ever? Understanding Eurozone Bank Risks," Journal of Financial Economics, 115: 215-236.

[3] Acharya, V. and T. Yorulmazer (2007), "Too many to fail - an analysis of timeinconsistency in bank closure policies," Journal of Financial Intermediation, 16(1): 1-31.

[4] Amador, M. and M. Aguiar (2014) “Take the Short Route: How to Repay and Restructure with Multiple Maturities," mimeo, Minneapolis Fed and Princeton.

[5] Angeletos, G.M. (2002) "Fiscal Policy With Noncontingent Debt And The Optimal Maturity Structure," Quarterly Journal of Economics, 117(3): 1105-1131.

[6] Arellano, C. and A.Ramanarayanan (2012), "Default and the Maturity Structure in Sovereign Bonds," Journal of Political Economy, 120: 187-232.

[7] Battistini, N., Pagano, M. and S. Simonelli (2014), "Systemic Risk, Sovereign Yields and Bank Exposures in the Euro Crisis," Economic Policy, 29 (78): 203-251.

[8] Bianchi, J. (2016) "Efficient Bailouts?," accepted for publication, American Economic Review.

[9] Bizer, D., and P. DeMarzo (1992) "Sequential Banking," Journal of Political Economy, 100(1): 41-61.

[10] Bocola, L. (2016) “The Pass-Through of Sovereign Risk," Journal of Political Economy, 124(4): 879-926.

[11] Bolton, P. and O. Jeanne (2009) "Structuring and Restructuring Sovereign Debt: The Role of Seniority," Review of Economic Studies, 76(3): 879-902.

[12] Bolton, P. and O. Jeanne (2011) "Sovereign Default Risk and Bank Fragility in Financially Integrated Economies," IMF Economic Review, 59: 162-194.

[13] Broner, F., Erce, A., Martin, A. and J. Ventura (2014) "Sovereign Debt Markets in Turbulent Times: Creditor Discrimination and Crowding-out Effects", Journal of Monetary Economics, 61: 114-142.

[14] Broner, F. and J. Ventura (2011) "Globalization and Risk Sharing," Review of Economic Studies, 78: 49-82. 
[15] Broner, F., Lorenzoni, G. and S. Schmukler (2013) "Why Do Emerging Economies Borrow Short Term?" Journal of the European Economic Association, 11: 67-100.

[16] Brunnermeier, M. and M. Oehmke (2013) "The Maturity Rat Race," Journal of Finance, 68: 483-521.

[17] Buera, F. and J.P. Nicolini (2004) "Optimal maturity of government debt without state contingent bonds," Journal of Monetary Economics, 51(3): 531-554.

[18] Bulow, J. and K. Rogoff (1988) “The Buyback Boondogle," Brookings Papers on Economic Activity, 675-698.

[19] Bulow, J. and K. Rogoff (1991) "Sovereign Debt Repurchases: No Cure for Overhang," Quarterly Journal of Economics, 106: 1219-1235.

[20] Calomiris, C. and C. Kahn (1991), "The Role of Demandable Debt in Structuring Optimal Banking Arrangements," American Economic Review, 81: 497-513.

[21] Chari, V.V. and P. Kehoe (2016) "Bailouts, Time Inconsistency, and Optimal Regulation: A Macroeconomic View," American Economic Review, 106(9): 2458-93.

[22] Chari, V.V, Dovis, A. and P. Kehoe (2014) “On the Optimality of Financial Repression," mimeo Minneapolis Fed.

[23] Chatterjee, S. and B. Eyigungor (2012), "Maturity, Indebtedness, and Default Risk," American Economic Review, 102(6): 2674-2699.

[24] Calvo, G. (1988) "Servicing the Public Debt: The Role of Expectations," American Economic Review, 78(4): 647-661.

[25] Cooper, R. and Nikolov (2013) “Government Debt and Banking Fragility: The Spreading of Strategic Uncertainty," mimeo, Penn State University and ECB.

[26] Diamond, D., and P. Dybvig (1983) "Bank Runs, Deposit Insurance, and Liquidity," Journal of Political Economy, 91: 401-419.

[27] Diamond, D., and R. Rajan (2001) "Liquidity Risk, Liquidity Creation, and Financial Fragility: A Theory of Banking," Journal of Political Economy, 109: 283-327.

[28] Diamond, D., and R. Rajan (2012) "Illiquid Banks, Financial Stability, and Interest Rate Policy," Journal of Political Economy, 120(3), 552-591.

[29] Dovis, A. (2012) “Efficient Sovereign Default," mimeo. 
[30] Farhi, E. and J. Tirole (2012) "Collective Moral Hazard, Maturity Mismatch, and Systemic Bailouts," American Economic Review, 102(1): 60-93.

[31] Fernandez, R. and F. Martin (2015) "The Long and Short of It: Sovereign Debt Crises and Debt Maturity," NBER working paper.

[32] Galichon, A., (2016) Optimal Transport Methods in Economics, Princeton University Press.

[33] Gennaioli, N., Martin, A. and S. Rossi (2014,a) “Sovereign Default, Domestic Banks and Financial Institutions," Journal of Finance, 69(2): 819:866.

[34] Gennaioli, N., Martin, A. and S. Rossi $(2014, b)$ “Banks, Government Bonds and Defaults: What Do the Data Say?" mimeo.

[35] Gennaioli, N., Shleifer, A. and R. Vishny (2012) “Neglected Risk, Financial Innovation, and Financial Fragility," Journal of Financial Economics, 104: 452-468.

[36] Hatchondo, J. and L. Martinez (2009) "Long-duration bonds and sovereign defaults," Journal of International Economics, 79(1): 117-125.

[37] Hatchondo, J., Martinez, L., and C. Sosa Padilla (2014) "Voluntary Sovereign Debt Exchanges," Journal of Monetary Economics, 61: 32-50.

[38] Holmström, B. and J. Tirole (1997) "Financial Intermediation, Loanable Funds, and the Real Sector," Quarterly Journal of Economics, 112: 663-691.

[39] Jeanne, O. (2009) "Debt Maturity and the International Financial Architecture," American Economic Review, 99(5): 2135-2148

[40] Keister, T. (2016) "Bailouts and Financial Fragility," Review of Economic Studies, 83(2): 704-736.

[41] Lagarde, C. (2012), Opening Remarks to IMF/CFP Policy Roundtable on the Future of Financial Regulation, International Monetary Fund, Washington DC, April 17.

[42] Livshits, I., and K. Schoors (2012) “Sovereign Default and Banking," mimeo.

[43] Mengus, E. (2013a) “Honoring Sovereign Debt or Bailing Out Domestic Residents? A Theory of Internal Cost of Default", mimeo, TSE.

[44] Mengus, E. (2013b) “International Bailouts: Why Did Banks' Collective Bet Lead Europe to Rescue Greece?" mimeo, TSE. 
[45] Livshits, I. and K. Schoors (2009) "Sovereign Defaults and Banking," mimeo, University of Western Ontario.

[46] Nosal, J. and G. Ordonez (2016) “Uncertainty as Commitment," Journal of Monetary Economics, 80: 124-140.

[47] Perez, D. (2015) "Sovereign Debt, Domestic Banks and the Provision of Public Liquidity," mimeo, NYU.

[48] Philippon, T. and V. Skreta (2012) "Optimal Interventions in Markets with Adverse Selection," American Economic Review, 102(1): 1-28.

[49] Rancière, R., A. Tornell, and F. Westermann (2008) "Systemic Crises and Growth," The Quarterly Journal of Economics, 123(1): 359-406.

[50] Reinhart, C. and K. Rogoff (2009) This Time Is Different: Eight Centuries of Financial Folly, Princeton University Press.

[51] Schneider, M. and A. Tornell (2004) "Balance Sheet Effects, Bailout Guarantees and Financial Crises," Review of Economic Studies, 71: 883-913.

[52] Stavrakeva, V. (2013) "Optimal Bank Regulation and Fiscal Capacity," mimeo London Business School.

[53] Tirole, J. (2012) "Overcoming Adverse Selection: How Public Intervention Can Restore Market Functioning," American Economic Review, 102(1): 29-59.

[54] Tirole, J. (2015) "Country Solidarity in Sovereign Crises," American Economic Review, 105(8): 2333-63.

[55] Uhlig, H. (2014) "Sovereign Default Risk and Banks in a Monetary Union," mimeo, U. of Chicago.

[56] Woodford, M. (1990) "Public Debt as Private Liquidity," American Economic Review, 80(2): 382-388.

\section{A Appendix: Proofs}

\section{A.1 Proof of Proposition 2}

The choice of $r$ for a given $p_{0}$ involves off-equilibrium calculations. We therefore cannot make use of the decomposition (4) provided earlier, which only holds in equilibrium when the 
martingale property of prices (2) holds. Instead, we use the decomposition (8), which holds both in equilibrium when the martingale property of prices (2) holds and off equilibrium when it does not. Hence we write

$$
\mathcal{W}_{0}=\mathcal{E}_{0}-\mathcal{R}_{0}+\mathcal{C}_{0}
$$

where

$$
\begin{gathered}
\mathcal{E}_{0}=\int\left[\int_{B_{1}(s)}^{\infty}\left[E-B_{0}\right] f(E \mid s) d E+\int_{0}^{B_{1}(s)}[E-\Phi] f(E \mid s) d E\right] d \pi(s) \\
+\int\left[\beta^{I}(s)+\beta^{B}\left[\rho_{1}(s)-I(s)+A\right]\right] d \pi(s), \\
\mathcal{R}_{0}=-\left(1-\beta^{B}\right) \int \min \left\{r+(A-r) \frac{p_{1}(s)}{p_{0}}-I(s), 0\right\} d \pi(s), \\
\mathcal{C}_{0}=\beta^{B} \int\left[r+(A-r) \frac{p_{1}(s)}{p_{0}}-A\right] d \pi(s) .
\end{gathered}
$$

The supervisor sets $r \leq \bar{r}$ in order to maximize $W_{0}$ taking $p_{0}$ as given but subject to the two constraints

$$
\begin{gathered}
p_{1}(s)=1-F\left(B_{1}(s) \mid s\right), \\
p_{1}(s)\left[B_{1}(s)-B_{0}\right]=\max \left\{I(s)-r-(A-r) \frac{p_{1}(s)}{p_{0}}, 0\right\} .
\end{gathered}
$$

We denote the resulting dependence of the solution on $r$ given $p_{0}$ as $p_{1}\left(s, r ; p_{0}\right), B_{1}\left(s, r ; p_{0}\right)$, $\mathcal{W}_{0}\left(r ; p_{0}\right), \mathcal{E}_{0}\left(r ; p_{0}\right), \mathcal{R}_{0}\left(r ; p_{0}\right)$ and $\mathcal{C}_{0}\left(r ; p_{0}\right)$.

Towards a contradiction, consider a candidate equilibrium with $r<\bar{r}$, and suppose that there are bailouts with strictly positive probability. The date- 0 prices $p_{0}$ satisfies the fixed point equation $p_{0}=\int p_{1}\left(s, r ; p_{0}\right) d \pi(s)$. Given this price $p_{0}$, consider setting $r^{\prime} \in(r, \bar{r})$. We now proceed to show that $\mathcal{W}_{0}\left(r^{\prime} ; p_{0}\right)>\mathcal{W}_{0}\left(r ; p_{0}\right)$, a contradiction. We do so by showing that $\mathcal{E}_{0}\left(r^{\prime} ; p_{0}\right)>\mathcal{E}_{0}\left(r ; p_{0}\right), \mathcal{R}_{0}\left(r^{\prime} ; p_{0}\right)<\mathcal{R}_{0}\left(r ; p_{0}\right)$, and $\mathcal{C}_{0}\left(r^{\prime} ; p_{0}\right)>\mathcal{C}_{0}\left(r ; p_{0}\right)$.

It is easy to see that $p_{1}\left(s, r^{\prime} ; p_{0}\right) \geq p_{1}\left(s, r ; p_{0}\right)$ and $B_{1}\left(s, r^{\prime} ; p_{0}\right) \leq B_{1}\left(s, r ; p_{0}\right)$ for all $s$, where the inequalities are strict with positive probability. Using $B_{1}\left(s, r^{\prime} ; p_{0}\right) \leq B_{1}\left(s, r ; p_{0}\right)$ with a strict inequality with positive probability, we get

$$
\begin{aligned}
\int_{B_{1}\left(s, r^{\prime} ; p_{0}\right)}^{\infty}\left[E-B_{0}\right] f(E \mid s) d E & +\int_{0}^{B_{1}\left(s, r^{\prime} ; p_{0}\right)}[E-\Phi] f(E \mid s) d E \\
& \geq \int_{B_{1}\left(s, r ; p_{0}\right)}^{\infty}\left[E-B_{0}\right] f(E \mid s) d E+\int_{0}^{B_{1}\left(s, r ; p_{0}\right)}[E-\Phi] f(E \mid s) d E,
\end{aligned}
$$

where the inequality is strict with positive probability. This implies that $\mathcal{E}_{0}\left(r^{\prime} ; p_{0}\right)>\mathcal{E}_{0}\left(r ; p_{0}\right)$. 
Using the fact that $r^{\prime}>r$ and $p_{1}\left(s, r^{\prime} ; p_{0}\right) \geq p_{1}\left(s, r ; p_{0}\right)$ with a strict inequality with positive probability, we get

$$
\min \left\{r^{\prime}+\left(A-r^{\prime}\right) \frac{p_{1}\left(s, r^{\prime} ; p_{0}\right)}{p_{0}}-I(s), 0\right\} \geq \min \left\{r+(A-r) \frac{p_{1}\left(s, r ; p_{0}\right)}{p_{0}}-I(s), 0\right\}
$$

where the inequality is strict with positive probability. This follows because given that $A \geq \bar{I}$, we necessarily have $\frac{p_{1}\left(s, r ; p_{0}\right)}{p_{0}}<1$ whenever $r+(A-r) \frac{p_{1}\left(s, r ; p_{0}\right)}{p_{0}}-I(s)<0$. This implies that $\mathcal{R}_{0}\left(r^{\prime} ; p_{0}\right)<\mathcal{R}_{0}\left(r ; p_{0}\right)$.

Finally note that using the fact that $r^{\prime}>r, p_{1}\left(s, r^{\prime} ; p_{0}\right) \geq p_{1}\left(s, r ; p_{0}\right)$ with a strict inequality with positive probability and $p_{0}=\int p_{1}\left(s, r ; p_{0}\right) d \pi(s)$, we get

$$
\begin{aligned}
\int\left[r^{\prime}+\left(A-r^{\prime}\right) \frac{p_{1}\left(s, r^{\prime} ; p_{0}\right)}{p_{0}}-A\right] d \pi(s) & \\
=r+(A-r) \frac{\int p_{1}\left(s, r^{\prime} ; p_{0}\right) d \pi(s)}{p_{0}}-A & \\
& >0=\int\left[r+(A-r) \frac{p_{1}\left(s, r ; p_{0}\right)}{p_{0}}-A\right] d \pi(s) .
\end{aligned}
$$

This implies that $\mathcal{C}_{0}\left(r^{\prime} ; p_{0}\right)>\mathcal{C}_{0}\left(r ; p_{0}\right)$.

\section{A.2 Proof of Proposition 3}

We use the decomposition given (4) and write

$$
\mathcal{W}_{0}=\mathcal{E}_{0}-\mathcal{R}_{0}
$$

Suppose first that $B_{0}$ is kept constant as we consider lowering $\bar{r}$ below $\bar{I}$. We have the following bounds

$$
\begin{aligned}
& \mathcal{E}_{0} \leq \int\left[\int_{B_{0}}^{\infty}\left[E-B_{0}\right]\right.\left.f(E \mid s) d E+\int_{0}^{B_{0}}[E-\Phi] f(E \mid s) d E\right] d \pi(s) \\
&+\int\left[\beta^{I}(s)+\beta^{B}\left[\rho_{1}(s)-I(s)+A\right]\right] d \pi(s),
\end{aligned}
$$

$\mathcal{R}_{0} \geq 0$,

with strict inequalities if there are bailouts with positive probability and equalities otherwise. Both bounds are attained for $\bar{r}=\bar{I}$ where there are no bailouts. The result in the proposition follows. In the case where $p_{0} B_{0}$ is kept constant instead, the result is even stronger since $B_{0}$ increases (and $p_{0}$ decreases) as we lower $\bar{r}$. 


\section{A.3 Proof of Proposition 4 and Collective Moral Hazard}

Proof of Proposition 4. Differentiating the first-order condition for the choice of $b_{0}^{*}$ by banks, the equilibrium date- 0 and date- 1 price conditions (10) and (11) leads to the following linear system of three equations in three unknowns $\frac{d p_{0}}{d \xi}, \frac{d p_{1}(s)}{d \xi}$, and $\frac{d b_{0}^{*}}{d \xi}$ :

$$
\begin{gathered}
\frac{d b_{0}^{*}}{d \tilde{\zeta}} \Psi^{\prime \prime}\left(\bar{r}-b_{0}^{*}\right)=\frac{d p_{0}}{d \tilde{\zeta}} \int_{s \geq \tilde{s}} \frac{p_{1}(s)}{p_{0}^{2}} d \pi(s), \\
\frac{d p_{1}(s)}{d \tilde{\zeta}}=\left\{\begin{array}{c}
0 \text { if } s \geq \tilde{s}, \\
\frac{-\frac{\partial F\left(B_{1}(s) \mid s\right)}{\partial \tilde{\xi}}+f\left(B_{1}(s) \mid s\right)\left[\frac{1}{p_{1}(s)}-\frac{1}{p_{0}}\right] \frac{d b_{0}^{*}}{d \tilde{\xi}}-f\left(B_{1}(s) \mid s\right) \frac{A-b_{0}^{*}}{p_{0}^{2}} \frac{d p_{0}}{d \tilde{\xi}}}{1-\frac{A-r}{p_{1}(s)^{2}} f\left(B_{1}(s) \mid s\right)} \text { if } s<\tilde{s},
\end{array}\right. \\
\frac{d p_{0}}{d \tilde{\zeta}}=\frac{d b_{0}^{*}}{d \tilde{\zeta}} \int_{s<\tilde{s}} \frac{f\left(B_{1}(s) \mid s\right)\left[\frac{1}{p_{1}(s)}-\frac{1}{p_{0}}\right]}{1-\frac{A-r}{p_{1}(s)^{2}} f\left(B_{1}(s) \mid s\right)} d \pi(s)-\frac{d p_{0}}{d \tilde{\zeta}} \int_{s<\tilde{s}} \frac{f\left(B_{1}(s) \mid s\right) \frac{A-b_{0}^{*}}{p_{0}^{2}}}{1-\frac{A-r}{p_{1}(s)^{2}} f\left(B_{1}(s) \mid s\right)} d \pi(s) \\
-\int_{s<\tilde{s}} \frac{\frac{\partial F\left(B_{1}(s) \mid s\right)}{\partial \tilde{\xi}}}{1-\frac{A-r}{p_{1}(s)^{2} f\left(B_{1}(s) \mid s\right)} d \pi(s) .}
\end{gathered}
$$

Solving this linear system of equations yields the results in Proposition 4.

Collective moral hazard. We now show that for a given supervisory capacity, the incentives for banks to take on domestic sovereign debt are increased when other banks do so-a manifestation of the strategic complementarities in financial risk-taking at work in the model一so that the effectiveness of supervision depends on the risk taken by the banking system as a whole. The main difference with the collective moral hazard problem in Farhi-Tirole (2012) is that bailouts are perfectly targeted here while imperfect targeting was key to the strategic complementarity result of Farhi-Tirole (2012). ${ }^{50}$ There are also strategic complementarities in financial risk-taking, which justify macroprudential supervision, but through a different, general equilibrium effect on the pricing of debt and the occurrence of default rather than through untargeted bailouts. ${ }^{51}$

\footnotetext{
${ }^{50}$ This paper belongs to a literature that studies the combination of limited commitment on the part of the Sovereign, and ex-post bailouts. This gives rise to strategic complementarities in financial risk-taking, and provides a rationale for macroprudential regulation (see e.g. Schneider-Tornell 2004, Acharya-Yorulmazer 2008, Ranciere et al. 2008, Diamond-Rajan 2012, Farhi-Tirole 2012, and Chari-Kehoe 2016). This literature relies on mechanisms by which bailouts are extended only when sufficiently many banks are in trouble ex post, so that the incentives for individual financial risk taking increase with collective financial risk taking ex ante. A crucial feature of these mechanisms is that bailouts cannot be perfectly targeted ex post to troubled banks.

${ }^{51}$ In Farhi-Tirole (2012), we study a model where the combination of limited commitment on the part of the Sovereign, and ex-post untargeted bailouts gives rise to strategic complementarities in financial risk-taking,
} 
The banks' choices of opaqueness, and thereby the exposures to the domestic Sovereign, are strategic complements: Incurring the cost of making one's balance sheet more opaque is more tempting if the put on taxpayer money is more attractive; in turn, this put is more attractive when the sovereign bond price is more volatile, which it is when the other banks take a larger gamble.

To show this, note that for an individual bank $i$, given an aggregate $b_{0}^{*}$, the payoff from investing $b_{0}^{*}(i)$ is

$$
V_{0}^{B}\left(b_{0}^{*}(i) ; b_{0}^{*}\right)=\int \rho_{1}(s) d \pi(s)+\int_{\tilde{s}}^{\infty}\left(A-b_{0}^{*}(i)\right)\left(\frac{p_{1}(s)}{p_{0}}-1\right) d \pi(s)-\Psi\left(\bar{r}-b_{0}^{*}(i)\right),
$$

where we have left the dependence of $p_{0}$ and $p_{1}(s)$ on $b_{0}^{*}$ implicit. The next proposition performs comparative statics with respect to $b_{0}^{*}$ taking into account the effect of $b_{0}^{*}$ on $p_{0}$.

Proposition 14 (Strategic Complementarities in Banks' Domestic Exposures). Suppose that $I(s)=\bar{I}$ is independent of $s$, and that $A=\bar{I}$. There are strategic complementarities across banks in the choice of $b_{0}^{*}(i)$, i.e. the marginal benefit $\frac{\partial V_{0}^{B}\left(b_{0}^{*}(i) ; b_{0}^{*}\right)}{\partial b_{0}^{*}(i)}$ for a bank of increasing its individual investment $b_{0}^{*}(i)$ in foreign bonds is increasing in the aggregate investment $b_{0}^{*}$ of banks in foreign bonds.

Proof. Denote by $\epsilon$ the random variables $\frac{p_{1}(s)}{p_{0}}$. For a given aggregate $b_{0}^{*}$, the random variable $\epsilon$ follows some distribution $H(\epsilon)$ such that $\int_{0}^{1}(1-\epsilon) d H(\epsilon)=\int_{1}^{\infty}(\epsilon-1) d H(\epsilon)$. For an individual bank $i$, the payoff from investing $b_{0}^{*}(i)$ is

$$
V_{0}^{B}\left(b_{0}^{*}(i) ; b_{0}^{*}\right)=\int \rho_{1}(s) d \pi(s)+\int_{1}^{\infty}\left(A-b_{0}^{*}(i)\right)(\epsilon-1) d H(\epsilon)-\Psi\left(\bar{r}-b_{0}^{*}(i)\right) .
$$

The marginal benefit of reducing $b_{0}^{*}(i)$ is given by

$$
-\frac{\partial V_{0}^{B}\left(b_{0}^{*}(i) ; b_{0}^{*}\right)}{\partial b_{0}^{*}(i)}=\int_{1}^{\infty}(\epsilon-1) d H(\epsilon)-\Psi^{\prime}\left(\bar{r}-b_{0}^{*}(i)\right) .
$$

Now consider two aggregate level $b_{0}^{*}$ and $b_{0}^{* \prime}$ with $b_{0}^{*}>b_{0}^{* \prime}$ with associated prices $p_{0}$, $p_{1}(s), p_{0}^{\prime}, p_{1}^{\prime}(s)$ and distributions $H$ and $H^{\prime}$. Let $\tilde{s}$ be such that $\frac{p_{1}(\tilde{s})}{p_{0}}=1$ (and so bailouts occur if and only if $s<\tilde{s})$. We proceed in two steps.

and provides a rationale for macroprudential regulation. The origin of the strategic complementarities there is the following: when other banks take on more financial risk ex ante, the Sovereign increases its untargeted bailout by lowering interest rates ex post; the anticipation of lower interest rates ex post in turn induces any given bank to take on more financial risk ex ante. This mechanism is entirely shut down here since ex-post bailouts come in the form of perfectly targeted transfers to troubled banks instead of untargeted reductions in interest rates that benefit all banks, healthy and troubled. Instead strategic complementarities arise through a completely different mechanism: When other banks take on more financial risk ex ante, domestic sovereign bonds become riskier, and hence a more tempting way to gamble on ex-post perfectly targeted bailouts by the Sovereign. 
In the first step, we prove that $p_{0}^{\prime}<p_{0}, p_{1}^{\prime}(s)=p_{1}(s)$ for $s \geq \tilde{s}$, and $\frac{p_{1}^{\prime}(s)}{p_{0}^{\prime}}>\frac{p_{1}(s)}{p_{0}}$ for $s \geq \tilde{s}$. Indeed, the price $p_{1}(s)$ is a locally stable solution of the following fixed-point equation

$$
p_{1}(s)=1-F\left(B_{0}+\left(A-b_{0}^{*}\right) \max \left\{\frac{1}{p_{1}(s)}-\frac{1}{p_{0}}, 0\right\} \mid s\right) .
$$

Towards a contradiction, suppose that $p_{0}^{\prime} \geq p_{0}$. Then for any $p_{1}(s)$, the right-hand side of the above equation decreases when $b_{0}^{*}$ is replaced by $b_{0}^{* \prime}$. Hence $p_{1}^{\prime}(s)<p_{1}(s)$ decreases for all $s$, and strictly decreases for $s<\tilde{s}$. This contradicts the martingale property of prices, and proves that $p_{0}^{\prime}<p_{0}$. For all $s \geq \tilde{s}, \frac{p_{1}(\tilde{s})}{p_{0}^{\prime}}>\frac{p_{1}(\tilde{s})}{p_{0}} \geq 1$. Hence for all $s \geq \tilde{s}$ the pre-bailout net worth of banks satisfies $b_{0}^{* \prime}+\left(A-b_{0}^{* \prime}\right) \frac{p_{1}(\tilde{s})}{p_{0}^{\prime}}>b_{0}^{*}+\left(A-b_{0}^{*}\right) \frac{p_{1}(\tilde{s})}{p_{0}}$. This in turn implies that it is still the case that there are no bailouts for $s>\tilde{s}$ when aggregate debt is $b_{0}^{* \prime}$. By implication, $p_{1}^{\prime}(s)=p_{1}(s)$ is the same for $s \geq \tilde{s}$.

In the second step, we use the first step to get

$$
\int_{1}^{\infty}(\epsilon-1) d H^{\prime}(\epsilon) \geq \int_{1}^{\infty}\left(\frac{p_{0}}{\tilde{p}_{0}} \epsilon-1\right) d H(\epsilon)>\int_{1}^{\infty}(\epsilon-1) d H(\epsilon) .
$$

The incentive to marginally reduce $b_{0}^{*}(i)$ is therefore higher when the aggregate foreign debt level is $b_{0}^{* \prime}$ than when it is $b_{0}^{*}$ :

$$
-\frac{\partial V_{0}^{B}\left(b_{0}^{*}(i) ; b_{0}^{* \prime}\right)}{\partial b_{0}^{*}(i)}>-\frac{\partial V_{0}^{B}\left(b_{0}^{*}(i) ; b_{0}^{*}\right)}{\partial b_{0}^{*}(i)} .
$$

Depending on the exact shape of the cost function $\Psi$, these strategic complementarities can be strong enough to lead to multiple equilibria: Equilibria with low exposure of domestic banks to domestic sovereign default risk (high $b_{0}^{*}$ ) and equilibria with high exposure of domestic banks to domestic sovereign default risk (low $b_{0}^{*}$ ). Because multiplicity is not the focus of this paper, we simply illustrate this possibility with a simple example in Appendix C.2. 


\section{A.4 Proof of Proposition 5}

Suppose first that there is debt forgiveness but no bailout in state $s$. Then we have $\bar{B}_{0}(s)=$ $B_{1}\left(s ; \bar{B}_{0}(s)\right)=\bar{B}_{1}(s)$, proving the first statement in the proposition. We also have

$$
\bar{B}_{1}(s) \frac{f\left(\bar{B}_{1}(s) \mid s\right)}{1-F\left(\bar{B}_{1}(s) \mid s\right)}=1
$$

This shows that $\bar{B}_{0}(s)=\bar{B}_{1}(s)$ is increasing in $s$, proving the second statement in the proposition.

Suppose now that there is debt forgiveness and a bailout in state $s$. The bailout equation

$$
\left[1-F\left(B_{1}\left(s ; \tilde{B}_{0}\right) \mid s\right)\right]\left[B_{1}\left(s ; \tilde{B}_{0}\right)-\tilde{B}_{0}\right]=I(s)-r-\frac{A-r}{p_{0} B_{0}} \tilde{B}_{0}\left[1-F\left(B_{1}\left(s ; \tilde{B}_{0}\right) \mid s\right)\right],
$$

can be manipulated into

$$
\left[1-\frac{A-r}{p_{0} B_{0}}\right] \tilde{B}_{0}\left[1-F\left(B_{1}\left(s ; \tilde{B}_{0}\right) \mid s\right)\right]=\left[1-F\left(B_{1}\left(s ; \tilde{B}_{0}\right) \mid s\right)\right] B_{1}\left(s ; \tilde{B}_{0}\right)-[I(s)-r] .
$$

This immediately implies that the date- 1 debt after debt forgiveness and issuance corresponds to the peak of the Laffer curve $B_{1}\left(s ; \bar{B}_{0}(s)\right)=\bar{B}_{1}(s)$, proving the first statement in the proposition. We therefore have the following characterization of $\bar{B}_{0}(s)$ and $\bar{B}_{1}(s)$ :

$$
\begin{gathered}
\bar{B}_{1}(s) \frac{f\left(\bar{B}_{1}(s) \mid s\right)}{1-F\left(\bar{B}_{1}(s) \mid s\right)}=1, \\
\bar{B}_{1}(s)=\bar{B}_{0}(s)-(A-r) \frac{\bar{B}_{0}(s)}{p_{0} B_{0}}+\frac{I(s)-r}{1-F\left(\bar{B}_{1}(s) \mid s\right)} .
\end{gathered}
$$

The first equation shows that $\bar{B}_{1}(s)$ is increasing in $s$. The second equation shows that $\bar{B}_{0}(s)$ is increasing in $\bar{B}_{1}(s)$ and in $s$. This immediately implies that $\bar{B}_{0}(s)$ is increasing in $s$, proving the second statement in the proposition.

\section{A.5 Proof of Proposition 6}

Differentiating

$$
p_{0}=\int \frac{B_{0}(s)}{B_{0}}\left[1-F\left(B_{1}(s) \mid s\right)\right] \pi(s) d s,
$$

and using the fact that $\frac{d B_{1}(s)}{d r}=\frac{d \bar{B}_{1}(s)}{d r}=0$ for $s \leq \tilde{s}$ and $\frac{d B_{1}(s)}{d r}=\frac{d B_{0}(s)}{d r}=\frac{d B_{0}}{d r}=0$ for $s>\tilde{s}$, we find that

$$
\frac{d p_{0}}{d r}=\int_{\{s \leq \tilde{s}\}} \frac{1}{B_{0}} \frac{d B_{0}(s)}{d r}\left[1-F\left(B_{1}(s) \mid s\right)\right] \pi(s) d s .
$$




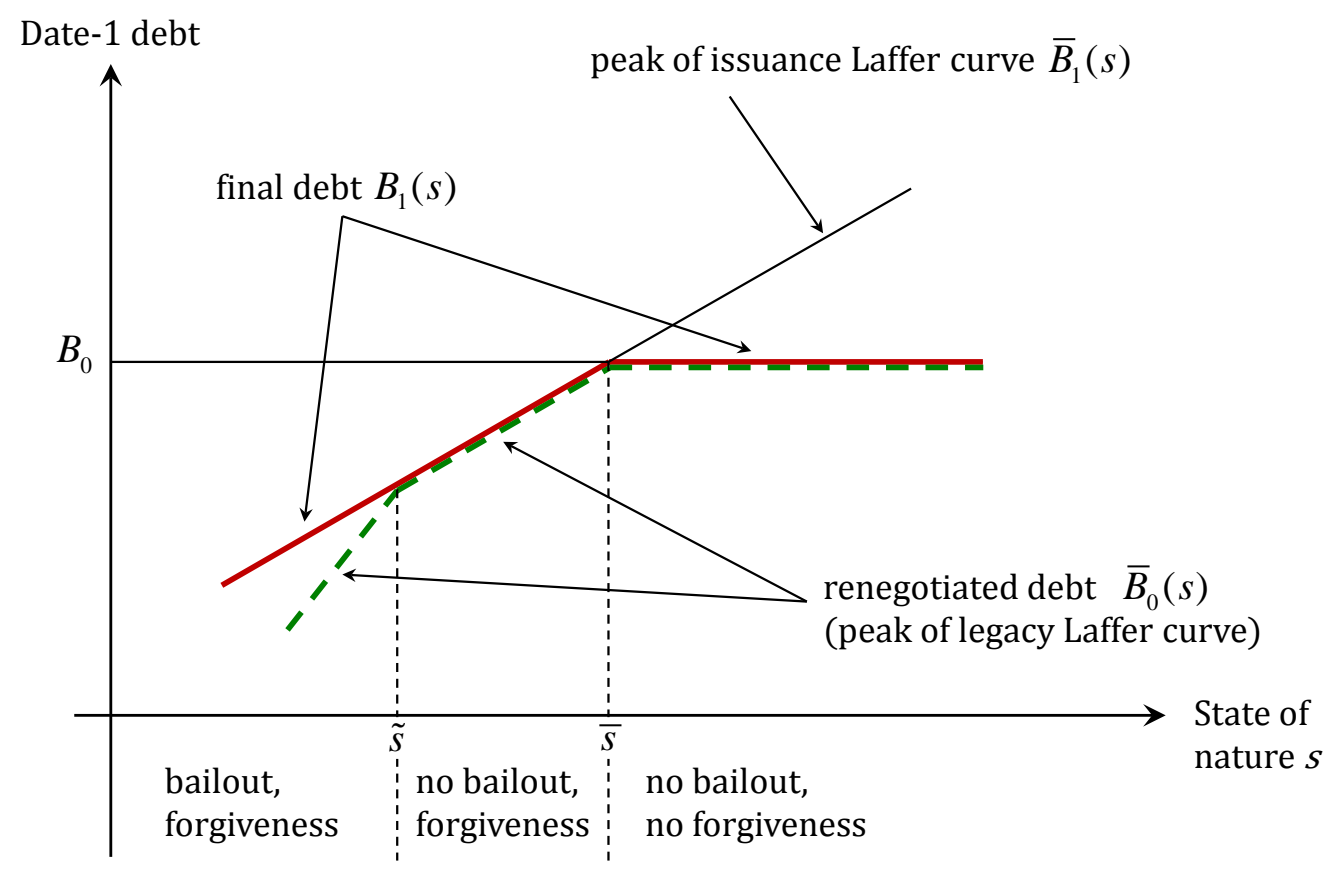

Figure 5: Debt Forgiveness when the Equilibrium is Bailout-Shifting.

For $s \leq \tilde{s}$, we have

$$
B_{1}(s)=B_{0}(s)-(A-r) \frac{B_{0}(s)}{p_{0} B_{0}}+\frac{A-r}{1-F\left(B_{1}(s) \mid s\right)} .
$$

Differentiating this equality and using the fact that $\frac{d B_{1}(s)}{d r}=0$ for $s \leq \tilde{s}$, we get

$$
\frac{d B_{0}(s)}{d r}\left[1-\frac{A-r}{p_{0} B_{0}}\right]+(A-r) \frac{B_{0}(s)}{p_{0}^{2} B_{0}} \frac{d p_{0}}{d r}=\frac{1}{1-F\left(B_{1}(s) \mid s\right)}\left[1-\frac{B_{0}(s)}{B_{0}} \frac{p_{1}(s)}{p_{0}}\right] .
$$

Integrating this equation over $s \leq \tilde{s}$ with measure $d \pi(s)$, and combining with equation (16) and the fact that $1-\frac{A-r}{p_{0} B_{0}}>0, A-r>0$, and $1-\frac{B_{0}(s)}{B_{0}} \frac{p_{1}(s)}{p_{0}}>0$, this implies that $\frac{d p_{0}}{d r}>0$. Going back to the definition (15) of $\tilde{s}$, this in turn implies that $\frac{d \tilde{s}}{d r} \geq 0$. Together with the implication from the definition (14) of $\bar{s}$ that $\frac{d \bar{s}}{d r}=0$, this proves the first statement in the proposition.

We now turn to the second statement in the proposition. We consider the equilibrium for a given fixed diversification requirement $0<r \leq \bar{r}$. We fix the value of $p_{0}$ and characterize the dependence of welfare $\mathcal{W}_{0}$ on the choice of $\tilde{r}$ by the supervisor, given $p_{0}$, in the corresponding subgame. In what follows, all the derivatives should therefore be understood as keeping $p_{0}$ fixed. Once again, we leave the dependence of all variables on $p_{0}$ and $\tilde{r}$ implicit to make the notation lighter. We next prove that $\left.\frac{d \mathcal{W}_{0}}{d \tilde{r}}\right|_{\tilde{r}=r}<0$. This implies that $0<r$ cannot be an equilibrium with endogenous supervisory leniency. 
We have

$$
\mathcal{W}_{0}=\int \mathcal{W}_{0}(s) \pi(s) d s
$$

with

$$
\begin{aligned}
\mathcal{W}_{0}(s)=\int_{B_{1}(s)}^{\infty}\left[E-B_{1}(s)\right] f(E \mid s) d E & +\int_{0}^{B_{1}(s)}[E-\Phi] f(E \mid s) d E+\beta^{I}(s) \\
& +\beta^{B} \rho_{1}(s)+\beta^{B} \max \left\{\tilde{r}+(A-\tilde{r}) \frac{B_{0}(s)}{B_{0}} \frac{p_{1}(s)}{p_{0}}-A, 0\right\} .
\end{aligned}
$$

For $s \leq \tilde{s}$, there is debt forgiveness and a bailout, and we have $\frac{d B_{1}(s)}{d r}=\frac{d \bar{B}_{1}(s)}{d r}=0$ and $\tilde{r}+(A-\tilde{r}) \frac{B_{0}(s)}{B_{0}} \frac{p_{1}(s)}{p_{0}}-A<0$, so that

$$
\frac{d \mathcal{W}_{0}(s)}{d \tilde{r}}=0
$$

For $\tilde{s}<s \leq \bar{s}$, there is debt forgiveness and no bailout, and we have $\frac{d B_{1}(s)}{d r}=\frac{d \bar{B}_{1}(s)}{d r}=0$ and $\tilde{r}+(A-\tilde{r}) \frac{B_{0}(s)}{B_{0}} \frac{p_{1}(s)}{p_{0}}-A>0$, so that

$$
\frac{d \mathcal{W}_{0}(s)}{d \tilde{r}}=\beta^{B}\left[1-\frac{B_{0}(s)}{B_{0}} \frac{p_{1}(s)}{p_{0}}\right]<0
$$

For $s>\bar{s}$, there is no debt forgiveness and no bailout, and we have $\frac{d B_{1}(s)}{d r}=\frac{d B_{0}(s)}{d r}=\frac{d B_{0}}{d r}=0$ and $\tilde{r}+(A-\tilde{r}) \frac{B_{0}(s)}{B_{0}} \frac{p_{1}(s)}{p_{0}}-A>0$, so that

$$
\frac{d \mathcal{W}_{0}(s)}{d \tilde{r}}=\beta^{B}\left[1-\frac{p_{1}(s)}{p_{0}}\right]<0
$$

Together with the fact that $\mathcal{W}_{0}(s)$ is continuous (so that infinitesimal changes in the thresholds $\tilde{s}$ and $\bar{s}$ do not change welfare), this implies that

$$
\frac{d \mathcal{W}_{0}}{d \tilde{r}}=\int \frac{d \mathcal{W}_{0}(s)}{d \tilde{r}} \pi(s) d s<0
$$

\section{A.6 Proof of Proposition 7}

We first prove the first result of the proposition, i.e. that the domestic country is better off committing to tough supervision. We need to show that $\mathcal{W}_{0}^{\prime}<\mathcal{W}_{0}$.

We have $p_{0}^{\prime} B_{0}^{\prime}=p_{0} B_{0}$. It is easy to verify that $p_{0}^{\prime}<p_{0}, B_{0}^{\prime}>B_{0}$, and $\tilde{s}^{\prime}=\tilde{s}<\bar{s}<\bar{s}^{\prime}$. And moreover: for all $s<\tilde{s}=\tilde{s}^{\prime}, B_{1}^{\prime}(s)=B_{1}(s)$, and $B_{0}^{\prime}(s)<B_{0}(s)$; for all $\tilde{s}=\tilde{s}^{\prime} \leq s \leq \bar{s}$, 
$B_{0}^{\prime}(s)=B_{0}(s)=B_{1}(s)=B_{1}^{\prime}(s)$; for all $\bar{s}<s \leq \bar{s}^{\prime}, B_{1}(s)=B_{0}(s)=B_{0}<B_{1}^{\prime}(s)=B_{0}^{\prime}(s)<B_{0}^{\prime}$; and for all $\bar{s}<s, B_{1}(s)=B_{0}(s)=B_{0}<B_{1}^{\prime}(s)=B_{0}^{\prime}(s)=B_{0}^{\prime}{ }^{52}$

We write $\mathcal{W}_{0}=\mathcal{E}_{0}-\mathcal{R}_{0}$ and $\mathcal{W}_{0}^{\prime}=\mathcal{E}_{0}^{\prime}-\mathcal{R}_{0}^{\prime}$. Because $B_{1}^{\prime}(s) \geq B_{1}(s)$ for all $s$ with a strict inequality with positive probability, and because

$$
\iint_{B_{1}^{\prime}(s)}^{\infty} B_{0}^{\prime}(s) f(E \mid s) d E \pi(s) d s=\iint_{B_{1}(s)}^{\infty} B_{0}(s) f(E \mid s) d E \pi(s) d s=p_{0}^{\prime} B_{0}^{\prime}=p_{0} B_{0},
$$

we have $\mathcal{E}_{0}^{\prime}<\mathcal{E}_{0}$.

We will show shortly that we also have $\mathcal{R}_{0}^{\prime}>\mathcal{R}_{0}$, which proves the proposition. We have

$$
\begin{gathered}
\mathcal{R}_{0}=-\left(1-\beta^{B}\right) \int_{\{s \leq \tilde{s}\}} \min \left\{\bar{r}+(A-\bar{r}) \frac{B_{0}(s)}{B_{0}} \frac{p_{1}(s)}{p_{0}}-A, 0\right\} \pi(s) d s, \\
\mathcal{R}_{0}^{\prime}=-\left(1-\beta^{B}\right) \int_{\left\{s \leq \tilde{s}^{\prime}\right\}} \min \left\{A \frac{B_{0}^{\prime}(s)}{B_{0}^{\prime}} \frac{p_{1}^{\prime}(s)}{p_{0}^{\prime}}-A, 0\right\} \pi(s) d s .
\end{gathered}
$$

We use $\tilde{s}=\tilde{s}^{\prime}$. For all $s<\tilde{s}=\tilde{s}^{\prime}$, we have $B_{1}^{\prime}(s)=B_{1}(s)$ and $B_{0}^{\prime}(s)<B_{0}(s)$. Together with the fact that $p_{0} B_{0}=p_{0}^{\prime} B_{0}^{\prime}$, this implies that for all $s \leq \tilde{s}=\tilde{s}^{\prime}$ we have $A \frac{B_{0}^{\prime}(s)}{B_{0}^{\prime}} \frac{p_{1}^{\prime}(s)}{p_{0}^{\prime}}<A \frac{B_{0}(s)}{B_{0}} \frac{p_{1}(s)}{p_{0}}<$ $\bar{r}+(A-\bar{r}) \frac{B_{0}(s)}{B_{0}} \frac{p_{1}(s)}{p_{0}}<A$. The first result in the proposition follows.

The second result, i.e. that a supranational supervisor who puts the same welfare weight on international investors and domestic consumers implements the commitment solution is immediate. Indeed, supervisory leniency increases the total rents of banks (who carry a welfare weight of $\beta^{B}<1$ for the international supervisor) at the expense of domestic consumers and international investors (who both carry an equal welfare weight of 1 for the international supervisor).

\section{A.7 Proof of Propositions 8 and 11}

In the presence of transfers but without bailouts, the problem of foreign countries is

$$
\min _{B_{1} \leq B_{0}}\left\{\Gamma F\left(B_{1} \mid s\right)-\left[1-F\left(B_{1} \mid s\right)\right]\left[B_{1}-B_{0}\right]\right\}
$$

${ }^{52}$ The only nontrivial part is to show that for all $s \leq \tilde{s}^{\prime}=\tilde{s}, B_{0}^{\prime}(s)<B_{0}(s)$. This can be seen as follows. For $s<\tilde{s}^{\prime}=\tilde{s}$, we have $B_{1}^{\prime}(s)=B_{1}(s)$ and $p_{1}^{\prime}(s)=p_{1}(s)$, which together $p_{0}^{\prime} B_{0}^{\prime}=p_{0} B_{0}$ and the fact that $A=I(s)$ can be used to rewrite the bailout equations as

$$
B_{0}(s)=B_{1}(s) \frac{1-\frac{A-\bar{r}}{B_{1}(s)\left[1-F\left(B_{1}(s) \mid s\right)\right]}}{1-\frac{A-\bar{r}}{p_{0} B_{0}}} \quad \text { and } \quad B_{0}^{\prime}(s)=B_{1}(s) \frac{1-\frac{A}{B_{1}(s)\left[1-F\left(B_{1}(s) \mid s\right)\right]}}{1-\frac{A}{p_{0} B_{0}}} \text {. }
$$

Since $B_{1}(s)\left[1-F\left(B_{1}(s) \mid s\right)\right]<p_{0} B_{0}$ for $s<\tilde{s}=\tilde{s}^{\prime}$, this implies that $B_{0}^{\prime}(s)<B_{0}(s)$. 


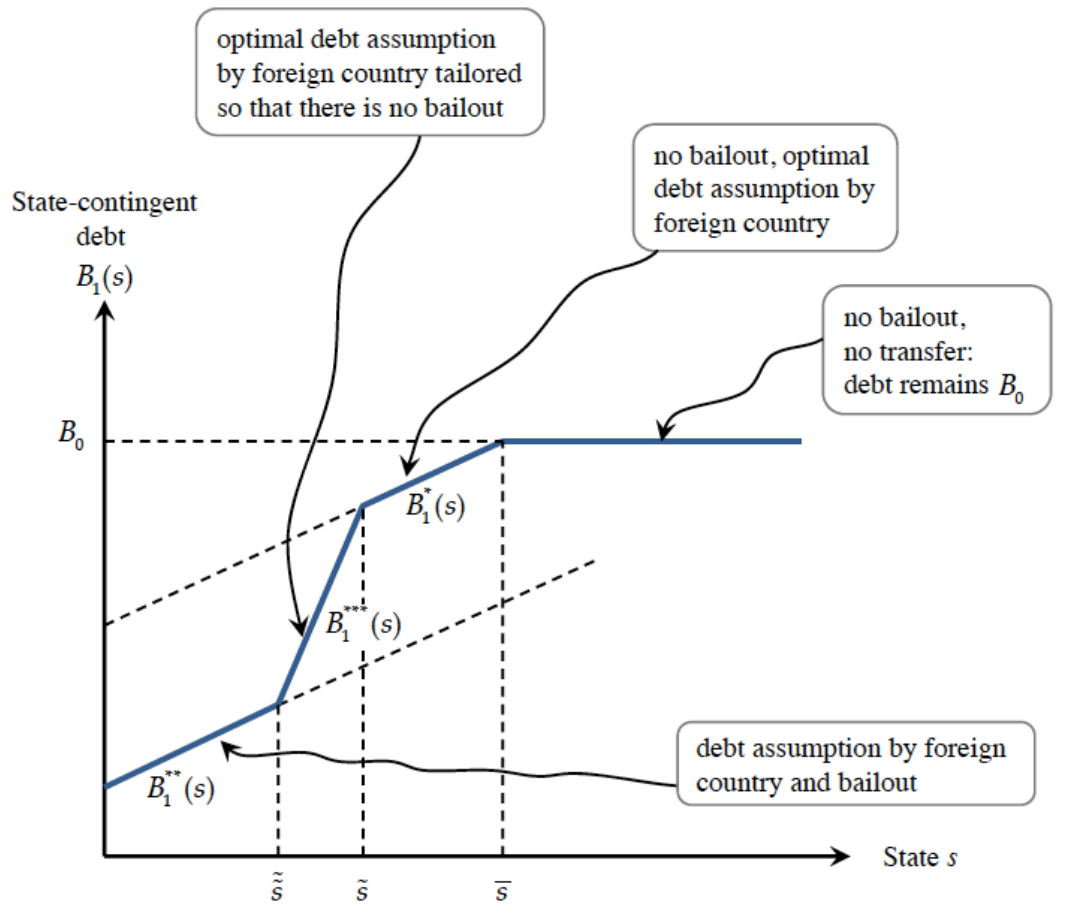

Figure 6: Country Solidarity and International Transfers when the Equilibrium is Bailout-Shifting.

The solution $B_{1}^{*}(s)$ is characterized by the first-order condition $\Gamma+B_{1}^{*}(s)-B_{0}=\frac{1-F\left(B_{1}^{*}(s) \mid s\right)}{f\left(B_{1}^{*}(s) \mid s\right)}$. Transfers are indeed strictly positive $T^{*}(s)>0$ when $s<\bar{s}$ where the threshold $\bar{s}$ is defined by $B_{1}^{*}(\bar{s})=B_{0}$.

In the presence of transfers, bailouts matter if and only if $s \leq \tilde{s}$ where the threshold $\tilde{s}$ is defined implicitly by $\frac{1-F\left(B_{1}^{*}(\tilde{s}) \mid \tilde{s}\right)}{p_{0}}=1$. If there are strictly positive bailouts and transfers, the problem of foreign countries is $\min _{B_{1}}\left\{\Gamma F\left(B_{1} \mid s\right)-\left[1-F\left(B_{1} \mid s\right)\right]\left[B_{1}-B_{0}+b_{0}\right]\right\}$. The solution $B_{1}^{* *}(s)<B_{1}^{*}(s)$ is characterized by the first-order condition $\Gamma+B_{1}^{* *}(s)-\left(B_{0}-b_{0}\right)=$ $\frac{1-F\left(B_{1}^{* *}(s) \mid s\right)}{f\left(B_{1}^{* *}(s) \mid s\right)}$, the associated level of transfers and bailouts are $T^{* *}(s)$ and $X^{* *}(s)$.

Finally, we define $T^{* * *}(s)$ and $B_{1}^{* * *}(s)$ by $T^{* * *}(s)=-\left[1-F\left(B_{1}^{* * *}(s) \mid s\right)\right]\left(B_{1}^{* * *}(s)-B_{0}\right)$ and $\frac{1-F\left(B_{1}^{* * * *}(s) \mid s\right)}{p_{0}}=1$. We assume that $F(E \mid s)=F(E-s)$. Then $\frac{d B_{1}^{*}(s)}{d s}=\frac{d B_{1}^{* *}(s)}{d s} \in(0,1)$ and $\frac{d B_{1}^{* * *}(s)}{d s}=1$ for all $s$. We have $B_{1}^{* * *}(\tilde{s})=B_{1}^{*}(\tilde{s})$. Define $\tilde{s}$ by $B_{1}^{* * *}(\tilde{s})=B_{1}^{* *}(\tilde{s})$.

As in Section 4.1, we assume that the equilibrium given the fixed diversification requirement $r=\bar{r}$ is bailout shifting with $\tilde{s}<\bar{s}$. This situation is guaranteed to occur in bad times when $\Gamma$ is large. Then the equilibrium is as follows: For $s \geq \bar{s}$, there are neither transfers nor bailouts $T(s)=X(s)=0$, and date-1 debt is given by $B_{1}(s)=B_{0}$; for $\tilde{s} \leq s<\bar{s}$, there are transfers $T(s)=T^{*}(s)>0$ but no bailouts $X(s)=0$, and date-1 debt is given by $B_{1}(s)=B_{1}^{*}(s)$; for $\tilde{s} \leq s<\tilde{s}$, there are transfers $T(s)=T^{* * *}(s)>0$ but no bailouts $X(s)=0$, and date- 1 debt is given by $B_{1}(s)=B_{1}^{* * *}(s)$; and for $s<\tilde{\tilde{s}}$ there are transfers

\footnotetext{
${ }^{53}$ The second-order condition is satisfied if the density $f$ is decreasing.
} 
$T(s)=T^{* *}(s)>0$ and bailouts $X(s)=X^{* *}(s)>0$.

The threshold $\tilde{s}$ is decreasing in $r \leq \bar{r}$ and $\bar{s}$ is independent of $r \leq \bar{r}$, so that the equilibrium given the fixed diversification requirement $r$ remains bailout shifting for all $r \leq \bar{r}$. For a given $p_{0}$ and $B_{0}, B_{1}(s)$ is independent of $r$ when $s>\tilde{s}$, but crucially, it is strictly increasing in $r$ when $s<\tilde{\tilde{s}}$. This last property is key, and means that for a given $p_{0}$ and $B_{0}$, a lower $r$ leads to such an increase in transfers $T(s)$ that it actually decreases $B_{1}(s)$ even though it increases the required bailout absent transfers. It arises because the doom loop, which is stronger when $r$ is lower, makes transfers more attractive at the margin for foreigners by magnifying the reduction in the probability of default resulting from a transfers. As a result, the only equilibrium features maximal supervisory leniency $r=0$.

Starting from that equilibrium and given $p_{0}$ and $B_{0}$, if the Sovereign unexpectedly forced banks to invest in an exogenous risky asset with the same payoff as the equilibrium payoff of the domestic sovereign bond instead of the risky domestic sovereign bond, then $B_{1}(s)$ would be given by $B_{1}^{*}(s)$ for all $s<\bar{s}$, and hence the probability of default would be strictly higher, and welfare strictly lower.

\section{A.8 Proof of Proposition 10}

Denote by $\mathcal{W}_{0}=\mathcal{E}_{0}-\mathcal{R}_{0}$ and $\mathcal{W}_{0}^{\prime}=\mathcal{E}_{0}^{\prime}-\mathcal{R}_{0}^{\prime}$ the welfare levels in the true economy under shared supervision when $r=\bar{r}$ and under domestic supervision when $r=0$. Denote by $\mathcal{W}_{0}^{\text {fictitious }}=\mathcal{E}_{0}^{\text {fictitious }}-\mathcal{R}_{0}^{\text {fictitious }}$ and $\mathcal{W}_{0}^{\text {ffictitious }}=\mathcal{E}_{0}^{\prime \text { fictitious }}-\mathcal{R}_{0}^{\prime \text { fictitious }}$ the corresponding welfare levels in the fictitious economy. We have $\mathcal{W}_{0}=\mathcal{W}_{0}^{\text {fictitious }}$. The welfare gains achieved by shared supervision are $\mathcal{W}_{0}-\mathcal{W}_{0}^{\prime}>0$ and $\mathcal{W}_{0}^{\text {fictitious }}-\mathcal{W}_{0}^{\prime \text { fictitious }}>0$ respectively.

The intuition for magnification of the welfare gains from shared supervision by the doom loop is that when supervision is relaxed: (1) The doom loop leads to bigger bailouts and more ex-post debt forgiveness, which is priced-in ex ante by international investors, leading to lower ex-ante domestic sovereign debt prices, higher legacy debt, and more defaults so that $\mathcal{E}_{0}^{\prime \text { fictitious }}>\mathcal{E}_{0}^{\prime} ;(2)$ the doom loop makes domestic sovereign debt riskier, leading to more rents for bankers $\mathcal{R}_{0}^{\prime \text { fictitious }}<\mathcal{R}_{0}^{\prime}$. As a result, $\mathcal{W}_{0}^{\prime}=\mathcal{E}_{0}^{\prime}-\mathcal{R}_{0}^{\prime}<\mathcal{E}_{0}^{\prime \text { fictitious }}-\mathcal{R}_{0}^{\prime \text { fictitious }}=$ $\mathcal{W}_{0}^{\prime \text { fictitious }}$ and hence $\mathcal{W}_{0}^{\text {fictitious }}-\mathcal{W}_{0}^{\prime \text { fictitious }}<\mathcal{W}_{0}-\mathcal{W}_{0}^{\prime}$.

We have $p_{0}^{\prime} B_{0}^{\prime}=p_{0}^{\prime \text { fictitious }} B_{0}^{\prime \text { fictitious }}=p_{0} B_{0}$. It is easy to verify that $p_{0}^{\prime}<p_{0}^{\prime \text { fictitious }}<p_{0}$, $B_{0}^{\prime}>B_{0}^{\prime \text { fictitious }}>B_{0}$, and $\tilde{s}=\tilde{s}^{\prime}=\tilde{s}^{\text {fictitious }}=\tilde{s}^{\prime \text { fictitious }}<\bar{s}<\bar{s}^{\prime \text { fictitious }}<\bar{s}^{\prime}$. And moreover: for all $s<\tilde{s}, B_{1}^{\prime}(s)=B_{1}^{\prime \text { fictitious }}(s)=B_{1}(s)$, and $B_{0}^{\prime}(s)<B_{0}^{\text {fictitious }}(s)<B_{0}(s)$; for all $\tilde{s}=\tilde{s}^{\prime} \leq$ $s \leq \bar{s}, B_{0}^{\prime}(s)=B_{0}^{\prime \text { fictitious }}(s)=B_{0}(s)=B_{1}(s)=B_{1}^{\prime}(s)=B_{1}^{\prime \text { fictitious }}(s)$; for all $\bar{s}<s \leq \bar{s}^{\prime \text { fictitious }}$, $B_{1}(s)=B_{0}(s)=B_{0}<B_{1}^{\prime}(s)=B_{1}^{\prime \text { fictitious }}(s)=B_{0}^{\prime}(s)=B_{0}^{\text {ffictitious }}(s)<B_{0}^{\text {fictitious }}<B_{0}^{\prime}$; for all $\bar{s}^{\prime \text { fictitious }} \leq s<\bar{s}^{\prime}, B_{1}(s)=B_{0}(s)=B_{0}<B_{1}^{\prime \text { fictitious }}(s)=B_{0}^{\prime \text { fictitious }}(s)=B_{0}^{\prime \text { fictitious }}<$ 
$B_{1}^{\prime}(s)=B_{0}^{\prime}(s)<B_{0}^{\prime}$; and for all $\bar{s}^{\prime}<s, B_{1}(s)=B_{0}(s)=B_{0}<B_{1}^{\prime \text { fictitious }}(s)=B_{0}^{\prime \text { fictitious }}(s)=$ $B_{0}^{\prime \text { fictitious }}<B_{1}^{\prime}(s)=B_{0}^{\prime}(s)=B_{0}^{\prime} \cdot{ }^{54}$

We have

$$
\begin{gathered}
\mathcal{R}_{0}^{\prime}=-\left(1-\beta^{B}\right) A \int_{\left\{s \leq \tilde{s}^{\prime}\right\}} \min \left\{\frac{B_{0}^{\prime}(s)}{B_{0}^{\prime}} \frac{p_{1}^{\prime}(s)}{p_{0}^{\prime}}-1,0\right\} \pi(s) d s, \\
\mathcal{R}_{0}^{\prime \text { fictitious }}=-\left(1-\beta^{B}\right) A \int_{\left\{s \leq \tilde{s}^{\prime} \text { fictitious }\right\}} \min \left\{R_{1}(s)-1,0\right\} \pi(s) d s .
\end{gathered}
$$

We use $\tilde{s}=\tilde{s}^{\prime}=\tilde{s}^{\text {fictitious }}=\tilde{s}^{\prime \text { fictitious }}$. For all $s<\tilde{s}$, we have $B_{1}^{\prime}(s)=B_{1}(s)$ and $B_{0}^{\prime}(s)<B_{0}(s)$. Together with the fact that $p_{0} B_{0}=p_{0}^{\prime} B_{0}^{\prime}$, this implies that for all $s \leq \tilde{s}$ we have $\frac{B_{0}^{\prime}(s)}{B_{0}^{\prime}} \frac{p_{1}^{\prime}(s)}{p_{0}^{\prime}}<$ $\frac{B_{0}(s)}{B_{0}} \frac{p_{1}(s)}{p_{0}}=R_{1}(s)$. This implies that $\mathcal{R}_{0}^{\prime \text { fictitious }}<\mathcal{R}_{0}^{\prime}$.

Because $B_{1}^{\prime}(s) \geq B_{1}^{\prime \text { fictitious }}(s)$ for all $s$ with a strict inequality with positive probability, and because

$$
\iint_{B_{1}^{\prime}(s)}^{\infty} B_{0}^{\prime}(s) f(E \mid s) d E \pi(s) d s=\iint_{B_{1}^{\prime f i c t i t i o u s}(s)}^{\infty} B_{0}^{\prime \text { fictitious }}(s) f(E \mid s) d E \pi(s) d s=p_{0} B_{0}
$$

we have $\mathcal{E}_{0}^{\text {fictitious }}>\mathcal{E}_{0}^{\prime}$.

\section{A.9 Proof of Proposition 12}

A symmetric equilibrium is characterized by the following pricing equations

$$
\begin{gathered}
p_{1}\left(s^{d}, s^{f}\right)=1-F\left(B_{1}\left(s^{d}, s^{f}\right) \mid s^{d}\right), \\
p_{0}=\int p_{1}\left(s^{d}, s^{f}\right) d \pi\left(s^{d}, s^{f}\right),
\end{gathered}
$$

with

$$
B_{1}\left(s^{d}, s^{f}\right)=B_{0}+\max \left\{\frac{I\left(s^{d}\right)-b_{0}^{*}}{p_{1}\left(s^{d}, s^{f}\right)}-\frac{b_{0}^{d}}{p_{0}}-\frac{b_{0}^{f}}{p_{0}} \frac{p_{1}\left(s^{f}, s^{d}\right)}{p_{1}\left(s^{d}, s^{f}\right)}, 0\right\},
$$

${ }^{54}$ The only nontrivial part is to show that for all $s \leq \tilde{s}, B_{0}^{\prime}(s)<B_{0}^{\text {ffictitious }}(s)<B_{0}(s)$. This can be seen as follows. For $s<\tilde{s}$, we have $B_{1}^{\prime}(s)=B_{1}^{\prime \text { fictitious }}(s)=B_{1}(s)$ and $p_{1}^{\prime}(s)=p_{1}^{\text {fictitious }}(s)=p_{1}(s)$, which together with $p_{0}^{\prime} B_{0}^{\prime}=p_{0} B_{0}$ and the fact that $A=I(s)$ can be used to rewrite the bailout equations as

$$
B_{0}(s)=B_{1}(s) \frac{1-\frac{A-\bar{r}}{B_{1}(s)\left[1-F\left(B_{1}(s) \mid s\right)\right]}}{1-\frac{A-\bar{r}}{p_{0} B_{0}}} \quad \text { and } \quad B_{0}^{\prime}(s)=B_{1}(s) \frac{1-\frac{A}{B_{1}(s)\left[1-F\left(B_{1}(s) \mid s\right)\right]}}{1-\frac{A}{p_{0} B_{0}}} .
$$

Similarly, we can write

$$
B_{0}(s)=B_{1}(s)-(A-\bar{r}) \frac{1-R_{1}(s)}{1-F\left(B_{1}(s) \mid s\right)} \quad \text { and } \quad B_{0}^{\prime f i c t i t i o u s ~}(s)=B_{1}(s)-A \frac{1-R_{1}(s)}{1-F\left(B_{1}(s) \mid s\right)} .
$$

Since $B_{1}(s)\left[1-F\left(B_{1}(s) \mid s\right)\right]<p_{0} B_{0}$ for $s<\tilde{s}$, this implies that $B_{0}^{\prime}(s)<B_{0}(s)$. It is easy to verify that $B_{0}^{\prime \text { fictitious }}(s)<B_{0}(s)$ and $B_{0}^{\prime}(s)<B_{0}^{\text {fictitious }}(s)$. 
together with the requirement that bank portfolios $\left(b_{0}^{*}, b_{0}^{d}, b_{0}^{f}\right)$ solve the following maximization problem

$$
\max _{\left(\tilde{b}_{0}^{*}, \tilde{b}_{0}^{d}, \tilde{b}_{0}^{f}\right)} \int\left[\rho_{1}\left(s^{d}\right) I\left(s^{d}\right)+\max \left\{\tilde{b}_{0}^{*}+p_{1}\left(s^{d}, s^{f}\right) \tilde{b}_{0}^{d}+p_{1}\left(s^{f}, s^{d}\right) \tilde{b}_{0}^{f}-I\left(s^{d}\right), 0\right\}\right] d \pi\left(s^{d}, s^{f}\right),
$$

subject to

$$
\tilde{b}_{0}^{*}+p_{0}\left(\tilde{b}_{0}^{d}+\tilde{b}_{0}^{f}\right)=A \quad \text { and } \quad \tilde{b}_{0}^{*} \geq \bar{r} .
$$

We denote by $B_{0}$ the quantity of debt at date 0 and by $p_{0}$ the price of debt at date 0 in both risky countries. We assume that in each country $i \in\{\mathcal{A}, \mathcal{B}\}$, supervision forces banks of country $i$ to hold a portfolio with holdings of safe foreign sovereign bonds of at least $r \leq \bar{r}$, but does not place constraints on the relative holding of risky sovereign debt of countries $\mathcal{A}$ and $\mathcal{B}$. We start by assuming that there is no debt forgiveness (we reintroduce this possibility later). Each Sovereign chooses not to engage in supervisory leniency and sets $r=\bar{r}$, which we assume from now on.

In each country $i$, we denote by $b_{0}^{*} \geq \bar{r}, b_{0}^{d} \geq 0$ and $b_{0}^{f} \geq 0$ the holdings of foreign safe debt, risky domestic debt (of country $i$ ) and risky foreign debt (of country $-i$ ) with $b_{0}^{*}+p_{0}\left(b_{0}^{d}+b_{0}^{f}\right)=A$. We denote by $B_{1}\left(s^{d}, s^{f}\right)$ the quantity of debt at date 1 and by $p_{1}\left(s^{d}, s^{f}\right)$ the price of debt at date 1 when the domestic when country $i$ is in state $s^{i}=s^{d}$ and country $-i$ is in state $s^{-i}=s^{f}$.

Assume that the equilibrium is of the form given by the proposition. Under the assumed equilibrium, we have $p_{1}\left(s^{d}, s^{f}\right)=p_{1}\left(s^{d}\right)$ and $p_{1}\left(s^{f}, s^{d}\right)=p_{1}\left(s^{f}\right)$, for some increasing function $p_{1}(s)$. We now show that banks then indeed choose portfolios $b_{0}^{*}=\bar{r}, b_{0}^{d}=\frac{A-\bar{r}}{p_{0}}$, and $b_{0}^{f}=0$, and that this preference is strict. This proves that the assumed equilibrium is indeed an equilibrium, and that it is strict.

We use the following result. Take a supermodular function $g\left(x_{1}, x_{2}\right)$ and take two marginals $F_{1}$ and $F_{2}$. Consider the problem of maximizing $E\left[g\left(X_{1}, X_{2}\right)\right]$ subject to the marginals of $\left(X_{1}, X_{2}\right)$ being given by $F_{1}$ and $F_{2}$. Then the maximum is reached when the two variables are co-monotone. This is a well-known solution of the Monge-Kantorovich optimal transport problem in the case of supermodular objective functions. ${ }^{55}$

We apply this result with $g\left(x_{1}, x_{2}\right)=\max \left\{x_{1}+x_{2}, 0\right\}$, with $F_{1}$ given by the distribution of $\tilde{b}_{0}^{*}+p_{1}\left(s^{d}\right)\left(A-\tilde{b}_{0}^{*}\right)$ and $F_{2}$ given by the distribution of $-I\left(s^{d}\right)$. The random variables $X_{1}=p_{1}\left(s^{d}\right) \tilde{b}_{0}^{d}+p_{1}\left(s^{f}\right)\left(A-\tilde{b}_{0}^{*}-\tilde{b}_{0}^{d}\right)$ and $X_{2}=-I\left(s^{d}\right)$ are such that the marginals of $\left(X_{1}, X_{2}\right)$ are given by $F_{1}$ and $F_{2}$. They are co-monotone if and only if $\tilde{b}_{0}^{d}=A-\tilde{b}_{0}^{*}$.

This shows given $\tilde{b}_{0}^{*} \geq \bar{r}$, banks strictly prefer $\tilde{b}_{0}^{d}=A-\tilde{b}_{0}^{*}$ and $\tilde{b}_{0}^{f}=0$. It is then immediate to see that banks strictly prefer $\tilde{b}_{0}^{*}=\bar{r}, \tilde{b}_{0}^{d}=A-\tilde{b}_{0}^{*}$, and $\tilde{b}_{0}^{f}=0$.

\footnotetext{
${ }^{55}$ See Galichon (2016) and references therein.
} 


\section{A.10 Proof of Proposition 13}

When choosing the portfolio of banks, the domestic Sovereign takes $p_{0}$ as given and maximizes the following welfare function in $\left(b_{0}^{*}, b_{0}^{d}, b_{0}^{f}\right)$ for a given $p_{0}$ :

$$
\mathcal{W}_{0}=\int \mathcal{W}_{0}\left(s^{d}, s^{f}\right) \Pi\left(s^{d}, s^{f}\right) d s^{d} d s^{f},
$$

with

$$
\begin{gathered}
\mathcal{W}_{0}\left(s^{d}, s^{f}\right)=\int_{B_{1}\left(s^{d}, s^{f}\right)}^{\infty}\left[E-B_{1}\left(s^{d}, s^{f}\right)\right] f\left(E \mid s^{d}\right) d E+\int_{0}^{B_{1}\left(s^{d}, s^{f}\right)}[E-\Phi] f\left(E \mid s^{d}\right) d E+\beta^{I}\left(s^{d}\right) \\
+\beta^{B} \rho_{1}\left(s^{d}\right)+\beta^{B} \max \left\{b_{0}^{*}+b_{0}^{d} \frac{B_{0}\left(s^{d}, s^{f}\right)}{B_{0}} p_{1}\left(s^{d}, s^{f}\right)+b_{0}^{f} \frac{B_{0}\left(s^{f}, s^{d}\right)}{B_{0}} p_{1}\left(s^{f}, s^{d}\right)-I\left(s^{d}\right), 0\right\} .
\end{gathered}
$$

It is clear that $b_{0}^{*}=0, b_{0}^{d}=\frac{A}{p_{0}}$, and $b_{0}^{f}=0$ is a maximizer of the default term

$\iint_{B_{1}\left(s^{d}, s^{f}\right)}^{\infty}\left[E-B_{1}\left(s^{d}, s^{f}\right)\right] f\left(E \mid s^{d}\right) d E \Pi\left(s^{d}, s^{f}\right) d s^{d} d s^{f}+\int_{0}^{B_{1}\left(s^{d}, s^{f}\right)}[E-\Phi] f\left(E \mid s^{d}\right) d E \Pi\left(s^{d}, s^{f}\right) d s^{d} d s^{f}$.

This is because with this portfolio, all bank bailouts occur in states where there is debt forgiveness, and in these states, the amount of post-debt forgiveness debt is independent of the banks' portfolios. This implies that for all $\left(s^{d},{ }^{f}\right)$, post-debt forgiveness $B_{1}\left(s^{d}, s^{f}\right)$ is greater for any other portfolio for banks.

It remains to show that $b_{0}^{*}=0, b_{0}^{d}=\frac{A}{p_{0}}$, and $b_{0}^{f}=0$ is a maximizer of the the banks' rents term

$$
\int \beta^{B} \max \left\{b_{0}^{*}+b_{0}^{d} \frac{B_{0}\left(s^{d}, s^{f}\right)}{B_{0}} p_{1}\left(s^{d}, s^{f}\right)+b_{0}^{f} \frac{B_{0}\left(s^{f}, s^{d}\right)}{B_{0}} p_{1}\left(s^{f}, s^{d}\right)-I\left(s^{d}\right), 0\right\} \Pi\left(s^{d}, s^{f}\right) d s^{d} d s^{f} .
$$

The first-order term in $A=\bar{I}$ in this expression is given by

$$
\int \beta^{B} \max \left\{b_{0}^{*}+b_{0}^{d} \frac{\hat{B}_{0}\left(s^{d}\right)}{B_{0}} \hat{p}_{1}\left(s^{d}\right)+b_{0}^{f} \frac{\hat{B}_{0}\left(s^{f}\right)}{B_{0}} \hat{p}_{1}\left(s^{f}\right)-\bar{I}, 0\right\} \Pi\left(s^{d}, s^{f}\right) d s^{d} d s^{f},
$$

where $\hat{B}_{0}\left(s^{d}\right)$ and $\hat{p}_{1}\left(s^{d}\right)$ are the equilibrium values for $A=\bar{I}=0$ (and the value of $p_{0}$ under consideration). Using the same result for the Monge-Kantorovich optimal transport problem in the case of supermodular objective functions as in the proof of Proposition 12, it follows this expression is maximized when either $b_{0}^{d}=0$ or $b_{0}^{f}=0$ and in addition $b_{0}^{*}=0$. 


\section{B Online Appendix: Extensions}

\section{B.1 Sovereign Debt Maturity}

In this section, we investigate the role of sovereign debt maturity. More specifically, we compare our economy with long-term sovereign bonds which are claims to coupons accruing at date 2 with an economy where sovereign bonds are short-term, one-period bonds which are rolled over at date 1.

We assume that there is no debt forgiveness (either because debt is on the right side of the legacy creditors' Laffer curve, or because debt is on the wrong side of the legacy creditors' Laffer curve but investors have difficulties coordinating on a debt relief package). It is easy to see that the absence of supervisory leniency extends to the setting of this section. We therefore make use of the fact that $r=\bar{r}$ throughout.

With long-term bonds, welfare is given by the decomposition (4) so that

$$
\mathcal{W}_{0}=\mathcal{E}_{0}-\mathcal{R}_{0}
$$

with

$$
\begin{gathered}
\mathcal{E}_{0}=\int\left[\int_{B_{1}(s)}^{\infty}\left[E-B_{0}\right] f(E \mid s) d E+\int_{0}^{B_{1}(s)}[E-\Phi] f(E \mid s) d E\right] d \pi(s) \\
+\int\left[\beta^{I}(s)+\beta^{B}\left[\rho_{1}(s)-I(s)+A\right]\right] d \pi(s), \\
\mathcal{R}_{0}=-\int\left(1-\beta^{B}\right) \min \left\{\bar{r}+(A-\bar{r}) \frac{p_{1}(s)}{p_{0}}-I(s), 0\right\} d \pi(s) .
\end{gathered}
$$

We now consider the economy with short-term bonds. We denote all variables with a tilde. To make the comparison with the economy with short-term bonds meaningful, we impose that the Sovereign must raise the same amount of revenues $G_{0}$ in period 0, i.e.

$$
\tilde{B}_{0}=B_{0} \int\left[1-F\left(B_{1}(s) \mid s\right)\right]=G_{0}
$$

In addition, the Sovereign must raise exactly enough revenues at date 1 to repay the date- 0 debt that is coming due, i.e. we must have for all $s^{56}$

$$
\tilde{B}_{1}(s)\left[1-F\left(\tilde{B}_{1}(s) \mid s\right)\right]=\tilde{B}_{0} .
$$

\footnotetext{
${ }^{56}$ To give short-term debt a good shot, we assume that the Sovereign is always able to roll over its short-term debt. This is indeed the case if negative shocks $s$ are not too catastrophic, so that the debt can be rolled over by pledging income in the good realizations at date 2.
} 
Because $\bar{I} \leq A$, no bailouts are required. Welfare is given by

$$
\tilde{\mathcal{W}}_{0}=\tilde{\mathcal{E}}_{0}-\tilde{\mathcal{R}}_{0}
$$

with

$$
\begin{gathered}
\tilde{\mathcal{E}}_{0}=\int\left[\int_{\tilde{B}_{1}(s)}^{\infty}\left[E-\tilde{B}_{1}(s)\right] f(E \mid s) d E+\int_{0}^{\tilde{B}_{1}(s)}[E-\Phi] f(E \mid s) d E\right] d \pi(s) \\
+\int\left[\beta^{I}(s)+\beta^{B}\left[\rho_{1}(s)-I(s)+A\right]\right] d \pi(s), \\
\tilde{\mathcal{R}}_{0}=0 .
\end{gathered}
$$

Using (17) and (18), we can write

$$
\mathcal{W}_{0}-\tilde{\mathcal{W}}_{0}=\left(\mathcal{E}_{0}-\tilde{\mathcal{E}}_{0}\right)-\left(\mathcal{R}_{0}-\tilde{\mathcal{R}}_{0}\right),
$$

with

$$
\begin{gathered}
\mathcal{E}_{0}-\tilde{\mathcal{E}}_{0}=\int \Phi\left[F\left(\tilde{B}_{1}(s) \mid s\right)-F\left(B_{1}(s) \mid s\right)\right] d \pi(s), \\
\mathcal{R}_{0}-\tilde{\mathcal{R}}_{0}=-\left(1-\beta^{B}\right) \int \min \left\{\bar{r}+(A-\bar{r}) \frac{p_{1}(s)}{p_{0}}-I(s), 0\right\} d \pi(s) .
\end{gathered}
$$

The term $\left(\mathcal{E}_{0}-\tilde{\mathcal{E}}_{0}\right)$ is given by the difference in default costs, and the second term $-\left(\mathcal{R}_{0}-\right.$ $\left.\tilde{\mathcal{R}}_{0}\right)$ represents the welfare impact of the rents extracted by bankers at the expense of consumers because of bailouts when domestic sovereign bonds are long term. In the proof of the proposition below, we show that under some additional assumptions on the distributions of $E$, the first term is positive. ${ }^{57}$ The second term is always negative and arises because by issuing short-term bonds, the Sovereign reduces the risk-taking possibilities of banks and insulates the banks from fiscal developments-there is no feedback loop between banks and the Sovereign. As a result, the intuitive asset-liability management (ALM) principle of matching maturities of incomes and payments holds when the minimum diversification requirement $\bar{r}$ is high enough: Long-term debt then leads to a strictly lower expected probability of default than short-term debt.

Intuitively, a short maturity has both benefits and costs. The cost is that a short maturity is bad for fiscal hedging. The benefit is that a short maturity reduces the risk-shifting possibilities of banks. A short maturity is therefore a costly substitute to supervision. As a result, a long maturity is preferable when supervision is efficient enough ( $\bar{r}$ is high enough) or when

\footnotetext{
${ }^{57}$ The additional assumptions are that $F(E \mid s)=F(E-s)$ where $F$ is increasing and convex. These assumptions, which imply the monotone hazard rate properties $\frac{\partial(f(E \mid s) /(1-F(E \mid s)))}{\partial s} \leq 0$ and $\frac{\partial(f(E \mid s) /(1-F(E \mid s)))}{\partial E}>0$, are sufficient but not necessary to prove the result.
} 
the banking sector is small enough ( $A$ and $\bar{I}$ are small enough).

Proposition 15 (Optimal Debt Maturity). Suppose that $F(E \mid s)=F(E-s)$ where $F$ is increasing and convex. Then for $\bar{r}$ high enough or for $A$ and $\bar{I}$ low enough, welfare is higher with long-term sovereign bonds than with short-term sovereign bonds $\mathcal{W}_{0}>\tilde{\mathcal{W}}_{0}$.

Proof. We prove the result for $\bar{r}$ high enough. The proof of the result for for $A$ and $\bar{I}$ low enough is similar. Note that $B_{1}(s) \geq B_{0}$ and that $B_{1}(s)$ converges to $B_{0}$ for all $s$ as $\bar{r}$ goes to $\bar{I}$, while $\tilde{B}_{1}(s)$ is independent of $\bar{r}$. Hence the result follows if we can show that $\int \Phi\left[F\left(\tilde{B}_{1}(s) \mid s\right)-\right.$ $\left.F\left(B_{0} \mid s\right)\right] d \pi(s)<0$. We now proceed to prove this result, which we refer to as result $\mathrm{A}$. The result is a direct consequence of the following related (dual) result, which we refer to as result B. Let $B_{0}$ be defined by

$$
\int B_{0}\left[1-F\left(B_{0} \mid s\right)\right] d \pi(s)=G_{0}
$$

as above, and let $\tilde{\tilde{B}}_{1}(s)$ and $\tilde{\tilde{G}}_{0}$ be defined by the system of equations

$$
\begin{aligned}
& \tilde{\tilde{B}}_{1}(s)\left[1-F\left(\tilde{\tilde{B}}_{1}(s) \mid s\right)\right]=\tilde{\tilde{G}}_{0} \text { for all } s, \\
& \int F\left(\tilde{\tilde{B}}_{1}(s) \mid s\right) d \pi(s)=\int F\left(B_{0} \mid s\right) d \pi(s) .
\end{aligned}
$$

Result $B$ is that $\tilde{\tilde{G}}_{0}<G_{0}$. We now prove result $B$, which in turn directly implies result A.

Since

$$
\tilde{\tilde{G}}_{0} \int \frac{B_{0}}{\tilde{\tilde{B}}_{1}(s)} d \pi(s)=G_{0},
$$

we need to show that

$$
\int \frac{B_{0}}{\tilde{\tilde{B}}_{1}(s)} d \pi(s)>1 .
$$

By Jensen's inequality, result B is implied by the following result, which we refer to as result C:

$$
\frac{B_{0}}{\int \tilde{\tilde{B}}_{1}(s) d \pi(s)}>1 .
$$

Since $\int F\left(\tilde{\tilde{B}}_{1}(s)-s\right) d \pi(s)=\int F\left(B_{0}-s\right) d \pi(s)$ and $F$ is increasing, result $C$ is equivalent to

$$
\int F\left(\int \tilde{\tilde{B}}_{1}\left(s^{\prime}\right) d \pi\left(s^{\prime}\right)-s\right) d \pi(s)<\int F\left(\tilde{\tilde{B}}_{1}(s)-s\right) d \pi(s) .
$$

Define

$$
g(\lambda)=\int F\left[\int \tilde{\tilde{B}}_{1}\left(s^{\prime}\right) d \pi\left(s^{\prime}\right)+\lambda\left(\tilde{\tilde{B}}_{1}(s)-\int \tilde{\tilde{B}}_{1}\left(s^{\prime}\right) d \pi\left(s^{\prime}\right)\right)-s\right] d \pi(s)
$$


We have

$g^{\prime}(\lambda)=\int f\left[\int \tilde{\tilde{B}}_{1}\left(s^{\prime}\right) d \pi\left(s^{\prime}\right)+\lambda\left(\tilde{\tilde{B}}_{1}(s)-\int \tilde{\tilde{B}}_{1}\left(s^{\prime}\right) d \pi\left(s^{\prime}\right)\right)-s\right]\left[\tilde{\tilde{B}}_{1}(s)-\int \tilde{\tilde{B}}_{1}\left(s^{\prime}\right) d \pi\left(s^{\prime}\right)\right] d \pi(s)$.

Because $f\left[\int \tilde{\tilde{B}}_{1}\left(s^{\prime}\right) d \pi\left(s^{\prime}\right)+\lambda\left(\tilde{\tilde{B}}_{1}(s)-\int \tilde{\tilde{B}}_{1}\left(s^{\prime}\right) d \pi\left(s^{\prime}\right)\right)-s\right]$ and $\tilde{\tilde{B}}_{1}(s)-\int \tilde{\tilde{B}}_{1}\left(s^{\prime}\right) d \pi\left(s^{\prime}\right)$ are decreasing in $s$ for all $\lambda \geq 0$, the right-hand side is the covariance of two decreasing functions of the random variable $s$ and is therefore positive. It follows that $g^{\prime}(\lambda)>0$ for all $\lambda \geq 0$. Since $g(0)=\int F\left(\int \tilde{\tilde{B}}_{1}\left(s^{\prime}\right) d \pi\left(s^{\prime}\right)-s\right) d \pi(s)$ and $g(1)=\int F\left(\tilde{\tilde{B}}_{1}(s)-s\right) d \pi(s)$, we get result C. Results B and A follow, concluding the proof of the Proposition.

There are obvious extensions of our setup that would reinforce the conclusion of Proposition 15. For example, the desirable features of short-term sovereign debt in terms of limiting the risk-taking possibilities of banks, bailouts and feedback loops between banks and sovereigns, would be mitigated in a model with a richer set of risk taking possibilities apart from domestic sovereign debt, or in an infinite horizon version of our model with overlapping generations of bankers, consumers and investors, where some banks hold domestic sovereign debt for liquidity in all periods.

Connection to the sovereign debt literature on debt maturity. The result in Proposition 15 is related to a set of arguments in the sovereign debt literature that seek to rationalize the empirical observation that Sovereigns tend to shorten the maturity of their debt when the probability of default increases. ${ }^{58,59}$ This literature has two branches. The first one focuses on the different hedging properties of short-term bonds and long-term bonds. The second one focuses on the different incentive effects (for the Sovereign) of short-term bonds and long term bonds: Short-term bonds limit the possibilities of dilution, increase the incentives to pay down debt and implement pro-market reforms in order to lower interest rates for future borrowing. Proposition 15 identifies a novel tradeoff in debt maturity choice that requires balancing hedging effects and a different form of incentive effects. On the one hand, a long maturity structure might be desirable for fiscal hedging. On the other hand, a short maturity structure might be desirable to reduce the risk-shifting opportunities of banks when the Sovereign cannot commit not to bail them out ex post and cannot adequately supervise

\footnotetext{
${ }^{58}$ See e.g., Angeletos (2002), Buera-Nicolini (2004), Jeanne (2009), Bolton-Jeanne (2009), HatchondoMartinez (2009), Chaterjee-Eyigungor (2012), Arellano-Ramanarayanan (2012), Dovis (2012), Broner-LorenzoniSchmukler (2013), Aguiar-Amador (2014), and Fernandez-Martin (2015).

${ }^{59}$ There is also a corporate finance literature on debt maturity. For example, Calomiris-Kahn (1991) and Diamond-Rajan (2001) show that the threat of not rolling over short-term debt can be used to discipline a manager. The fact that existing long-term bondholders hold a claim on liquidated assets which makes them vulnerable to dilution has been the focus of a large literature since Fama-Miller (1972). Brunnermeier-Oehmke (2013) shows how this can lead to a maturity rat race towards short maturities. Sovereign default differs from bankruptcy in that there is no liquidation after default.
} 
them ex ante.

Corollary. Countries with effective supervision or with a small banking sector or are less likely to shift towards short maturities when the probability of default increases.

\section{B.2 Limited Bailouts and Endogenous Diversification}

So far, we have maintained the assumption that no matter what portfolios banks hold, the Sovereign can always raise enough funds at date 1 to bail them out completely. We now relax this assumption. ${ }^{60}$ We show that when the Sovereign's ability to bail out the banking system is limited, banks naturally limit their exposure to domestic sovereign default risk.

We assume that there is no debt forgiveness. It is easy to see that the absence of supervisory leniency extends to the setting of this section. We therefore make use of the fact that $r=\bar{r}$ throughout.

To simplify, we assume that $I(s)=\bar{I}$ is independent of $s$ so that there are no financial shocks but only fiscal shocks. Because $A \geq \bar{I}$, if banks choose $b_{0}^{*}=\bar{I}$, they do not need a bailout. But we assume that there are some states of the world where the Sovereign is not able to fully bail out banks if they choose $b_{0}^{*}=\bar{r}$. In states of the world $s$ where funds are insufficient to bail out all the banks, the Sovereign optimally bails out as many banks as possible, saving first the banks with the highest pre-bailout net worth. This pecking order maximizes the number of banks that can be saved and hence ex-post welfare.

While banks are ex-ante identical, equilibria can be asymmetric. We therefore look for an equilibrium in which bankers invest different amounts in foreign bonds, according to a probability distribution with $G$ with support contained in $[\bar{r}, \bar{I}]$. This probability distribution $G$ is an endogenous object, to be solved for as part of the equilibrium. It might be a degenerate atom, in which case the equilibrium is symmetric.

In every state $s$, there is an endogenous threshold $b_{0}^{*}(s)$ such that bankers with $b_{0}^{*} \geq b_{0}^{*}(s)$ secure enough post-bailout funds to finance their investment. This threshold is monotonically decreasing in $s$. There is also an endogenous threshold $\tilde{b}_{0}^{*}(s) \geq b_{0}^{*}(s)$ such that bankers with $b_{0}^{*} \geq \tilde{b}_{0}^{*}(s)$ can finance their investment without any bailout. This threshold is defined by $\bar{I}-\tilde{b}_{0}^{*}(s)-\left(A-\tilde{b}_{0}^{*}(s)\right) \frac{p_{1}(s)}{p_{0}}=0$, and is also monotonically decreasing in $s$.

In states where $b_{0}^{*}(s)>\bar{r}$ so that bailouts are partial, the following bailout equations must hold

$$
\int_{b_{0}^{*} \in\left[b_{0}^{*}(s), \tilde{b}_{0}^{*}(s)\right)}\left(A-b_{0}^{*}\right) \frac{1}{p_{0}} d G\left(b_{0}^{*}\right)=\frac{p_{1}(s)}{f\left(B_{1}(s) \mid s\right)}-\left[B_{1}(s)-B_{0}\right],
$$

\footnotetext{
${ }^{60}$ Here it is important to restrict the concept of "banking union" to the notion of "shared supervision"; for, by providing a larger pool of bailout funds a banking union could increase incentives for risk shifting if the domestic Sovereign cannot raise enough funds itself.
} 


$$
\int_{b_{0}^{*} \in\left[b_{0}^{*}(s), \tilde{b}_{0}^{*}(s)\right)}\left[\bar{I}-b_{0}^{*}-\left(A-b_{0}^{*}\right) \frac{p_{1}(s)}{p_{0}}\right] d G\left(b_{0}^{*}\right)=\left[B_{1}(s)-B_{0}\right] p_{1}(s),
$$

where

$$
B_{1}(s)=B_{0}+\int_{b_{0}^{*} \in\left[b_{0}^{*}(s), \tilde{b}_{0}^{*}(s)\right)} \max \left\{\frac{I-b_{0}^{*}}{p_{1}(s)}-\frac{A-b_{0}^{*}}{p_{0}}, 0\right\} d G\left(b_{0}^{*}\right) .
$$

This simply guarantees that the Sovereign determines how much debt to issue at date 1 in order to maximize the number of banks that can be saved. ${ }^{61}$ Note that the Sovereign necessarily issues less debt than the amount that would maximize the revenues from this issuance. This is because at the peak of the Laffer curve (the value of $B_{1}(s)$ which maximizes $\left[B_{1}(s)-B_{0}\right]\left[1-F\left(B_{1}(s) \mid s\right)\right]$, a marginal reduction in issuance $B_{1}(s)-B_{0}$ brings about a second-order reduction in issuance revenues $\left[B_{1}(s)-B_{0}\right]\left[1-F\left(B_{1}(s) \mid s\right)\right]$ but a first-order improvement in banks' pre-bailout net worth $b_{0}^{*}+\left(A-b_{0}^{*}\right) \frac{1-F\left(B_{1}(s) \mid s\right)}{p_{0}}$, and hence a firstorder reduction in required bailouts and by implication a first-order increase in the number of banks that can be saved.

In addition, the following pricing equations must hold

$$
\begin{gathered}
p_{1}(s)=1-F\left(B_{1}(s) \mid s\right), \\
p_{0}=\int p_{1}(s) d \pi(s) .
\end{gathered}
$$

An individual banker who invests $b_{0}^{*}$ gets a bailout in states $s>s\left(b_{0}^{*}\right)$ but no bailout in states $s<s\left(b_{0}^{*}\right)$, where $s\left(b_{0}^{*}\right)$ is the inverse of $b_{0}^{*}(s)$ and is hence monotonically decreasing in $b_{0}^{*}$. There is another threshold $\tilde{s}\left(b_{0}^{*}\right)$ such that the entrepreneur does not need a bailout to finance his investment when $s>\tilde{s}\left(b_{0}^{*}\right)$, where $\tilde{s}\left(b_{0}^{*}\right)$ is the inverse of $\tilde{b}_{0}^{*}(s)$ and is hence monotonically decreasing in $b_{0}^{*}$. This banker now faces a meaningful tradeoff in his portfolio decision. By increasing his investment $b_{0}^{*}$ in foreign bonds, he secures a bailout in some states of the world where he did not get a bailout by rising in the Sovereign bailout pecking order, but loses out in states where he does not need a bailout to fund his investment. The

${ }^{61}$ Indeed equation (19) is the first-order condition for the following planning problem:

$$
b_{0}^{*}(s)=\min _{\left\{\hat{b}_{0}^{*}(s), B_{1}(s)\right\}} \hat{b}_{0}^{*}(s)
$$

s.t.

$$
\int_{b_{0}^{*} \geq \hat{b}_{0}^{*}(s)} \max \left\{I-b_{0}^{*}-\left(A-b_{0}^{*}\right) \frac{1-F\left(B_{1}(s) \mid s\right)}{p_{0}}, 0\right\} d G\left(b_{0}^{*}\right)=\left[B_{1}(s)-B_{0}\right]\left[1-F\left(B_{1}(s) \mid s\right)\right] .
$$


corresponding optimality conditions states that $b_{0}^{*}$ maximizes his welfare ${ }^{62}$

$$
b_{0}^{*} \in \arg \max _{b_{0}^{*}(i)} V_{0}^{B}\left(b_{0}^{*}(i)\right),
$$

where

$$
\begin{aligned}
V_{0}^{B}\left(b_{0}^{*}(i)\right)=\int \rho_{1}(s) \bar{I} d \pi(s)+ & \int_{\left\{s \geq \tilde{s}\left(b_{0}^{*}(i)\right)\right\}}\left[b_{0}^{*}(i)+\left(A-b_{0}^{*}(i)\right) \frac{p_{1}(s)}{p_{0}}-\bar{I}\right] d \pi(s) \\
& +\int_{\left\{s<s\left(b_{0}^{*}(i)\right)\right\}}\left[b_{0}^{*}(i)+\left(A-b_{0}^{*}(i)\right) \frac{p_{1}(s)}{p_{0}}-\rho_{1}(s) \bar{I}\right] d \pi(s) .
\end{aligned}
$$

The determination of equilibrium resembles that of equilibria of full-information firstprice auctions or wars of attrition. The complication here comes from the fact that the object that competitors vie for-here subsidies-is itself endogenous, as from equation (19), the pot of subsidies depends on the distribution of "bids", namely the holdings of foreign bonds.

An interesting feature of these equilibria is that they display a force for endogenous diversification. Bankers choose to hold foreign bonds even in the absence of regulation. This is because they cannot be certain to count on a bailout by the Sovereign. We illustrate this possibility with two simple examples in Section C.7. In the first example, the distribution $G$ is a degenerate atom. In the second example, it is non-degenerate. In both cases, we abstract away from regulation and set $\bar{r}=0 .{ }^{63}$

\section{B.3 The Role of Leverage}

In this section, we introduce leverage into the model. We assume that a fraction $\rho_{0}(s)$ of the return $\rho_{1}(s)$ is pledgeable to outside international investors at date 1 . Bankers can now

\footnotetext{
${ }^{62}$ For $b_{0}^{*}$ in the interior of the support of $G, \pi$ must be absolutely continuous with respect to the Lebesgue measure in the neighborhood of $s\left(b_{0}^{*}\right)$ with Radon-Nikodym derivative $d \pi(s)=\pi(s) d s$, and the entrepreneur must be left indifferent by marginal changes in $b_{0}^{*}$, which requires that the following differential equation in $s\left(b_{0}^{*}\right)$ hold on the interior of the support of $G$ :

$$
-s^{\prime}\left(b_{0}^{*}\right) \pi\left(s\left(b_{0}^{*}\right)\right)\left[\rho_{1}\left(s\left(b_{0}^{*}\right)\right) \bar{I}-\left(b_{0}^{*}+\left(A-b_{0}^{*}\right) \frac{p_{1}\left(s\left(b_{0}^{*}\right)\right)}{p_{0}}\right)\right]=\int_{\tilde{s}\left(b_{0}^{*}\right)}^{\infty}\left(\frac{p_{1}(s)}{p_{0}}-1\right) \pi(s) d s .
$$

The left-hand-side represents the marginal utility gain from securing bailouts in more states of the world, while the right-hand-side represents the utility loss in states where no bailout is required to fund the investment.

${ }^{63}$ Another form of bailout rat race is developed in Nosal-Ordonez (2016). In their paper as in ours, the Sovereign ex ante dislikes bailing out banks, but cannot help doing so when faced with the fait accompli. The innovation of their paper is that a bank can be rescued either by the Sovereign or (more cheaply) by a healthy bank and the Sovereign prefers a private takeover to a public takeover. The Sovereign however does not know whether the first distressed bank's shock is idiosyncratic or aggregate (in which case there will be no healthy bank to rescue the distressed one). In a situation in which the conditional probability of an aggregate shock is not too large, the Sovereign waits, and therefore banks prefer not to be the first distressed institution. If they can sink resources to augment the probability of not being first, they will do so, a behavior akin to a rat race.
} 
raise $\rho_{0}(s)<1$ units of funds per unit of investment at date 1 . Consistent with our previous assumptions, we assume that financial claims on $\rho_{0}(s)$ are issued abroad. This can be accommodated by our formalization along the lines of Holmström-Tirole (1997). Because we assume away the possibility of debt forgiveness, there is no supervisory leniency. We make use throughout of the fact that $r=\bar{r}$.

Leverage and financial shocks. Because bankers can lever up, they only need a net worth of $I(s)-\rho_{0}(s)$ in order to invest $I(s)$. As a result, the required bailout is now

$$
X(s)=\max \left\{I(s)-\rho_{0}(s)-\left(b_{0}^{*}+p_{1}(s) b_{0}\right), 0\right\} .
$$

The pricing equation (10) is unchanged, leading to the following fixed-point for the date-1 price $p_{1}(s)$ of domestic sovereign bonds

$$
p_{1}(s)=1-F\left(B_{1}(s) \mid s\right),
$$

where

$$
B_{1}(s)=B_{0}+\max \left\{\frac{I(s)-\rho_{0}(s)-\bar{r}}{p_{1}(s)}-\frac{A-\bar{r}}{p_{0}}, 0\right\} .
$$

Proposition 16 (Feedback Loop and Leverage). When a fraction $\rho_{0}(s)$ of the date-2 return of the investment project of bankers is pledgeable, the sensitivity of date- 1 bond prices $p_{1}(s)$ to the state $s$ when a bailout is required is given by

$$
\frac{d p_{1}(s)}{d s}=\frac{-\frac{\partial F\left(B_{1}(s) \mid s\right)}{\partial s}-\frac{1}{p_{1}(s)} f\left(B_{1}(s) \mid s\right) \frac{d\left[\left(1-\rho_{0}(s)\right) I(s)\right]}{d s}}{1-\frac{I(s)-\rho_{0}(s)-\bar{r}}{p_{1}^{2}(s)} f\left(B_{1}(s) \mid s\right)} .
$$

Proposition 16 extends Proposition 1 to the case where leverage is positive. The main difference is that the financing needs $I(s)$ are replaced by $I(s)\left(1-\rho_{0}(s)\right)$. This is simply because bankers can leverage every unit of bailout with private funds by borrowing $\rho_{0}(s)$ units of funds from international investors.

Joint defaults. So far we have ignored the possibility that private debt contracts of bankers might be defaulted upon. In other words, we have assumed that the enforcement of private debt contracts is perfect. In reality, whether or not to enforce private contracts is to a large extent a decision by the domestic Sovereign. And the decisions to enforce private debt contracts and to repay sovereign debt tend to be correlated. After all, not enforcing private 
debt contracts is another way for the Sovereign to default on the country's obligations. ${ }^{64} \mathrm{We}$ capture this idea by assuming that the costs of not enforcing debt contracts and to default on sovereign debt take the form of a single fixed cost. This feature builds in a complementarity between the two decisions. As a result, sovereign defaults come together with defaults on the private debt contracts issues by bankers, resulting in a positive correlation between bank and sovereign spreads.

Private debt contracts are priced fairly and reflect the probability that they will not be enforced. As a result, leverage becomes endogenous. Entrepreneurs can raise $\rho_{0}(s) p_{1}(s)$ units of funds per unit of investment. The fact that the debt that they raise bears enforcement risk limits their ability to raise funds at date 1 , and increases the size of the required bailout to

$$
X(s)=\max \left\{I(s)\left(1-\rho_{0}(s) p_{1}(s)\right)-\left(b_{0}^{*}+p_{1}(s) b_{0}\right), 0\right\} .
$$

The pricing equation (10) is unchanged, leading to the following fixed-point for the date-1 price $p_{1}(s)$ of domestic sovereign bonds

$$
p_{1}(s)=1-F\left(B_{1}(s) \mid s\right),
$$

where

$$
B_{1}(s)=B_{0}+\max \left\{\frac{I(s)-\rho_{0}(s) p_{1}(s)-\bar{r}}{p_{1}(s)}-\frac{A-\bar{r}}{p_{0}}, 0\right\} .
$$

Proposition 17 (Feedback Loop and Joint Defaults). When a fraction $\rho_{0}(s)$ of the date-2 return of the investment project of bankers is pledgeable and private debt contracts are defaulted upon when there is a sovereign default, the sensitivity of date-1 bond prices $p_{1}(s)$ to the state s when a bailout is required is given by

$$
\frac{d p_{1}(s)}{d s}=\frac{-\frac{\partial F\left(B_{1}(s) \mid s\right)}{\partial s}-\frac{1}{p_{1}(s)} f\left(B_{1}(s) \mid s\right) \frac{d\left[I(s)-\rho_{0}(s) p_{1}(s)\right]}{d s}}{1-\frac{I-\bar{r}}{p_{1}^{2}(s)} f\left(B_{1}(s) \mid s\right)} .
$$

There are two key differences between Proposition 17 and Proposition 16. The first difference is that the second term in the numerator is now $-\frac{1}{p_{1}(s)} f\left(B_{1}(s) \mid s\right) \frac{d\left[I(s)-\rho_{0}(s) p_{1}(s)\right]}{d s}$ instead of $-\frac{1}{p_{1}(s)} f\left(B_{1}(s) \mid s\right) \frac{d\left[I(s)-\rho_{0}(s)\right]}{d s}$, reflecting the dependence of the liquidity needs of bankers on $p_{1}(s)$ through the pledgeability of returns and leverage. The second difference is in the

\footnotetext{
${ }^{64}$ In our model, private financial contracts are between domestic agents (bankers) and foreign agents (international investors). A more general model would also feature private financial contracts between domestic agents. To the extent that enforcement decisions cannot discriminate between contracts based on the identities of the parties to the contract, this introduces potential additional costs to the decision of not enforcing private contracts. These costs are both ex-post in the form of undesirable redistribution and ex-ante in the form of a reduction in private trade between domestic agents (see e.g. Broner and Ventura 2011). We purposefully stay away from these fascinating issues, which are not the focus of this paper.
} 
denominator. For given values of the date- 1 bond price $p_{1}(s)$, of the reinvestment need $I(s)$, of the bailout $X(s)$, and hence of date- 1 debt $B_{1}(s)$, the denominator is now smaller at $1-\frac{I(s)-\bar{r}}{p_{1}^{2}(s)} f\left(B_{1}(s) \mid s\right)$ instead of $1-\frac{I(s)-\rho_{0}(s) p_{1}(s)-\bar{r}}{p_{1}^{2}(s)} f\left(B_{1}(s) \mid s\right)$. As a result the sensitivity $\frac{d p_{1}(s)}{d s}$ of the price $p_{1}(s)$ to the state $s$ is larger.

The feedback loop is stronger, because of a new mechanism operating through the endogenous leverage of banks. As sovereign risk rises, banks have to reduce leverage. This is because banks' borrowing spreads increase, reflecting the increased probability of a default on the private debt that they issue. This requires a larger bailout, which puts further pressure on the Sovereign budget etc., ad infinitum.

\section{B.4 Foreign Banks in the Foreign (Safe) Country}

In our basic model, we abstracted from foreign banks in the foreign (safe) country. We can introduce such banks. These face a similar problem to domestic banks. They have some net worth $A^{F}$ at date 0 , and some investment opportunities $I^{F}(s)$ at date 1 with private and foreign social returns given by $\rho_{1}^{F}(s)$ and $\beta^{I, F}(s)$. We assume that with $A^{F} \geq \bar{I}^{F}$ where $\bar{I}^{F}=\max _{s \in S} I^{F}(s)$. Foreign banks invest their net worth at date 0 in a portfolio of risky "domestic" bonds (bonds of the domestic economy) and safe "foreign" bonds (bonds of the foreign economy). ${ }^{65}$ The return on their portfolio at date 1 determines their net worth at date 1. If it falls short of their investment need, then they are bailed out by the foreign Sovereign. But these bailouts do not endanger the ability of the foreign Sovereign to repay its debt. The domestic and foreign countries differ only in the riskiness of their sovereign bonds. Domestic sovereign bonds are risky and foreign sovereign bonds are safe. We denote by $\bar{r}^{F}$ the supervisory capability of the foreign Sovereign, and by $r^{F}$ the effective minimum diversification requirement.

Our analysis goes through in this extended model as long as risk-neutral international investors who do not benefit from bailout guarantees (not foreign banks) remain the marginal buyers of domestic and foreign sovereign bonds. In particular, Propositions 1-15 still hold without any modification. The key observation is that foreign banks' portfolio decisions are irrelevant for equilibrium prices, domestic bailouts and sovereign default probabilities, and domestic banks' portfolio decisions. Foreign banks' risk exposures do not give rise to any feedback loop, because the foreign Sovereign has enough fiscal capacity to bail them out without endangering its ability to repay its debt.

\footnotetext{
${ }^{65}$ Of course domestic bonds are foreign bonds from the perspective of foreign banks, and similarly foreign bonds are domestic bonds from the perspective of foreign banks. To avoid confusion, we always refer to domestic bonds as the sovereign bonds of the domestic economy, independently of whether they are held by domestic or foreign agents. Similarly, we refer to foreign bonds as the bonds of the foreign economy, independently of whether they are held by domestic of foreign agents.
} 
The extended model has additional predictions on the incentives of foreign banks and of the foreign Sovereign. Because of the bailout guarantees, foreign banks have an incentive to load up on risky domestic debt. The foreign Sovereign has an incentive to regulate foreign banks so that they do not take on too much domestic sovereign risk. We elaborate on these issues now.

Frictionless supervision of foreign banks in the foreign (safe) country. We first consider first optimal supervision in the foreign (safe) country as in Section 3.1. We can derive the following equivalent of Propositions 2 and 3.

Proposition 18 (Supervision in Foreign (Safe) Country). When the basic model in Section 3.1 is extended to include foreign banks in the foreign (safe) country, there is no supervisory leniency in the foreign (safe) country so that $r^{F}=\bar{r}^{F}$. Moreover when the supervisory capability $\bar{r}^{F}$ can be chosen at no cost by the foreign Sovereign (first-best frictionless supervision), it is optimal to set $\bar{r}^{F}=\bar{I}^{F}$. All these statements are true whether or not debt forgiveness is allowed.

Just like the domestic Sovereign in the absence of debt forgiveness, the foreign Sovereign has an incentive to prevent its banks from taking on (domestic) sovereign risk. This is because when foreign banks take on more risk, they receive a bailout from the foreign Sovereign following a bad shock, which has adverse distributional effects.

In the presence of debt forgiveness, Proposition 18 displays a sharp contrast between the supervisory incentives of the domestic Sovereign and those of the foreign Sovereign. Because foreign sovereign debt is safe, the foreign Sovereign cannot extract any concessions from its creditors. As a result, the foreign Sovereign has no incentive to engage in strategic supervisory leniency. Instead it always seeks to strictly limit the exposure of foreign banks to domestic sovereign risk. We refer the reader to Section C.6 for additional results in the context of the simple example of Section C.1 which can be solved in closed form. In particular, we uncover an additional rationale for a banking union in the presence of costly or imperfect supervision: Domestic supervision has positive external effects for the foreign country, these effects are not internalized by the domestic Sovereign, and as a result, supervision is too lax in the domestic economy. ${ }^{66}$

\footnotetext{
${ }^{66}$ Bolton-Jeanne (2011) also study the international contagion of sovereign debt crises through the financial sector and their international fiscal implications.
} 


\section{Online Appendix: Illustration of Some Results and Addi- tional Results in a Simple Example}

In this appendix, we construct a simple example of our general setup, which can be solved in closed form. We then put to it to use to illustrate some of the results in the paper, and to derive additional results.

\section{C.1 Illustrative Example}

We assume that $I(s)=\bar{I}=A$ and $\rho_{1}(s)=\rho_{1}$ for all $s$, and that $\bar{r} \leq A$. The structure of uncertainty is as follows. With probability $\pi$, the state $s$ is $H$ and the endowment is high enough at $E$ that there is no default. With probability $1-\pi$, the state is $L$ and the endowment is high enough at $E$ so that there is no default with conditional probability $x$, intermediate $e$ with conditional probability $y$, and 0 with conditional probability $1-x-y$. In addition, we assume that $e>B_{0}$.

For $E \geq B_{1}(L)>e$, we have $1-F\left(B_{1}(L) \mid L\right)=x$ and so $p_{1}(L)=x$ and $p_{0}=\pi+(1-\pi) x$. For $e \geq B_{1}(L) \geq 0$, we have $1-F\left(B_{1}(L) \mid L\right)=x+y$ and so $p_{1}(L)=x+y$ and $p_{0}=$ $\pi+(1-\pi)(x+y)$. Depending on which of $\left(E-B_{0}\right) x$ and $(x+y)\left(e-B_{0}\right)$ is greater, the level of debt $B_{1}(L)$ that maximizes revenue in state $L$ is either $E$ or $e$.

\section{C.2 Multiple Equilibria in a Simple Example for Appendix A.3}

In this section, se show that the strategic complementarities identified in Appendix A.3 can lead to multiple equilibria. We demonstrate this possibility in the simple example introduced in Section C.1, which can be solved in closed form. We also provide global comparative statics results in the context of this example.

We assume that $\left(E-B_{0}\right) x>(x+y)\left(e-B_{0}\right)$ so that the revenue maximizing level of debt $B_{1}(L)$ in state $L$ is $E$. We assume throughout that $\left(\Psi^{\prime}\right)^{-1}\left(\frac{\pi(1-\pi)(1-\theta)}{\pi+(1-\pi) \theta}\right) \in(0, \bar{r})$ for $\theta \in$ $\{x, x+y\}$. There are two possible equilibria depending on whether $B_{1}(L) \leq e$ or $B_{1}(L)>e$, which determines the probability $\theta$ of repayment in state $L$. When $B_{1}(L) \leq e$, we have $\theta=x+y$, and when $B_{1}(L)>e$, we have $\theta=x$. And prices are given by $p_{1}(L)=\theta$, $p_{0}=\pi+(1-\pi) \theta$.

The welfare of a banker $i$ who invests $b_{0}^{*}(i)$ is

$\pi\left[\rho_{1} A+\left(A-b_{0}^{*}(i)\right)\left(\frac{1}{p_{0}}-1\right)\right]+(1-\pi) \rho_{1} A=\rho_{1} A+\pi\left(A-b_{0}^{*}(i)\right) \frac{(1-\pi)(1-\theta)}{\pi+(1-\pi) \theta}-\Psi\left(\bar{r}-b_{0}^{*}(i)\right)$. 
In order for bankers to choose $b_{0}^{*} \in(0, \bar{r})$, we must have

$$
\Psi^{\prime}\left(\bar{r}-b_{0}^{*}(i)\right)=\frac{\pi(1-\pi)(1-\theta)}{\pi+(1-\pi) \theta} .
$$

The debt issuance condition is then

$$
B_{1}(L)=B_{0}+\Phi(\theta)
$$

where $\Phi$ is a decreasing function defined by

$$
\Phi(\theta)=\frac{1}{\theta} \frac{\pi(1-\theta)}{\pi+(1-\pi) \theta}\left[A-\bar{r}+\left(\Psi^{\prime}\right)^{-1}\left(\frac{\pi(1-\pi)(1-\theta)}{\pi+(1-\pi) \theta}\right)\right] .
$$

We have an equilibrium with $B_{1}(L) \leq e$ if and only if

$$
\Phi(x+y) \leq e-B_{0} .
$$

Similarly, we have an equilibrium with $B_{1}(L)>e$ if and only if

$$
e-B_{0}<\Phi(x) \leq E-B_{0} .
$$

The two equilibria coexist if and only if

$$
E-B_{0} \geq \Phi(x)>e-B_{0} \geq \Phi(x+y) .
$$

Because the function $\Phi$ is decreasing, we can always find values of $B_{0}, E$ and $e$ such that condition (25) is verified so that there can be multiple equilibria for a range of parameter values. These multiple equilibria are a consequence of the strategic complementarities in the banks' individual exposures to domestic sovereign default risk.

Proposition 19 (Multiple Equilibria). In the illustrating example, there are two possible equilibria. There is an equilibrium with low diversification $b_{0}^{*}=\bar{r}-\left(\Psi^{\prime}\right)^{-1}\left(\frac{\pi(1-\pi)(1-x)}{\pi+(1-\pi) x}\right)$ and a high probability of default $(1-\pi)(1-x)$, which exists if and only if condition (23) is verified. There is also an equilibrium with high diversification $b_{0}^{*}=\bar{r}-\left(\Psi^{\prime}\right)^{-1}\left(\frac{\pi(1-\pi)(1-x-y)}{\pi+(1-\pi)(x+y)}\right)$ and a low probability of default $(1-\pi)(1-x-y)$, which exists if and only if condition (24) is verified. The two equilibria coexist if and only if condition (25) is verified.

This example also has other interesting implications.

Proposition 20 (Multiple Equilibria and Debt Re-nationalization). In the illustrating example, for $B_{0} \in(0, E-\Phi(x))$, the equilibrium with low diversification and high probability of default 
is more likely to exist, the higher is legacy debt $B_{0}$ and the lower is fiscal capacity (proxied by the intermediate value of the endowment e). Conversely, the equilibrium with high diversification and low probability of default is more likely to exist, the lower is legacy debt and the higher is fiscal capacity.

\section{C.3 Strategic Supervisory Leniency and Debt Re-Nationalization in a Sim- ple Example for Section 4.1}

In this section, we provide an illustration of the results in Section 4.1 in the context of the simple example introduced in Section C.1, which can be solved in closed form.

Recall that in this example, $I(s)=\bar{I}$ is independent of $s$ and $A=\bar{I}$. We assume that $e\left(1+\frac{y}{x}\right)>B_{0}>e$ and that $\beta^{I}(s)=\beta^{I}$ is independent of $s$. We assume that supervisory capability is not too low $A-\frac{\pi+(1-\pi) x}{\pi(1-x)}\left[e(x+y)-x B_{0}\right] \leq \bar{r}$. We now proceed to construct an equilibrium where it is optimal for the Sovereign $r<\bar{r}$ so as to obtain concessions from legacy creditors.

There is no debt forgiveness in state $H$ and no default. At date 1 , in state $L$, legacy creditors either forgive no debt so that $B_{0}(L)=B_{0}$ or forgive debt $B_{0}(L)<B_{0}$ in the following amount

$$
B_{0}(L)+\frac{\left[1-\frac{B_{0}(L)}{B_{0}} \frac{x+y}{p_{0}}\right](A-r)}{x+y}=e,
$$

in which case $B_{1}(L)=e$. There is debt forgiveness provided that when $B_{0}(L)$ is defined by equation (26), the following condition is verified:

$$
(x+y) B_{0}(L) \geq x B_{0}
$$

To summarize, using equations (26) and (27), there is debt forgiveness in state $L$ if

$$
\frac{x}{x+y} B_{0}+\frac{\left(1-\frac{x}{p_{0}}\right)(A-r)}{x+y} \leq e .
$$

In order to maximize welfare

$$
\begin{aligned}
\mathcal{W}_{0}=\pi\left(E-B_{0}\right)+(1-\pi)[x(E-e)-(1-x-y) \Phi] & +\beta^{I} A \\
& +\beta^{B}\left[\rho_{1} A+\pi(A-r)\left(\frac{1}{p_{0}}-1\right)\right] .
\end{aligned}
$$

It is then always optimal for the Sovereign to choose at date 0 the lowest value of $r$ that 
satisfies equation (28). This defines an increasing function

$$
r\left(p_{0}\right)=A-\frac{x+y}{1-\frac{x}{p_{0}}}\left(e-\frac{x}{x+y} B_{0}\right) .
$$

The date- 0 price is then given by $p_{0}=\pi+(1-\pi) x \cdot{ }^{67}$ And the equilibrium effective diversification requirement is then $r=r(\pi+(1-\pi) x)$ which is guaranteed to be less than $\bar{r}$ by our assumption that supervisory capability is not too low.

Proposition 21 (Strategic Supervisory Leniency). In the illustrating example, it is optimal for the Sovereign to engage in strategic supervisory leniency by setting $r=r(\pi+(1-\pi) x)<\bar{r}$. The equilibrium effective diversification requirement $r$ is decreasing in the probability $1-\pi$ of the occurrence of the bad fiscal shock (state $L$ ).

The Sovereign reduces the effective diversification requirement (lowers $r$ ) when the probability $1-\pi$ of a bad fiscal shock where a debt renegotiation takes place increases, because it makes it more attractive to extract concessions from legacy creditors.

\section{C.4 Rationale for a Banking Union in a Simple Example for Section 4.1}

In this section, we provide an illustration of the results in Section 4.1 in the context of the simple example introduced in Section C.1, which can be solved in closed form.

We build on Section C.3. Consider the debt level $B_{0}^{\prime}>B_{0}$ that generates the same amount of revenue at date 0 when the effective diversification requirement is $r^{\prime}=r(\pi+(1-\pi) x)$ as the debt level $B_{0} w h \%$ n the effective diversification requirement is $r=\bar{r}$. This debt level is defined implicitly by the equation

$$
[\pi+(1-\pi) x] B_{0}^{\prime}=p_{0}\left(\bar{r} ; \pi, B_{0}\right) B_{0}
$$

where we assume that the solution of this equation satisfies $e\left(1+\frac{t}{r}\right)>B_{0}^{\prime}>e$, and where $p_{0}\left(\bar{r} ; \pi, B_{0}\right)$ denotes the date- 0 price when the effective diversification requirement is $r=$

\footnotetext{
${ }^{67}$ We have $p_{0}=\pi+(1-\pi)(x+y) \frac{B_{0}(L)}{B_{0}}$, which using $(x+y) B_{0}(L)=x B_{0}$ implies $p_{0}=\pi+(1-\pi) x$.
} 
$\bar{r}^{68,69,70,71}$

We necessarily have $\mathcal{W}_{0}>\mathcal{W}_{0}^{\prime} \cdot{ }^{72}$

Proposition 22 (Banking Union). If the relaxation of supervision is fully priced in by international investors at the time of the issuance of date-0 debt, then the domestic Sovereign faces a timeinconsistency problem. It is made better off by promising not to engage in supervisory leniency and to set a high effective diversification requirement $r=\bar{r}$ before issuing debt at date 0 , but it is tempted to relax this requirement after the issuance and lower $r$ below $\bar{r}$. A banking union removes this temptation and improves welfare.

\section{C.5 Multiple Risky Countries in a Simple Example for Section 5.2}

In this section, we illustrate the results of Section 5.2 in the context of the simple example introduced in Section C.1, which can be solved in closed form.

For simplicity, we carry out our multiple-country extension in the context of our illustrating example. There are two states $H$ and $L$ at date 1 for each country with probability $\pi$ and $1-\pi$. Let $k^{H}$ be the probability that country $\mathcal{B}$ is in state $H$ if country $\mathcal{A}$ is in state $H$. Let $k^{L}$ be the probability that country $\mathcal{B}$ is in state $L$ if country $\mathcal{A}$ is in state $L$. Symmetry imposes that

$$
(1-\pi)\left(1-k^{L}\right)=\pi\left(1-k^{H}\right)
$$

${ }^{68}$ The function $p_{0}\left(\bar{r} ; \pi, B_{0}\right)$ is itself defined implicitly by the following equation

$$
p_{0}=\pi+(1-\pi)(x+y) \frac{e-\frac{A-\bar{r}}{x+y}}{B_{0}-\frac{A-\bar{r}}{p_{0}}} .
$$

This equation has a unique solution (the left-hand side is increasing in $p_{0}$ while the right-hand side is decreasing in $\left.p_{0}\right)$, which defines a function $p_{0}\left(\bar{r} ; \pi, B_{0}\right)$ which is increasing in $\bar{r}$, decreasing in $B_{0}$ and increasing in $\pi$.

${ }^{69}$ The function $p_{0}\left(\bar{r} ; \pi, B_{0}\right)$ is locally increasing in $\bar{r}$ if and only if $e(x+y)<p_{0}\left(\bar{r} ; \pi, B_{0}\right) B_{0}$. It is easy to see that this inequality automatically holds when $\bar{r}=A$. This implies that it holds for all $\bar{r}$. Indeed, suppose that there exists $\bar{r}<A$ such that $e(x+y)>p_{0}\left(\bar{r} ; \pi, B_{0}\right) B_{0}$. Then as we increase $\bar{r}$ from that point towards $A, p_{0}\left(\bar{r} ; \pi, B_{0}\right)$ keeps decreasing and hence $e(x+y)>p_{0}\left(\bar{r} ; \pi, B_{0}\right) B_{0}$ keeps being verified, a contradiction. Therefore $e(x+y) \leq p_{0}\left(\bar{r} ; \pi, B_{0}\right) B_{0}$ for all $\bar{r}$. This in turn implies that $p_{0}\left(\bar{r} ; \pi, B_{0}\right)$ is increasing in $\bar{r}$.

${ }^{70}$ That the function is decreasing in $B_{0}$ follows from the fact that the left-hand side of equation (30) is increasing in $p_{0}$ and independent of $B_{0}$, while the right-hand side is decreasing in $p_{0}$ and decreasing in $B_{0}$.

${ }^{71}$ That the function is increasing in $\pi$ follows from the fact that the left-hand side of equation (30) is increasing in $p_{0}$ and independent of $\pi$, while the right-hand side is decreasing in $p_{0}$ and increasing in $\pi$. To see that the right-hand side of equation (30) is increasing in $\pi$, rewrite the right-hand side using equation (30) as $\pi+(1-$ $\pi)(x+y) \frac{B_{0}(L)-\frac{A-\bar{P}}{p_{0}}}{B_{0}-\frac{A-\bar{F}}{p_{0}}}$ where $B_{0}(L) \leq B_{0}$.

${ }^{72}$ This is immediate since under commitment and no commitment, all investments are financed, defaults occur in the same states, and foreigners are as well off. As a result, the sum of consumer welfare and banker welfare is the same under commitment and no-commitment $V_{0}^{C \prime}+V_{0}^{B \prime}=V_{0}^{C}+V_{0}^{B}$. However the welfare of bankers is higher and that of consumers lower under no commitment $V_{0}^{B}<V_{0}^{B \prime}$ and $V_{0}^{C}>V_{0}^{C \prime}$. Because $\beta^{B}<1$, this implies that $W_{0}=W_{0}^{C}+\beta^{B} V_{0}^{B}+\beta^{I} A-(1-\pi)(1-x-y) \Phi$ is greater than $W_{0}^{\prime}=V_{0}^{C \prime}+\beta^{B} V_{0}^{B \prime}+$ $\beta^{I} A-(1-\pi)(1-x-y) \Phi$. 
We assume that $k^{H}<1$ and $k^{L}<1$ so that shocks in the two countries are not perfectly correlated.

In state $H$ in country $i \in\{\mathcal{A}, \mathcal{B}\}$, date-2 fiscal revenues are equal to $E$ with probability 1 , and investment needs are equal to $\underline{I}$ and the return on investment is equal to $\rho_{1}^{H}$. In state $L$ in country $i \in\{\mathcal{A}, \mathcal{B}\}$, date-2 fiscal revenues are equal to $E$ with probability $x$, $e$ with probability $y$, and 0 with probability $1-x-y$, investment needs are equal to $\bar{I}$, and the return on investment is equal to $\rho_{1}^{H}$. We assume that $\underline{I}<\bar{I}=A$. Hence fiscal and balance sheet shocks are positively correlated in a given country. As will be clear below, it is important for our results that $\underline{I}<\bar{I}$, but the size of the gap between $\underline{I}$ and $\bar{I}$ is not important. In other words, it only matters that there be some positive correlation between balance sheet and fiscal shocks. Although this is not important, we assume that $\rho_{1}^{H} \underline{I}>\rho_{1}^{L} \bar{I}$ so that state $H$ (respectively $L$ ) corresponds to a state with high (respectively low) future profits but low (respectively high) liquidity needs.

Home bias with multiple risky countries. We assume that $E$ is large enough so that $p_{1}(H, H)=$ 1 and $p_{1}(H, L)=1$. But we have $p_{1}(L, L)<1$ and $p_{1}(L, H)<1$. We show that as long as $p_{1}(L, H)$ is not too high, then banks in country $j$ choose to hold as little safe foreign bonds and as much risky domestic bonds as allowed by supervision, but no risky foreign bonds.

Proposition 23 (Home Bias with Multiple Risky Countries). Consider the illustrating example with two symmetric risky countries $i \in\{\mathcal{A}, \mathcal{B}\}$. Then there exists a symmetric equilibrium in which $p_{1}(L, H) \leq p_{0}$ and banks in each country $i \in\{\mathcal{A}, \mathcal{B}\}$ choose to hold as little safe foreign bonds and as much risky domestic bonds as allowed by supervision, but no risky foreign bonds: $b_{0}^{*}=\bar{r}, b_{0}^{d}=\frac{A-\bar{r}}{p_{0}}$ and $b_{0}^{f}=0.73$ This equilibrium is strict. Moreover, there are no other symmetric equilibria with $p_{1}(L, H) \leq p_{0}$.

Proof. We show that in any symmetric equilibrium as long as $p_{1}(L, H) \leq p_{0}$, banks in each country $i \in\{\mathcal{A}, \mathcal{B}\}$ prefer to choose the following portfolio: $b_{0}^{*}=\bar{r}, b_{0}^{d}=\frac{A-\bar{r}}{p_{0}}$ and $b_{0}^{f}=0$. Together with the fact that when banks do indeed choose this portfolio, $p_{1}(L, H)=p_{1}(L, L)<$ $p_{0}<p_{1}(L, H)=p_{1}(H, H)=1$, this proves the proposition.

Consider a country $i \in\{\mathcal{A}, \mathcal{B}\}$. For the same reasons as in the main model, banks in country $i$ will choose holdings of safe sovereign bonds of exactly $\bar{r}$. The payoff of a banker in

\footnotetext{
${ }^{73}$ The condition that $p_{1}(L, H) \leq p_{0}$ is equivalent to the assumption that there are bailouts when state $L$ occurs in country $i$ and state $H$ occurs in country $-i$ if banks of country $i$ choose portfolio $b_{0}^{*}=\bar{r}, b_{0}^{d}=\frac{A-\bar{r}}{p_{0}}$ and $b_{0}^{f}=0$. Proposition 23 then shows that there exists a unique symmetric equilibrium that satisfies this condition, and that in this equilibrium, banks choose the aforementioned portfolio.
} 
country $i$ from holding portfolio $\left(b_{0}^{d}, b_{0}^{f}\right)$ with $b_{0}^{d}+b_{0}^{f}=b_{0}$ where $b_{0}=\frac{A-\bar{r}}{p_{0}}$ is

$$
\begin{aligned}
\pi k^{H}\left[\rho_{1}^{H} \underline{I}+\max \left\{A-\underline{I}+\left(1-p_{0}\right) b_{0}^{d}+\left(1-p_{0}\right) b_{0}^{f}, 0\right\}\right] \\
+(1-\pi) k^{L}\left[\rho_{1}^{L} \bar{I}+\max \left\{A-\bar{I}+\left(p_{1}(L, L)-p_{0}\right) b_{0}^{d}+\left(p_{1}(L, L)-p_{0}\right) b_{0}^{f}, 0\right\}\right] \\
\quad+\pi\left(1-k^{H}\right)\left[\rho_{1}^{H} \underline{I}+\max \left\{A-\underline{I}+\left(1-p_{0}\right) b_{0}^{d}+\left(p_{1}(L, H)-p_{0}\right) b_{0}^{f}, 0\right\}\right] \\
\quad+(1-\pi)\left(1-k^{L}\right)\left[\rho_{1}^{L} \bar{I}+\max \left\{A-\bar{I}+\left(p_{1}(L, H)-p_{0}\right) b_{0}^{d}+\left(1-p_{0}\right) b_{0}^{f}, 0\right\}\right] .
\end{aligned}
$$

Only the last two terms of the expression above matters for portfolio choice of the banker. The sum of the last two terms is a convex function of $b_{0}^{d}$ and $b_{0}^{f}$. The optimal portfolio is therefore necessarily a corner solution $\left(b_{0}, 0\right)$ or $\left(0, b_{0}\right)$. We now compute the value of the sum of the last two terms at these two corners.

For $b_{0}^{d}=b_{0}$, the value of the sum of the last two terms is

$$
\begin{aligned}
\pi\left(1-k^{H}\right)\left[\rho_{1}^{H} \underline{I}+\max \{A-\underline{I}\right. & \left.\left.+\left(1-p_{0}\right) b_{0}, 0\right\}\right] \\
& +(1-\pi)\left(1-k^{L}\right)\left[\rho_{1}^{L} \bar{I}+\max \left\{A-\bar{I}+\left(p_{1}(L, H)-p_{0}\right) b_{0}, 0\right\}\right] .
\end{aligned}
$$

Since $A-\bar{I}+\left(p_{1}(L, H)-p_{0}\right) b_{0} \leq 0$ (recall that $\left.A=\bar{I}\right)$, this can be re-expressed as

$$
\pi\left(1-k^{H}\right)\left[\rho_{1}^{H} \underline{I}+A-\underline{I}+\left(1-p_{0}\right) b_{0}\right]+(1-\pi)\left(1-k^{L}\right) \rho_{1}^{L} \bar{I} .
$$

For $b_{0}^{d}=0$, the value of the sum of the last two terms is

$$
\begin{aligned}
& \pi\left(1-k^{H}\right)\left[\rho_{1}^{H} \underline{I}+\max \left\{A-\underline{I}+\left(p_{1}(L, H)-p_{0}\right) b_{0}, 0\right\}\right] \\
& \quad+(1-\pi)\left(1-k^{L}\right)\left[\rho_{1}^{L} \bar{I}+\max \left\{A-\bar{I}+\left(1-p_{0}\right) b_{0}, 0\right\}\right] .
\end{aligned}
$$

If $A-\underline{I}+\left(p_{1}(L, H)-p_{0}\right) b_{0} \leq 0$, this can be re-expressed as

$$
\pi\left(1-k^{H}\right) \rho_{1}^{H} \underline{I}+(1-\pi)\left(1-k^{L}\right)\left[\rho_{1}^{L} \bar{I}+A-\bar{I}+\left(1-p_{0}\right) b_{0}\right]
$$

which is less than the value with $b_{0}^{d}=b_{0}$. If $A-\underline{I}+\left(p_{1}(L, H)-p_{0}\right) b_{0}>0$, this can be re-expressed as

$$
\begin{aligned}
& \pi\left(1-k^{H}\right)\left[\rho_{1}^{H} \underline{I}+A-\underline{I}+\left(p_{1}(L, H)-p_{0}\right) b_{0}\right]+(1-\pi)\left(1-k^{L}\right)\left[\rho_{1}^{L} \bar{I}+A-\bar{I}+\left(1-p_{0}\right) b_{0}\right] \\
= & \pi\left(1-k^{H}\right)\left[\rho_{1}^{H} \underline{I}+A-\underline{I}+\left(1-p_{0}\right) b_{0}\right]+(1-\pi)\left(1-k^{L}\right)\left[\rho_{1}^{L} \bar{I}+A-\bar{I}+\left(p_{1}(L, H)-p_{0}\right) b_{0}\right],
\end{aligned}
$$

which is again less than the value for $b_{0}^{d}=b_{0}$.

Therefore the banker in country $j$ chooses $b_{0}^{d}=b_{0}$ and $b_{0}^{f}=0$. 
Strategic supervisory leniency with multiple risky countries. We assume that $e\left(1+\frac{y}{x}\right)>$ $B_{0}>e$ and that $\beta^{I}(s)=\beta^{I}$ is independent of $s$. For simplicity, we consider the limit where $\underline{I}=\bar{I}=A$. We can derive the following counterpart to Proposition 21, which shows that Sovereigns in risky countries have an incentive to let their banks load up on risky domestic sovereign debt as opposed to risky foreign sovereign debt, in order to maximize the concessions from legacy creditors.

Proposition 24 (Strategic Supervisory Leniency and Debt Re-Nationalization with Multiple Risky Countries). Consider the illustrating example with two risky countries and assume that $B_{0}<$ $E$. In the limit where $A$ is small compared to $e$ and $B_{0}$, it is optimal for the Sovereign in country $i$ to force its banks to invest all their net worth $A$ in risky domestic sovereign bonds, and to invest zero in safe foreign sovereign bonds and zero in risky foreign sovereign bonds: $b_{0}^{*}=0, b_{0}^{d}=\frac{A}{p_{0}}$ and $b_{0}^{f}=0$.

Proof. We consider a symmetric equilibrium, and denote with a tilde the equilibrium values, assuming, as we will verify below, that $\tilde{b}_{0}^{f}=0$. And we look at the incentives of the Sovereign in country $i \in\{\mathcal{A}, \mathcal{B}\}$ to deviate from this equilibrium. Banks in country $i$ invest in portfolio $\left(b_{0}^{d}, b_{0}^{f}, b_{0}^{*}\right)$ with $b_{0}^{d}+b_{0}^{f}=b_{0}$ and $p_{0} b_{0}^{d}+\tilde{p}_{0} b_{0}^{f}+b_{0}^{*}=A$. The values of $b_{0}^{d}, b_{0}^{f}$ and $b_{0}^{*}$ are controlled by the Sovereign in country $i$.

We assume that $E$ is large enough that the price of debt in a given country is always one when this country is in state $H$ (this condition is guaranteed to hold in the limit where $A$ is small compared to $e$ and $B_{0}$ ).

If we have debt forgiveness in state $(L, H)$, then the post-debt forgiveness amount of debt $B_{0}(L, H)$ satisfies

$$
B_{0}(L, H)+\frac{p_{0}-(x+y) \frac{B_{0}(L, H)}{B_{0}}}{x+y} b_{0}^{d}+\frac{\tilde{p}_{0}-1}{x+y} b_{0}^{f}=e,
$$

and $B_{1}(L, H)=e$. If we have debt forgiveness in state $(L, L)$, then the post-debt forgiveness amount of debt $B_{0}(L, L)$ satisfies

$$
B_{0}(L, L)+\frac{p_{0}-(x+y) \frac{B_{0}(L, L)}{B_{0}}}{x+y} b_{0}^{d}+\frac{\tilde{p}_{0}-(x+y) \frac{\tilde{B}_{0}(L, L)}{B_{0}}}{x+y} b_{0}^{f}=e,
$$

and $B_{1}(L, L)=e$.

There is debt forgiveness provided that the following conditions are verified:

$$
(x+y) B_{0}(L, H) \geq x B_{0}
$$

and

$$
(x+y) B_{0}(L, L) \geq x B_{0} .
$$


These conditions are always verified when $A$ is small enough compared to $e$ and $B_{0}$,

It is then always optimal for the Sovereign to choose at date 0 the values of $\left(b_{0}^{d}, b_{0}^{f}\right)$ that maximize welfare (taking $p_{0}$ as given)

$$
\begin{aligned}
& \mathcal{W}_{0}=\pi\left(E-B_{0}\right)+(1-\pi)[x(E-e)-(1-x-y) \Phi]+\beta^{I} A+\beta^{B} \rho_{1} A \\
&+ \pi k^{H} G\left\{\left(1-p_{0}\right) b_{0}^{d}+\left(1-\tilde{p}_{0}\right) b_{0}^{f}\right\} \\
&+(1-\pi) k^{L} H\left\{\left((x+y) \frac{B_{0}(L, L)}{B_{0}}-p_{0}\right) b_{0}^{d}+\left((x+y) \frac{\tilde{B}_{0}(L, L)}{B_{0}}-\tilde{p}_{0}\right) b_{0}^{f}\right\} \\
&+\pi\left(1-k^{H}\right) G\left\{\left(1-p_{0}\right) b_{0}^{d}+\left((x+y) \frac{\tilde{B}_{0}(L, H)}{B_{0}}-\tilde{p}_{0}\right) b_{0}^{f}\right\} \\
&+(1-\pi)\left(1-k^{L}\right) H\left\{\left((x+y) \frac{B_{0}(L, H)}{B_{0}}-p_{0}\right) b_{0}^{d}+\left(1-\tilde{p}_{0}\right) b_{0}^{f}\right\},
\end{aligned}
$$

where $G(x)=\beta^{B} \max \{x, 0\}+\min \{x, 0\}$ and $H(x)=\beta^{B} \max \{x, 0\}$. This defines two functions $b_{0}^{d}\left(p_{0}\right)$ and $b_{0}^{f}\left(p_{0}\right)$.

The date- 0 price $p_{0}$ is then given by the fixed-point equation

$$
p_{0}=\pi+(1-\pi)(x+y) \frac{\left(1-k^{L}\right) B_{0}(L, H)+k^{L} B_{0}(L, L)}{B_{0}},
$$

with $B_{0}(L, H)$ and $B_{0}(L, L)$ defined as above with $b_{0}^{d}=b_{0}^{d}\left(p_{0}\right)$ and $b_{0}^{f}=b_{0}^{f}\left(p_{0}\right)$.

In the limit where $A$ is small compared to $e$ and $B_{0}$, the last four terms of the expression for welfare $W_{0}$ can be rewritten (up to a first order approximation),

$$
\begin{aligned}
& \pi k^{H} G\left\{\left(1-\left(\pi+(1-\pi)(x+y) \frac{e}{B_{0}}\right)\right) b_{0}^{d}+\left(1-\left(\pi+(1-\pi)(x+y) \frac{e}{B_{0}}\right)\right) b_{0}^{f}\right\} \\
+ & (1-\pi) k^{L} H\left\{\left((x+y) \frac{e}{B_{0}}-\left(\pi+(1-\pi)(x+y) \frac{e}{B_{0}}\right)\right) b_{0}^{d}+\left((x+y) \frac{e}{B_{0}}-\left(\pi+(1-\pi)(x+y) \frac{e}{B_{0}}\right)\right) b_{0}^{f}\right\} \\
+ & \pi\left(1-k^{H}\right) G\left\{\left(1-\left(\pi+(1-\pi)(x+y) \frac{e}{B_{0}}\right)\right) b_{0}^{d}+\left((x+y) \frac{e}{B_{0}}-\left(\pi+(1-\pi)(x+y) \frac{e}{B_{0}}\right)\right) b_{0}^{f}\right\} \\
+ & (1-\pi)\left(1-k^{L}\right) H\left\{\left((x+y) \frac{e}{B_{0}}-\left(\pi+(1-\pi)(x+y) \frac{e}{B_{0}}\right)\right) b_{0}^{d}+\left(1-\left(\pi+(1-\pi)(x+y) \frac{e}{B_{0}}\right)\right) b_{0}^{f}\right\} .
\end{aligned}
$$

The solution is clearly $b_{0}^{d}=\frac{A}{\pi+(1-\pi)(x+y) \frac{e}{B_{0}}}$ and $b_{0}^{f}=0$.

Obviously, if the Sovereign could not determine the relative holdings of domestic and foreign risky bond holdings, but only impose an effective requirement $b_{0}^{*} \geq r$ with $r \leq b_{0}^{*}$, then we would obtain (in the limit where $\underline{I}$ tends to $\bar{I}=A$ from below) that it is optimal to set $r=0$. Banks would then by themselves load up on domestic risky bonds, choosing $b_{0}^{d}=\frac{A}{\pi+(1-\pi)(x+y) \frac{e}{B_{0}}}$ and $b_{0}^{f}=0$. Proposition 24 shows the more interesting result that even if the supervisor could perfectly control the portfolios of banks, it would choose to encourage 
them to load up on domestic risky bonds.

\section{C.6 Foreign Banks in the Foreign (Safe) Country in a Simple Example for Section B.4}

In this section, we illustrate the results of Section B.4 in the context of the simple example of Section C.1, which can be solved in closed form. We also provide additional results.

First, note that specializing the model to the illustrating example, Proposition 18 can be used to show that as the probability $1-\pi$ of a bad domestic fiscal shock increases, domestic supervision of domestic banks gets laxer, but foreign supervision of foreign banks does not, and as a result domestic banks tilt their portfolios towards risky domestic bonds and away from safe foreign bonds, but foreign banks do not.

Collective moral hazard, debt re-nationalization, and foreign banks in the foreign (safe) country. It is also interesting to investigate the portfolio decisions of foreign banks in the environment of Section 3.3, assuming that foreign banks face a cost of making their balance sheets opaque $\Psi^{F}$ similar to that of domestic banks and that $I^{F}(s)=\bar{I}^{F}$ is independent of $s$ and that $A^{F}=\bar{I}^{F}$. Using the fact that $r^{F}=\bar{r}^{F}$, we can derive the following equivalent of Proposition 19.

Proposition 25 (Multiple Equilibria). When the illustrating example of Section 3.3 is extended to include foreign banks in the foreign (safe) country, the portfolio of foreign banks is given by $b_{0}^{F *}=\bar{r}^{F}-$ $\left(\Psi^{F^{\prime}}\right)^{-1}\left(\frac{\pi(1-\pi)(1-\theta)}{\pi+(1-\pi)(\theta)}\right)$ with $\theta=x$ in the low (domestic) diversification equilibrium and $\theta=x+y$ in the high (domestic) diversification equilibrium.

Foreign banks' exposure to domestic sovereign risk is higher in the low (domestic) diversification equilibrium than in the high (domestic) diversification equilibrium. ${ }^{74}$

The key observation that underlies these results is that there are strategic complementarities running from domestic banks' to foreign banks, but no strategic complementarities running in the other direction. Indeed, when domestic banks increase their exposure to domestic sovereign risk, the benefits of doing so also increases for foreign banks. But when foreign banks increase their exposure to domestic sovereign risk, the benefits of doing for domestic banks remains unchanged. This is because the riskiness of domestic debt increases in the former case but not in the latter.

This also implies that there are supervisory externalities running from the domestic country to the foreign (safe) country but not vice versa. Indeed, suppose that at some supervisory

\footnotetext{
${ }^{74}$ Note that contrary to domestic and foreign banks, international investors have less exposure to domestic sovereign risk in the low (domestic) diversification equilibrium than in the high (domestic) diversification equilibrium.
} 
$\operatorname{cost} R$ (respectively $R^{F}$ ), the domestic (respectively foreign) Sovereign can achieve perfect supervision with supervisory capability $\bar{r}=A$ (respectively $\bar{r}^{F}=A^{F}$ ), in which case, because our example assumes that there is no debt forgiveness, we also have $r=\bar{r}=A$ (respectively $r^{F}=\bar{r}^{F}=A^{F}$ ). Otherwise, supervision is inexistent ( $\Psi$ and $\Psi^{F}$ are both zero), so that banks can perfectly evade regulation. Assume that $B_{0}+\frac{1}{x} \frac{\pi(1-x)}{\pi+(1-\pi) x} A>e>B_{0}$.

If the domestic Sovereign chooses to incur the supervisory cost $R$, we have $B_{1}(L)=B_{0}$ and $\theta=x+y$. Otherwise $B_{1}(L)=B_{0}+\frac{1}{x} \frac{\pi(1-x)}{\pi+(1-\pi) x} A$ and $\theta=x$. In both cases, we have $p_{1}(L)=\theta$ and $p_{0}=\pi+(1-\pi) \theta$.

The net gain $(1-\pi)\left(1-\beta^{B}\right) A^{F} \frac{\pi(1-\theta)}{\pi+(1-\pi) \theta}-R^{F}$ from incurring the supervisory cost for the foreign Sovereign is lower $(\theta=x)$ when the domestic Sovereign incurs the supervisory cost than when it doesn't $(\theta=x+y)$. By contrast, the net gain from incurring the supervisory cost for the domestic Sovereign is independent of whether or not the domestic Sovereign incurs the supervisory cost. More interestingly, we have the following proposition.

Proposition 26 (Supervisory Externalities and Banking Union). In the illustrating example with either perfect or irrelevant supervision and foreign banks in the foreign (safe) country, foreign welfare increases with the supervisory effort (decreases with the supervisory cost) of the domestic country, but domestic welfare is independent of the supervisory effort (independent of the supervisory cost) of the foreign country.

Proposition 26 uncovers an additional rationale for a banking union. Domestic supervision has positive external effects for the foreign country. These effects are not internalized by the domestic Sovereign, and as a result, supervision is too lax in the domestic economy. By transferring supervisory decisions from the national to the international level, a banking union allows these effects to be internalized, leading to a toughening of supervision in the domestic country and an improvement of welfare.

\section{C.7 Limited Bailouts and Endogenous Diversification in a Simple Exam- ple for Appendix B.2}

In this section, we provide two illustrations of limited bailouts and endogenous diversification as outlined in Appendix B.2, in the context of the simple example introduced in Section 2.1, which can be solved in closed form. In the first example, the distribution $G$ is a degenerate atom. In the second example, it is non-degenerate. In both cases, we abstract away from regulation and set $\bar{r}=0$.

Illustrating example 1. Our first example is a variant of the example in Section 2.1. We assume that $\left(E-B_{0}\right) x<(x+y)\left(e-B_{0}\right)$, so that the revenue maximizing level of $B_{1}(L)$ in state $L$ is $e$. 
Our candidate equilibrium is symmetric with $B_{1}(L)=e, p_{1}(L)=x+y$ and $p_{0}=\pi+$ $(1-\pi)(x+y) \cdot{ }^{75}$ The limited-bailout condition is

$$
\frac{\pi(1-x-y)}{\pi+(1-\pi)(x+y)}\left(A-b_{0}^{*}\right)=\left(e-B_{0}\right)(x+y) .
$$

In order for bankers to prefer $b_{0}^{*}$ to 0 , we must have

$$
\pi\left[\frac{1}{\pi+(1-\pi)(x+y)}-1\right] b_{0}^{*} \leq(1-\pi) A\left[\rho_{1}-\frac{x+y}{\pi+(1-\pi)(x+y)}\right] .
$$

The solution $b_{0}^{*}$ of equation (31) always (strictly) verifies equation (32). This guarantees that our candidate equilibrium is indeed an equilibrium as long as the solution of equation (31) verifies $0<b_{0}^{*}<A$.

Illustrating example 2. We now consider a simple variant of the previous example. The structure of uncertainty is as follows. With probability $\pi$, the state $s$ is $H$ and the endowment is high enough at $E$ that there is no default. With probability $(1-\pi) z$, the state is $M$, and the endowment is high enough at $E$ so that there is no default with conditional probability $x$, intermediate $e_{M}$ with conditional probability $y$, and 0 with conditional probability $1-x-$ $y$. With probability $(1-\pi)(1-z)$, the state is $L$, and the endowment is high enough at $E$ so that there is no default with conditional probability $x$, intermediate $e_{L}$ with conditional probability $y$, and 0 with conditional probability $1-x-y$. What distinguishes states $M$ and $L$ is that $e_{M}>e_{L}$. We assume that $(x+y)\left(e_{L}-B_{0}\right)>\left(E-B_{0}\right) x$ so that the revenue maximizing level of debt is $e_{M}$ in state $M$ and $e_{L}$ in state $L$.

Our candidate asymmetric equilibrium is such that there are full bailouts in the medium state, but limited bailouts in the low state. Bankers invest $\hat{b}_{0}^{*}(L)$ with probability $\phi$ and 0 with probability $1-\phi$. Prices are $p_{0}=\pi+(1-\pi)(x+y), p_{1}(L)=p_{1}(M)=x+y$.

The bailout conditions are

$$
\begin{gathered}
\phi \frac{\pi(1-x-y)}{\pi+(1-\pi)(x+y)}\left(A-\hat{b}_{0}^{*}(L)\right)=\left(e_{L}-B_{0}\right)(x+y), \\
\phi \frac{\pi(1-x-y)}{\pi+(1-\pi)(x+y)}\left(A-\hat{b}_{0}^{*}(L)\right)+(1-\phi) \frac{\pi(1-x-y)}{\pi+(1-\pi)(x+y)} A \leq\left(e_{M}-B_{0}\right)(x+y) .
\end{gathered}
$$

In order for bankers to be indifferent between $b_{0}^{*}=\hat{b}_{0}^{*}(L)$ and $b_{0}^{*}=0$, we must have

$$
\pi\left[\frac{1}{\pi+(1-\pi)(x+y)}-1\right] \hat{b}_{0}^{*}(L)=A(1-z)(1-\pi)\left[\rho_{1}-\frac{x+y}{\pi+(1-\pi)(x+y)}\right] .
$$

\footnotetext{
${ }^{75}$ It can be shown that there are no asymmetric equilibria in this example.
} 
We can rewrite equation (35) as

$$
\hat{b}_{0}^{*}(L)=A(1-z)\left[\left(\rho_{1}-1\right) \frac{\pi+(1-\pi)(x+y)}{\pi(1-x-y)}+1\right] .
$$

Using equation (33), we find

$$
\phi=\frac{e_{L}-B_{0}}{A} \frac{(x+y) \frac{\pi+(1-\pi)(x+y)}{\pi(1-x-y)}}{1-(1-z)\left[\left(\rho_{1}-1\right) \frac{\pi+(1-\pi)(x+y)}{\pi(1-x-y)}+1\right]}
$$

We have an equilibrium if $\hat{b}_{0}^{*}(L)<A, 0<\phi<1$, and

$$
(1-\phi) \frac{\pi(1-x-y)}{\pi+(1-\pi)(x+y)} A \leq\left(e_{M}-e_{L}\right)(x+y),
$$

which can always be ensured for appropriate parameter values.

Proposition 27 (Bailout Rat-Race and Incentives for Diversification). In the illustrating examples with limited bailouts and symmetric or asymmetric equilibria, it is optimal for banks to not fully load up on domestic sovereign default risk and instead choose a non-zero degree of diversification $b_{0}^{*}>0$ with positive probability even when there is no regulation $(\bar{r}=0)$. 